\title{
Required Properties of High-Performance Steels
}

Theodore V. Galambos

Jerome F. Hajjar

Christopher J. Earls

Department of Civil Engineering

University of Minnesota

Minneapolis, Minnesota 55455

John L. Gross

Building and Fire Research Laboratory

National Institute of Standards and Technology

Gaithersburg, Maryland 20899

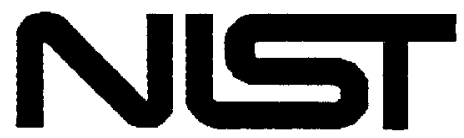

United States Department of Commerce Technology Administration

National Institute of Standards and Technology 


\section{Required Properties of High-Performance Steels}

Theodore V. Galambos

Jerome F. Hajjar

Christopher J. Earls

John L. Gross

May 1997

Building and Fire Research Laboratory

National Institute of Standards and Technology

Gaithersburg, MD 20899

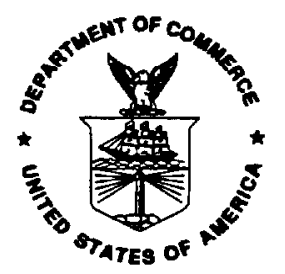

U.S. Department of Commerce

William M. Daley, Secretary

Technology Administration

Mary L. Good, Under Secretary for Technology

National Institute of Standards and Technology

Robert E. Hebner, Acting Director 


\begin{abstract}
This report presents the results of a study of high-performance steels with yield stress values between $480 \mathrm{MPa}$ and $690 \mathrm{MPa}(70 \mathrm{ksi}$ and $100 \mathrm{ksi}$ ). These materials are a new family of constructional steels. The impetus for the study was the need for the determination of the applicability of these steels for use with current structural design specifications for buildings and bridges. The following sources were considered in the study: the technical and scientific literature on the development of the current design requirements; discussion from a workshop on the topic of the new materials; and numerical studies performed for this project. The main conclusion from this investigation is that the use of high-performance steels for civil engineering structural applications is feasible, but that considerable data obtainable from steel mills and from further research, combined with technical and economic studies, are needed. In particular, experimental and finite element studies should be performed to define the compactness properties of sections, and the rotation capacity, as well as the rotation requirements, of members and frames. Sufficient statistical information on material properties needs to be amassed so that the probabilistic factors in the design specifications can be re-calibrated for the high-performance steels. Special emphasis in the required research should be placed on the behavior of bolted connections under monotonic and cyclic loads. The report concludes with a list of research recommendations.
\end{abstract}

Keywords: Bridges; buildings; building technology; codes; design; elastic design; high strength steel; plastic design; seismic design; steel. 


\section{Table of Contents}

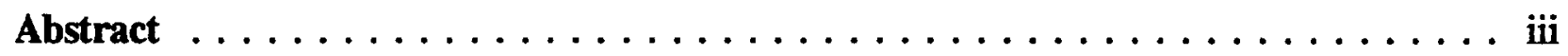

Table of Contents $\ldots \ldots \ldots \ldots \ldots \ldots \ldots \ldots \ldots \ldots \ldots \ldots \ldots \ldots$ iv

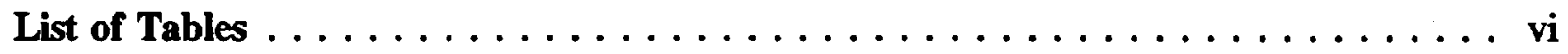

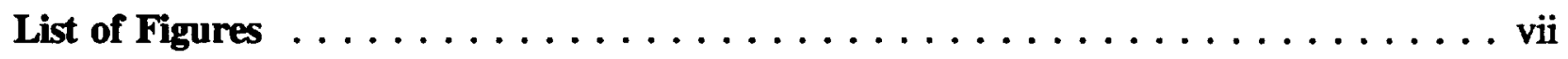

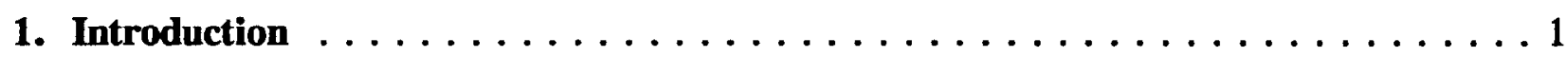

2. High-Performance Steels in Design and Construction $\ldots \ldots \ldots \ldots \ldots \ldots$

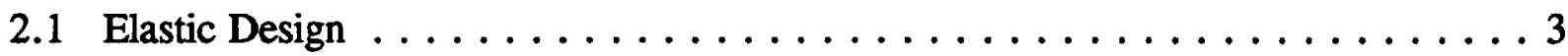

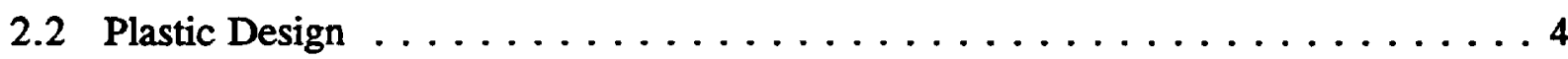

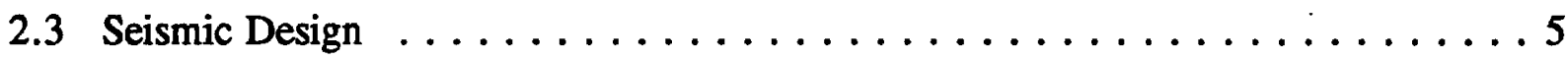

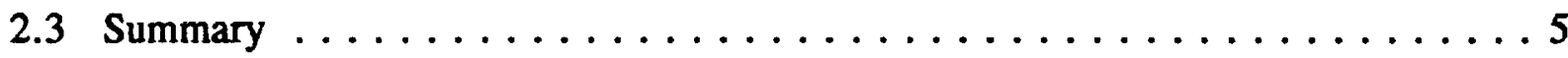

3. Stress-Strain Properties of High-Performance Steels $\ldots \ldots \ldots \ldots \ldots \ldots$. 6

3.1 Tension Test Data . . . . . . . . . . . . . . . . . . . 6

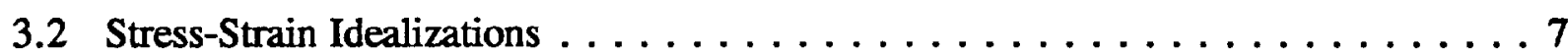

4. Inelastic In-Plane Behavior of Indeterminate Beams $\ldots \ldots \ldots \ldots \ldots \ldots$

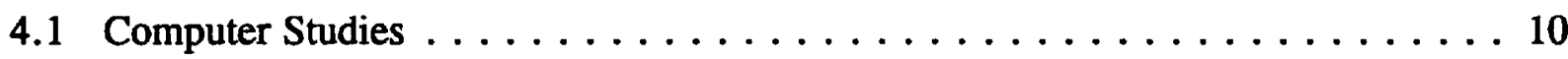

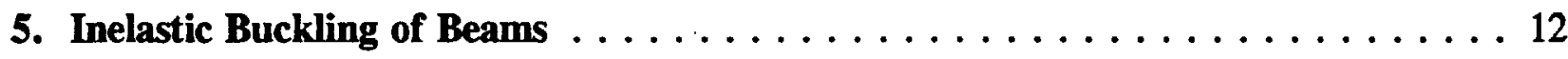

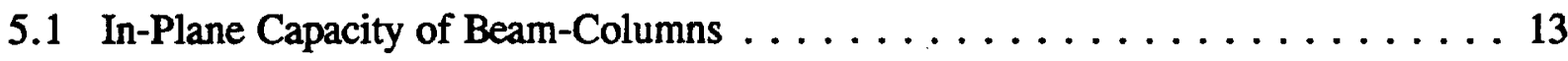

5.2 Review of Compactness Requirements of Beams . . . . . . . . . . 14

5.3 Extension of Current Compactness Criteria to High-Performance Steels . . . . . 17

6. Establishing Compactness Requirements For High-Performance Steels . . . . . 19

6.1 Experimental Results . . . . . . . . . . . . . . . . . . 19

6.2 Finite Element Computation Results $\ldots \ldots \ldots \ldots \ldots \ldots \ldots \ldots \ldots \ldots$

7. Summary of Research Needs Workshop Held at the University of Minnesota . . . 23

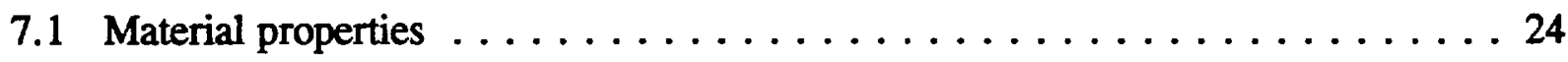

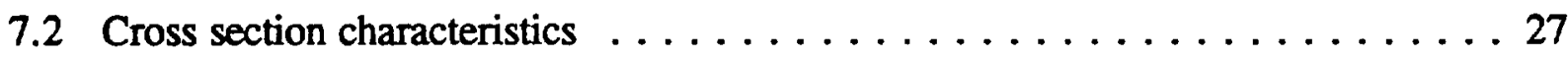

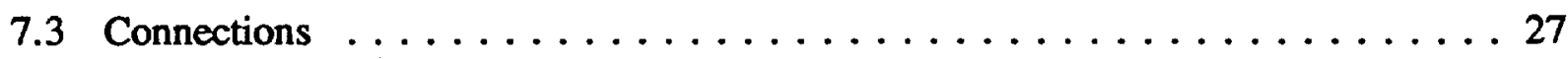

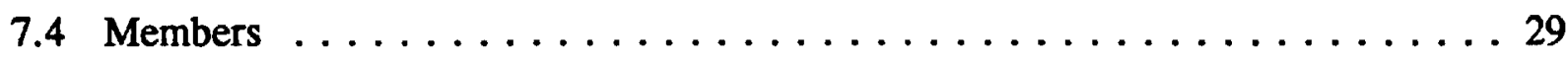

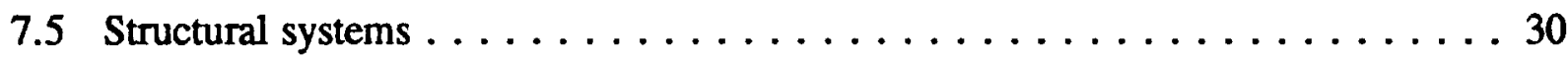


8. Summary and Recommendations

References ............................6 61

Tables . . . . . . . . . . . . . . . . . . . . . . . . . . 69

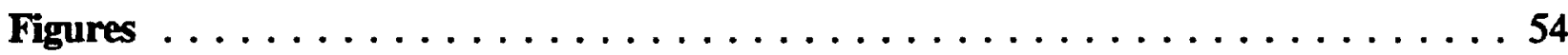

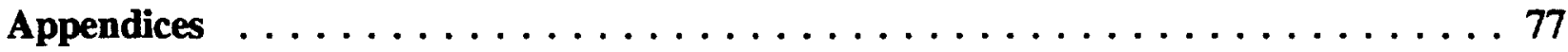

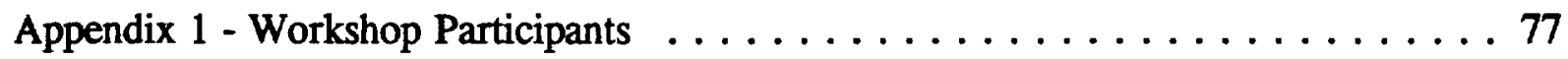

Appendix 2 - AISC-LRFD Stability Requirements . . . . . . . . . . 78

Appendix 3 - Work of Alan Kemp in South Africa $\ldots \ldots \ldots \ldots \ldots$

Appendix 4 - Work of George Lay at Lehigh University . . . . . . . . . . 89 


\section{List of Tables}

Table

Page

1 Tensile Coupon Properties of Japanese Steels $\ldots \ldots \ldots \ldots \ldots \ldots \ldots \ldots$

2 Tensile Coupon Properties of A514 Steel $\ldots \ldots \ldots \ldots \ldots \ldots \ldots \ldots$

3 Tensile Coupon Properties of HSLA80 Steel $\ldots \ldots \ldots \ldots \ldots \ldots$

4 Tensile Coupon Properties of TradeARBED Co. Steels $\ldots \ldots \ldots \ldots \ldots$

5 Representative Material Properties for Analysis $\ldots \ldots \ldots \ldots \ldots \ldots$

6 Coordinates for Elastic-Plastic Analysis of Three-Span Beam $\ldots \ldots \ldots \ldots$

7 Results of Tests on A514 Beams - Uniform Moment Case $\ldots \ldots \ldots \ldots \ldots$

8 Results of Tests on A514 Beams - Moment Gradient Case . . . . . . . . . . 49

9 Results of Tests on HSLA80 Wide-Flange Beams $\ldots \ldots \ldots \ldots \ldots \ldots$

10 Results of Finite Element Studies by Rickles $\ldots \ldots \ldots \ldots \ldots \ldots \ldots \ldots$

11 Results of Finite Element Studies by Earls $\ldots \ldots \ldots \ldots \ldots \ldots \ldots \ldots$

12 Results of Finite Element Studies by Earls $\ldots \ldots \ldots \ldots \ldots \ldots \ldots \ldots$ 


\section{List of Figures}

Table

Page

1 Comparison of HSLA80 and A36 Stress-Strain Relationships . . . . . . . . 54

2 Stress-Strain Curve Model No. $1 \ldots \ldots \ldots$

3 Stress-Strain Curve Model No. $2 \ldots \ldots \ldots \ldots$

4 Stress-Strain Curve Model No. $3 \ldots \ldots \ldots \ldots$

5 Effect of Stress-Strain Curve on Load-Deflection Relations of Rectangular Indeterminate Beams ....................... 58

6 Effect of End Restraint - Rectangular Section - for $s=10, h=30 \ldots 59$

7 Effect of End Restraint - Rectangular Section - for $s=1, h=200 \ldots 60$

8 Effect of $E / E_{s t}-$ Rectangular Section $\ldots \ldots \ldots \ldots \ldots$

9 Materials A, B, C, D - Rectangular Section .................. 62

10 Moment-Curvature Curves $\ldots \ldots \ldots \ldots \ldots \ldots$

11 Load-Deflection Curves for $\alpha=1.0$, Maximum Curvature $=10 \phi_{y} \ldots \ldots$

12 Effect of End Restraint, Steel A, W-Shape ................. 65

$13 \quad$ Load-Deflection Curves for $\alpha=2.0 \ldots \ldots \ldots \ldots \ldots$

14 Load-Deflection Curves for Maximum Curvature $=15 \phi_{y} \ldots \ldots \ldots 7$

15 Types of Buckling $\ldots \ldots \ldots \ldots \ldots \ldots$

16 Schematic Drawing of Buckling Domains ................. 69

17 Load-Deformation Curves with and without Buckling . . . . . . . . . 70

18 Figures 7 and 8 from Kuwamura $\ldots \ldots \ldots \ldots \ldots \ldots \ldots$

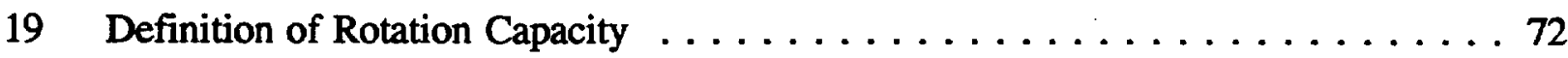

20 Comparison of ABAQUS Prediction with Test HT-52 from Adams . . . . . . . . 73 
21 Load-Deflection Curves from ABAQUS - 3-Point Loading . . . . . . . . . . 74

22 Load-Deflection Curves from ABAQUS - 3-Point Loading $\ldots \ldots \ldots \ldots \ldots$

23 Load-Deflection Curves from ABAQUS - 4-Point Loading $\ldots \ldots \ldots \ldots \ldots$ 


\section{Introduction}

This report addresses the properties of high-performance steels which are of importance to structural engineers in the design and evaluation of bridges, buildings and other structures. The information presented herein derives from the following three sources:

- relevant published technical literature,

- discussions in a workshop conducted at the University of Minnesota on June 1, 1996, and

- research performed by the authors in connection with the topic of this report.

For the purposes of this study, the term high-performance steel is used to represent a family of constructional steels with a yield stress in the range of $480 \mathrm{MPa}$ to $690 \mathrm{MPa}(70 \mathrm{ksi}$ to $100 \mathrm{ksi}$ ) which are economical to produce and which have all the properties needed for good performance in structures of usual civil engineering applications.

The purpose of this report is to define the research needed to develop the criteria for the inclusion of these high-performance steels in the structural design specifications of, for example, the American Institute of Steel Construction (AISC, 1993) or the American Association of State Highway and Transportation Officials (AASHTO, 1995). In conjunction with this effort, a workshop was held at the University of Minnesota on June 1, 1996 to discuss the state-of-knowledge of high-performance steels and to provide guidance on the direction of needed research. The participants of the workshop are given in Appendix 1.

The impetus for the recent interest in high-performance materials lies in the desire to produce more durable and more innovative structures. Representatives from steel makers, prestressed concrete fabricators, steel fabricators and design engineers met in April of 1993 to discuss in a global sense what research would be needed to bring the new materials into full acceptance in the construction world. The title of the workshop was High-Performance Construction Materials, An Essential Program for America and its Infrastructure. The emphasis of the meeting in 1993 was very broad, covering aspects of different materials (steel, concrete, composite steel-concrete), manufacturing, fabrication, welding, corrosion, structural analysis and many others (CERF, 1993). The work reported herein is more restricted and focuses on the questions of design suitability, with special emphasis on the properties which are important in the full utilization of the strength of the steel: ductility, energy absorption capacity and maximum strength. However, one should not lose sight of the broader aspects of the picture even though they are not covered here in great detail: improved corrosion resistance, weldability, fracture toughness, corrosion fatigue resistance, frame stability and robustness for fabrication, transportation and erection.

\section{High-Performance Steels in Design and Construction}

High strength steels, with yield stresses of $690 \mathrm{MPa}(100 \mathrm{ksi})$ or greater, have been available for many years. For example, ASTM A514 steel High-Yield Strength, Quenched and Tempered Alloy 
Steel, has been listed as one of the available steels as early as the 1969 edition of the AISC specification. This steel has not found extensive application in civil engineering structures, however, because of difficulties in weldability (Sause and Fisher, 1996) combined with high cost. Presently there is a renewed interest in developing and using new steels which would be suitable for general use in building and bridge design and construction.

Following are some of the possible technological advantages of these steels:

- The overall weight of the structures could be reduced so that savings would result in transportation costs to the site and smaller foundations could be constructed.

- Mass-dependent dynamic forces are lessened.

- Structures would have a larger elastic strength for resisting dynamic forces due to moderate earthquakes.

- Light weight and thin elements are desirable for the creative design of aesthetic members and structures where steel is architecturally exposed.

- The tendency in many applications for steel structures has been the use of thin-walled members, in both the prefabricated structures and the cold-formed steel industries for economic reasons. Introduction of high-performance steels for general civil engineering structures will extend this trend to a broader spectrum of structural applications.

- The advantages of using high-performance steels in concrete-steel composite bridges is explored in a paper by Sause and Fisher (1996). They investigated bridge plate-girders with thin double webs between which there was a layer of high-strength concrete. Another proposed type of plate-girders utilizes thin corrugated webs (from Kulicki presentation at the June 1, 1996 workshop).

- Kuwamura (1992) defines the desirability of a high-performance steel for structures in earthquake-prone areas as a material which a) has a low yield stress-to-tensile strength ratio, $b$ ) is weldable and c) has a narrow range of variation of the yield stress.

There are also some possible technological disadvantages as detailed below:

- Since there is no corresponding increase in the modulus of elasticity of the steel as the yield stress increases, the problems of serviceability become more pressing: deflection and vibration will need to be looked at carefully, and creative structural forms will need to evolve to minimize this problem (Sause and Fisher, 1996).

- Designers will need to be more aware of problems related to buckling at the high levels of stress under which high-performance steels are most efficient from the standpoint of strength. 
- There is no wide range of experience to establish confidence in the structural design profession.

There are a number of perceived problems with the high-performance steels which need to be addressed by research, and the ensuing parts of this report will consider these issues in more detail. A brief list of these problems is:

- Generally, high-performance steels have a higher yield stress-to-tensile strength ratio than do conventional steels and thus it is expected that the inelastic stability criteria in the structural design standards, which depend strongly on the strain-hardening properties, will be adversely affected.

- The slenderness limits imposed by the high yield stress and the high yield stress-to-tensile strength ratio to achieve efficient compact structural elements may result in uneconomical structures.

- It is possible that the members made from the high-performance steels will not be ductile enough for applications where large inelastic deformations are needed such as in seismic design.

If the use of the high-performance steels is restricted to stresses in the elastic range only, that is, the limit states are either the attainment of the yield stress or the elastic buckling stress at the critical locations, then there is little need for new research since existing knowledge is sufficient to solve the problems in the design office as they arise. This design method would result in less than cost-effective structures, however, since it would be necessary to keep the stresses quite low in the regions of the connections in order to avoid yielding at points of stress concentration. If, on the other hand, it is desired to utilize the new steels the same way as conventional steels having yield stresses which do not exceed $450 \mathrm{MPa}(65 \mathrm{ksi})$, then the requirements of the design specifications relating to compactness and rotation capacity will need to be re-evaluated. It is not likely that current criteria can be directly extrapolated.

Traditional design specifications for steel structures fabricated from hot-rolled elements (shapes or plates) are essentially based on one of three checking concepts: elastic design, plastic design or seismic design. These three design checking concepts are explained in more detail below.

\subsection{Elastic Design}

In the elastic design method the forces in the members of the structure are calculated by assuming that the material remains elastic. For statically indeterminate structures this means that slope continuity is maintained. Elastic structural analysis can, and often should, include geometric non-linearities, the so-called P- $\Delta$ effect. Once the forces are determined, the points of highest force are checked to determine if the required force exceeds the capacity of the cross section at that point. 
The capacity may be controlled by buckling, which can be either in the elastic or inelastic range of the material, or it may be controlled by the plastic strength. In the case of flexure, this strength is the full plastic moment. This full cross-sectional capacity can be achieved only if certain geometric slenderness limits are not exceeded. The flanges and the web must be compact and the member must be laterally braced at sufficiently close intervals. In addition to the requirement to reach the plastic moment, there is also a need to accommodate partial plastification to achieve a modest redistribution of moments from the points of support to the interior of the span in a redundant beam or frame.

All modern building and bridge specifications use "elastic" design as defined above. Strictly speaking, it is really not an elastic design because it requires a certain amount of plastification and inelastic rotation capacity. The implied rotation capacity underlying the AISC Specification is three times the elastic rotation at the plastic moment (AISC, 1993). The compactness requirements are based on theories which assume certain properties of the stress-strain curve: length of plastic plateau and strain-hardening modulus. Furthermore, these rules are backed up by extensive experiments which were used to simplify and modify the theoretical formulas. It is thus difficult to justify extension of these semi-empirical rules which were tested out for steels with yield stresses up to $345 \mathrm{MPa}$ ( $50 \mathrm{ksi}$ ) to steels with a yield stress twice that value or greater. The elastic method of design is the one used most frequently in the design of buildings and bridges and it would be the major target for the utilization of the new high-performance steels.

\subsection{Plastic Design}

The plastic design approach is permitted in design specifications when the sections are compact and are braced adequately so that plastic hinges can develop at enough locations for the formation of a plastic mechanism. It may also be possible that the ultimate strength is reached by overall frame instability before the full mechanism developed. In this case a second-order, advanced analysis must be performed.

The requirements for compact plate slenderness in the plastic design method are not consistent between the Allowable Stress Design (ASD) (AISC, 1989) and the Load and Resistance Factor Design (LRFD) (AISC, 1993) Specifications of the AISC. For example, if the yield stress is 345 MPa (50 ksi), the flange slenderness limit is 9.2 in LRFD and 7.0 in Chapter N Plastic Design of the ASD specification. The corresponding value is 7.4 in the AISC seismic criteria (AISC, 1992). Similar discrepancies exist for the web slenderness limit. It is obvious that the lower limits will deliver a higher rotation capacity. The seismic design requirements are similar to the limits in the plastic design part of the ASD specification, and the rotation capacity delivered by compact members is stated to be from 7 to 9 .

Plastic design is most suited for the design of continuous beam systems (non-composite and composite) and low-rise frames with rigid and semi-rigid joints. While methods of advanced analysis are beginning to be available in the form of computer programs, plastic design is not as yet used much in the design of multi-story frames. The same is true for bridges. The AASHTO Specification (1994) makes provisions for the plastic design of bridges, but at the present time, 
the method is seldom used. In bridges, the idea of shakedown is also permitted to be used, resulting in partial plastification and force redistribution after initial overloads until the stress fluctuations "shake down" into the elastic range. Whether or not the high-performance steels can be used for plastic design will depend on the outcome of considerable analytical and experimental research which still needs to be performed. Present steel design standards explicitly forbid the use of steel with a yield stress higher than $448 \mathrm{MPa}$ (65 ksi) in plastic design (e.g., AISC, 1993).

\subsection{Seismic Design}

There are several main types of steel framing systems which are employed to resist seismic forces. Some of these systems, such as concentrically braced frames, depend on the yielding of the tension braces for absorption of the energy imparted to the structure by the earthquake. Eccentrically braced frames absorb energy at specially designed sections where large shear deformations are required to be sustained. Yet another system is the rigid frame, which is intended to deform as a plastic mechanism with ductile hinges forming in the beams, the so-called weak-beam, strong-column concept. Whatever framing is used in seismic design, the steel member is going to have to be ductile so that the energy imparted by a large earthquake is absorbed by yielding. A fundamental part of the ductility requirement is the ability of the steel to deform to large strains without fracture.

Within the context of current seismic framing schemes the desirable characteristics for steels were defined by Kuwamura (1992) as: high yield stress, so that the steel will remain elastic in a moderate earthquake; low yield stress-to-tensile strength ratio so that the benefits of strain-hardening and ductility can be fully utilized; and a narrow range of variation of the yield stress level so that the occurrence of plastification in the beams, rather than the columns, can be assured. In addition, the steel must be weldable, making robust connections strong enough to remain relatively elastic while the ductile beams yield and absorb energy. Whether or not a steel can be produced which can deliver all the requirements listed, is a question which will be discussed later in this report. The types of steels which are permitted for use in the AISC Seismic Provisions for Structural Steel Buildings (AISC, 1992) for buildings more than one story tall do not contain any with a yield stress higher than $345 \mathrm{MPa}(50 \mathrm{ksi})$. In the aftermath of the failures of many steel connections in the recent Northridge (January 17, 1994) and Kobe (January 17, 1995) earthquakes, it is still difficult to know how the requirements for steels for seismic applications will be affected. It seems, however, that the current requirements will be upgraded. Whether there is any room for high-performance steels with high yield stresses is not clear. However, the future seismic steels will, in all other aspects, be "high-performance" materials.

\subsection{Summary}

From this review of the three types of design methods, it appears that the most likely earliest adoption of high-performance steels with high-yield stress will be in elastic design. For plastic 
design and seismic design it seems that there will be a call for an upgrading of all steels to a higher degree of performance than is now the case.

The following parts of this report will review the availability and character of high-performance steels, followed by an examination of the performance of these materials in the light of existing theories.

\section{Stress-Strain Properties of High-Performance Steels}

Constructional steels have many properties which are used implicitly or explicitly in the evaluation of the material for various applications. In general, much information is available for the traditionally used steels, but data on high-performance steels is still scant. However, even for the common types of steel, it is difficult to obtain some properties, such as strain-hardening characteristics and static yield stress values (Adams, 1964; Technical Memorandum 7 in Galambos, 1988), because these are not routinely measured in quality control tests. These properties are often only available from research reports. Other properties, such as the modulus of elasticity and Poisson's ratio, are difficult to measure precisely in a routine tensile coupon test, and thus specified values, which closely represent the means of the carefully measured values reported in the literature, are used in design calculations (Galambos and Ravindra,1978).

\subsection{Tension Test Data}

For the prediction of the strength and the energy-absorption capacity of steel structures, the most important qualities are obtained from a tensile coupon test. Such tests are performed in the mill as quality control and classification measures. More careful and extensive tests are conducted in research laboratories to obtain additional information. These more scientific tensile as well as compression test procedures are described in two Technical Memoranda of the Structural Stability Research Council (SSRC) (Galambos, 1988).

The mill test tensile coupon data comprise the yield stress, $F_{y}$, the tensile strength, $F_{u}$, and the gross measure of ductility as indicated by the percent elongation and the percent reduction of area. The yield stress is determined by noting the value of the load on the testing machine when the load indicator first stops before going down slightly. This "upper yield point" is dependent on the rate of straining. However, only this upper yield point data is available in sufficient quantities to allow meaningful statistical properties to be calculated. Such information is evaluated by Galambos and Ravindra (1978) for steels available about 20 years ago. An extensive data set was generated for steels produced by modern steel-making processes by the Structural Shapes Producers Council (SSPC, 1993) for US mills, and by Mazzolani et al. (1993) for European mills.

Research laboratories conducting structural engineering tests frequently perform tensile tests which present the entire stress-strain curve. At a minimum, these laboratories report the static yield stress; strain at onset of strain-hardening, $\varepsilon_{\mathrm{s}} ;$ strain-hardening modulus, $\mathrm{E}_{\mathrm{st}}=\mathrm{E} / \mathrm{h}$; and strain at the tensile strength, $\varepsilon_{u}$ (i.e., the strain at the maximum point on the stress-strain curve where the 
stress is $F_{u}$ ). There is very little of this type of information available, even for common constructional steels, but the available data was sufficient to arrive at statistical properties (Galambos and Ravindra, 1978) needed to develop probability-based design criteria.

Stress-strain data on high-performance steels is quite scarce. Two stress-strain curves from Sooi et al. (1995) are shown in Fig.1. The lower curve is for A36 steel while the upper curve is for HSLA80 steel. This latter material has been extensively studied over the last few years at the ATLSS Engineering Research Center, Lehigh University. The curves demonstrate the essential difference between the two types of steel: that structural carbon steel a) is more ductile, and b) has a smaller ratio of the yield stress-to-tensile strength (sometimes referred to as "yield ratio"). The yield stress-to-tensile strength ratios for the A36 and the HSLA80 steels are 0.71 and 0.87 , respectively. The significance of the difference between the two stress-strain curves will be examined later in this report as to the effect on moment redistribution in a statically indeterminate structure and on local and member stability. Considering that most of the straining in a structure will occur at strains much less than the strain at the tensile strength, the yield stress-to-tensile strength ratio may not be the most significant parameter at all. Other stress-strain curves for high-performance steels are given by Japanese researchers (Kuwamura, 1992; Fukumoto, 1994; Kuranishi, 1995; Yamao et al., 1995) and by McDermott (1969 a and b) and by Gerardy (1996).

\subsection{Stress-Strain Idealizations}

In further studies of the effects of the shape of the stress-stain curve on the load-deformation behavior of steel frames, it will be useful to have idealizations of the initial portions of the relationship, at most up to the tensile strength. Three models are discussed.

The first model is the simplest one and it is depicted in Fig.2. The stress-strain curve consists of an elastic part where stress and strain are proportional, a plastic plateau, and the initial part of the strain-hardening range in which stiffness is defined by the strain-hardening modulus, $E_{s t}=E / h$, where $\mathrm{E}$ is the elastic modulus and $\mathrm{h}$ is the ratio of the elastic modulus to the strain-hardening modulus. This representation has been used frequently in past research studies of structures in the inelastic range.

A model containing more information is shown in Fig.3. It encompasses the entire stress-strain curve up to the tensile strength, $F_{u}$ and the ultimate strain, $\varepsilon_{u}$. The bend of the stress-strain curve beyond the onset of strain-hardening is defined by the stress half-way between the yield stress and the tensile strength, $\left(F_{y}+F_{u}\right) / 2$, and the initial portion of the strain hardening curve having a slope of $\mathrm{E}_{\mathrm{st}}=\mathrm{E} / \mathrm{h}$ at a corresponding strain of $\varepsilon_{\mathrm{b}}$.

The final model is shown in Fig.4. The shape of the stress-strain curve is the same as that of the previous two models up to the start of strain-hardening. Beyond that point it follows a threeparameter expression introduced by Ramberg and Osgood (1943) and used by Haaijer (1959) to represent results of compression coupon tests in the strain-hardening range. The stress-strain relationship in the strain-hardening range may be expressed as: 


$$
\varepsilon-\varepsilon_{\mathrm{st}}=\frac{\sigma-F_{\mathrm{y}}}{E / \mathrm{h}}+\mathrm{K}\left(\frac{\sigma-\mathrm{F}_{\mathrm{y}}}{\mathrm{E} / \mathrm{h}}\right)^{\mathrm{m}}
$$

where Haaijer (1959) used $\mathrm{K}$ equal to 21 and $\mathrm{m}$ equal to 2.

Table 1 presents data for constructing the models from Japanese steel coupon test data; Table 2 has the values for the A514 steel investigated by McDermott (1969); data for the HSLA80 steel are contained in Table 3; and Table 4 has the information from the Gerardy (1996) paper for steel produced by the Trade-Arbed Company. Finally, Table 5 shows the assumed typical idealized values which will be used in later portions of this report.

While enough stress-strain data is available for the types of studies performed here, there is a need to obtain data in sufficient quantity for a statistically significant development of resistance factors required for structural design codes. This will be discussed later when we present research needs for the high-performance steel structures.

\section{Inelastic In-Plane Behavior of Indeterminate Beams}

The strength of statically determinate structures subjected to flexure is the load at which the limiting maximum moment is reached in the member at the point of maximum moment. This limiting moment is characterized by local and lateral-torsional buckling and by excessive yielding. Failure is finally due to large uncontrolled deflection of the beam. The next section of this report will deal with the issue of local and lateral-torsional buckling as it pertains to high- performance steels. For statically indeterminate structures there is an additional problem related to the in-plane behavior, namely, the redistribution of moments as the structure develops a plastic mechanism as the limiting condition of behavior. This section will address the effect of the stress-strain relationship, especially the strain-hardening portion, on the force-redistribution in indeterminate beams.

The inelastic behavior of structures subjected to flexure is directly dependent on the moment-curvature relationship of the member cross section. The moment-curvature relationship, in turn, is dependent on the shape of the cross-section as well as on the stress-strain curve of the steel. Since the slope and the deflection of the elastic curve is determined by integration of the beam curvature, the force deformation history can be calculated if the M- $\phi$ (i.e., the moment-curvature) relationship is known.

In-plane behavior is defined by the load-deformation history of a beam made from a doubly or singly symmetric cross section which is bent by loads applied in the plane of symmetry and where no out-of plane effects such as lateral or local deformations occur. If the beam is statically indeterminate, then plastic deformations will first occur at the point of highest moment, where extensive yielding takes place. However, the structure does not fail by excessive uncontrolled deflection because other portions of the system are still elastic and can take on the burden of the additional load. This can go on until so much moment redistribution has occurred that the 
structure begins to deform as a kinematic mechanism, i.e., the structure deforms in an uncontrollable manner, and so it fails. The calculation of this inelastic load-deflection behavior is time-consuming unless extreme simplifying assumptions are made as to the moment-curvature curve. One such assumed curve is the ideal elastic-plastic moment curvature curve consisting of a linear elastic part and a plastic plateau when the full plastic moment is reached. An even more radical idealization is the rigid-plastic moment-curvature curve, which assumes no elastic deflections and only plastic hinge deformations up to the point at which the whole structure becomes a plastic mechanism. With the assumptions of the rigid-plastic mechanism the collapse load of continuous structures can be easily calculated, resulting in the method of plastic analysis and design. Despite radical simplifications, the rigid plastic analysis gives excellent predictions of the ultimate strength of structures when compared to tests in both the laboratory and the field. Thus the method of plastic design is an acceptable and successful design criterion in most of the world's structural design codes.

Plastic design was first pioneered in England by John Baker of Cambridge University and in the United States by Lynn Beedle at Lehigh University in the decade after the end of WWII. In continental Europe, there was vehement opposition to plastic design, especially by Stuessi at the Swiss Federal Institute of Technology in Zurich. He characterized plastic design as a method suitable only for idiots (Schwachkoepfe = weak heads) in a serious technical journal in Switzerland. His opposition was considered by many as just a nuisance, but he and other critics of the method had one valid point: if, indeed, the material had an ideal elastic-plastic stress-strain relation, then the curvature, and so the stress in the extreme fiber of the cross section, would become infinitely large at a moment approaching the plastic moment. No material could survive such a large strain and so plastic design was not an acceptable design method. The answer to this objection was simple: tests showed that a plastic mechanism could be reached for a large number of indeterminate structures, and that, in addition, strain-hardening is present, which is ignored in the simple plastic method but which nevertheless exists and provides the justification.

The criticism, however, called for more than the intuitive and empirical answers provided by the apologists of plastic design. The first paper to deal with this problem was by Michael Horne who was a co-worker of Baker in England (Horne, 1951). Other early papers on this subject were produced by Vickery (1961) and Ang (1961). The criticism flared up again in the early 1960's when Hrennikoff (1965) in Canada published a paper that reported on tests of continuous beams made from aluminum which had no strain-hardening portion in its stress-strain curve. The stress-strain curve flattened out at the yield stress level without any increase until the material fractured. The beams tested were prevented from buckling locally and failed by fracture when the first hinge load was reached, as predicted by Hrennikoff in earlier papers. No redistribution or plastic mechanism formation was achieved. In reply to this work, a number of theoretical studies were published by Lay and Smith (1965), Lay (1966), Horne and Medland (1966), Adams and Galambos (1969). These papers, as well as the continually mounting experimental evidence from tests on steel structures, demonstrated that the constructional steels then in use were indeed suitable for plastic design. As a precaution, most specifications restricted the use of plastic design to steels with a yield stress of less than or equal to $450 \mathrm{MPa}$ (65 ksi). This is the way things stand at present (1996). 


\subsection{Computer Studies}

The issue of in-plane behavior must be examined in light of the stress-strain characteristics of the high-performance materials discussed in this report. No literature exists which directly addresses this problem, and therefore several computer studies were performed to explore the influence of the types of materials characterized by the properties listed in Table 5.

The first analysis was performed on a three-span beam with a distributed load in the center span and no load in the exterior spans (see Fig. 5). The cross section is a rectangular shape and the material has a stress-strain curve as shown at the bottom of Fig. 5, consisting of an elastic range, a plastic plateau, and a strain-hardening portion. The moment-curvature relation is then obtained from the stress-strain curve, geometry of the rectangular section, and the assumption of small strains and the plane section law. The equations for the $M-\phi$ curve are given by

$$
\begin{aligned}
& \frac{\phi}{\phi_{y}}=\frac{M}{M_{y}}, \text { for } \frac{M}{M_{y}} \leq 1.0 \\
& \frac{\phi}{\phi_{y}}=\frac{1}{\sqrt{3-2 \frac{M}{M_{y}}}} ; \text { for } 1.0 \leq \frac{M}{M_{y}} \leq 1.5-\frac{0.5}{s^{2}} \\
& \left(\frac{\phi}{\phi_{y}}\right)^{3}+\left(\frac{\phi}{\phi_{y}}\right)^{2}\left[1.5 h-h\left(\frac{M}{M_{y}}\right)-1.5 s\right]+0.5\left(s^{3}-h\right)=0 ; \text { for } \frac{M}{M_{y}} \geq 1.5
\end{aligned}
$$

where

$$
\begin{aligned}
& M_{y}=\frac{b d^{2} F_{y}}{6} \\
& \Phi_{y}=\frac{2 F_{y}}{E d}
\end{aligned}
$$

and $\mathrm{d}$ and $\mathrm{b}$ are the depth and width of the rectangular section, respectively; and $\mathrm{s}$ and $\mathrm{h}$ are defined in Fig. 5.

The relationship between the uniformly distributed load, $w$, and the deflection at the center of the interior span, $\Delta$, is calculated by the Newmark's numerical integration method, assuming slope compatibility at the interior supports. The effects of the various stress-strain curves are examined by comparison of non-dimensional load-deflection plots. Figures 6 to 8 show such curves where 
the deflection is plotted on the abscissa and the load is plotted on the ordinate. The solid curve is obtained with numerical integration, and the dashed curve is determined by assuming an ideal elastic-plastic moment-curvature relationship. The coordinates of the elastic-plastic load-deflection curves are presented in Table 6.

The curves in Fig. 6 represent the load-deflection behavior of a typical structural steel such as A36 steel with a yield plateau length of 10 times the yield strain $(s=10)$, and a ratio of the elastic modulus to the strain-hardening modulus of $h=30$. Four curves are shown for four values of the end-span ratio, $\alpha$. The load at the onset of the plastic mechanism in the center span as determined by simple plastic analysis is

$$
w_{u}=24 M / L^{2}
$$

The curves obtained by integration exceed this value in each case. The analysis was stopped at a value of 20 times the yield curvature. This is a large enough curvature so that problems with lateral buckling could occur. The material represented by $s=10$ and $h=30$ is thus shown to be satisfactory for plastic design.

In Fig. 7 a material with a zero plastic plateau ( $s=1$ on the stress-strain curve of Fig. 4 ) and a small amount of strain-hardening $(\mathrm{h}=200)$ is used to obtain the load-deflection curves. As can be seen, the simple plastic capacity at a curvature equal to 20 times the yield curvature is not reached for a side-span ratio of $\alpha=0.5$ and 3.0. Thus full moment redistribution was not achieved in these cases.

The curves in Fig. 8 show the same information that was given in Figs. 6 and 7 for one case of the side-span ratio $(\alpha=1.0)$. The load-deflection curves in Fig. 9 are for the steels for which the stress-strain data are given in Table 5. At a maximum curvature of 20 times the yield curvature and for a side-span ratio of 1.0 , the simple plastic moment capacity was achieved in all cases.

Another investigation of the three-span beam was performed on a typical wide-flange shape (W24X76). The stress-strain curve of Model 2 (Fig. 3) was used. Since interest is focused here on the behavior of the structure under strains which are fairly high (in the strain-hardening range), residual stresses were assumed to be zero. The moment-curvature relationship was obtained numerically using narrow horizontal strips in the cross section and assuming small strains and plane sections. The four non-dimensional M- $\phi$ curves for the four selected materials of Table 5 are presented in Fig. 10. The inelastic portions of these curves are quite different from each other. These moment-curvature relations were then used to calculate the load-deflection curves by Newmark's numerical integration method.

The load-deflection curves are presented in Figs. 11 through 14 for the four idealized materials of Table 5 and for various values of the side-span ratios $(\alpha=0.5,1.0,2.0,3.0)$, and the maximum curvature $\left(\phi_{\max }=10 \phi_{y}\right.$ and $\left.15 \phi_{y}\right)$. At these values of the maximum curvature it can be expected that severe local and/or lateral buckling is present. The steels with substantial strain-hardening, i.e., the Japanese steel and the A36 steel, reach the plastic mechanism load for the case of equal spans $(\alpha=1.0)$, but the other steels with less strain-hardening (the A514 and the 
HSLA80 steels) do not reach the plastic mechanism load. For the case where the side-spans are twice the center span $(\alpha=2.0)$, none of the steels are adequate.

The limited studies presented here for the in-plane behavior of a simple indeterminate structure do not point to a clear-cut answer as to what is needed to distinguish an acceptable stress-strain curve from one which is not acceptable. Steels with a lower yield stress-to-tensile strength ratio are better, but it is not clear whether or not the steels with a higher value are not acceptable in many situations since they often achieve the plastic mechanism load in these studies. Much more analysis is needed to define the required inelastic deformation capacity of many types of structures under different kinds of demands such as plastic design or seismic design. The adequacy of the high-performance steels will be discussed further at the conclusion of this report after issues arising from buckling are first reviewed in the next chapter.

\section{Inelastic Buckling of Beams}

Failure of a steel structure is due to either fracture or buckling. Buckling is a phenomenon where there are large changes in deformation in response to small changes in applied load. Two kinds of instability are illustrated in the sketches in Fig. 15: Bifurcation buckling occurs when a structure deforms along one path until, at some load (the critical value of the load), it begins to deform along another path. For example, a beam deflects first in the plane of loading and then suddenly deflects laterally and twists when the lateral-torsional buckling load is reached. Local buckling of plate elements and sidesway buckling of frames are other instances of bifurcation instability.

The other kind of instability shown in Fig. 15 is the attainment of the limit load. The structure starts to deform in a given mode and continues in this mode until a maximum load limit is attained. The in-plane behavior of a beam-column is a limit load type of failure. It always involves some amount of inelastic deformation in the member. The bifurcation buckling mode is an idealization which never actually occurs because geometric imperfections will always predispose the structure to fail at a limit load. However, computationally it is generally easier to determine the bifurcation buckling load and often it is an acceptably accurate predictor of the ultimate strength. Structures may become unstable as a whole system (frame instability), or their members may buckle individually in a more confined subassembly by local and/or lateral-torsional buckling. This discussion is restricted to member instability.

The buckling load of a member is dependent on the slenderness ratio of the member as a whole and on the slenderness ratio of its component plate elements. The sketch in Fig. 16 illustrates the general shape of a "buckling" curve which relates the strength (the ordinate) to the slenderness ratio (the abscissa). The heavier line represents an ideal elastic-perfectly plastic material and a geometrically perfect member. At stress-levels below yielding the member or element buckles by ideal elastic buckling defined by a typical Euler hyperbola. The thinner line is the schematic description of the behavior of an actual member.

At large slenderness ratios there may be a post-buckling strength which can be reached after the onset of bifurcation buckling. This post-buckling strength is of considerable significance for 
plates, but for beams failing by elastic lateral-torsional buckling it is quite small. Columns failing in the elastic buckling range also have only a very insignificant post-buckling strength. Members and plates in this range are known as slender elements in structural design specifications. Highperformance steels perform predictably in this range, and research performed on the use of high yield-stress steels in cold-formed members (Dhalla et al., 1971; Dhalla and Winter, 1974; Macadam, 1988; and AISI, 1996) has demonstrated this. Work is needed, however, to establish knowledge in this domain for other high-performance steels.

The next range of slenderness is characterized by yielding of the cross section prior to buckling, but where the full plastic capacity has not yet been achieved. Residual stress and initial imperfections play a dominant role in this domain, referred to as the non-compact range in design codes. The information on high-performance steels in this range of slenderness is not yet fully explored, although the subject has been researched for some high-strength steels (Rasmussen and Hancock, 1992; Beg and Hladnic, 1996). Further work needs to be performed to be able to confidently propose design rules.

The last range illustrated in Fig. 16 is the strain-hardening range, often referred to as the plastic range. Beams in this domain are able to achieve or exceed the full plastic moment, $M_{p}$. Such beams are designated as having compact sections. In the AISC Specifications (AISC, 1993) the beam is also required to attain an inelastic rotation capacity of three-times the rotation at the start of full plastification. In the AISC seismic design rules (AISC, 1992) more stringent slenderness limits are invoked to provide a rotation capacity of more than seven. Only beams with compact sections are permitted for use in plastic design. Thus, in the AISC Specification, a degree of ductility is expected for members of compact cross section. The definitions of slender, non-compact and compact behavior are further illustrated in Fig. 17 where a load-deflection plot is shown for a simply-supported beam under a concentrated central load. The heavy line represents the in-plane behavior, and the deviations from it define the types of buckling introduced by slenderness effects.

The classification of sections is defined somewhat differently in the Canadian Standard (CSA, 1994): Class 1 sections are permitted for plastic design, i.e., they must be able to rotate plastically after achieving the full plastic moment; Class 2 sections must reach the plastic moment but are not expected to have any appreciable ductility, Class 3 sections are non-compact, and Class 4 sections are slender profiles. Most of the world's modern design codes follow the Canadian example.

The next section presents a discussion of the effect of the shape of the stress-strain relationship on the stability of steel members. The following sections focus on the behavior of beams as an example of the applicability of current design theories to high-performance steels. Further extensions of these studies may be made for other types of structural behavior.

\subsection{In-Plane Capacity of Beam-Columns}

The load-deflection behavior of beam-columns is of great importance to the ultimate strength of frames. This behavior is a function of the stress-strain curve of the material, the cross-sectional 
shape, the residual stress distribution, the geometric imperfection, and the length of the member, in addition to the loads on the member. The in-plane behavior of beam-columns is well understood both from a theoretical and practical viewpoint, and methods of analysis have been long available to calculate the load-deflection curve up to and past the limit load (Galambos, 1988). Studies of the effect of two different high-performance steels were performed by Kuwamura (1992) to evaluate the effect of the yield stress-to-tensile strength ratio on the in-plane behavior of beam-columns. Two figures from Kuwamura's paper are reproduced in Fig. 18. The first set of graphs (Kuwamura's Fig. 7) are numerically obtained moment-rotation curves for constant axial loads for the two steels. The major-axis slenderness ratio for these members was 25. The termination of the curves corresponds to the attainment of the maximum inelastic stress equal to the tensile strength. One of these steels, $A$, has a low ratio of $F_{y} / F_{u}=0.74$, representative of the types of steel for which the original plastic design research was performed (e.g., A36 steel), while the other one, Steel B, has a much higher ratio of 0.93 . The load-deformation performance of steel A shows much more inelastic rotation capacity than does that of steel B.

The other figure from Kuwamura in Fig. 18 (Kuwamura's Fig. 8) presents experimental axial load-versus-axial shortening curves for stub-columns. The different curves are for various flange and web slenderness ratios. The load-deformation relationships are governed by local buckling.

These two sets of figures show that the shape of the stress-strain curve, especially the ability to strain-harden, has a significant effect on the ductility of the member when instability is important. Further research is needed to explore the limit strength of beam-columns for other types of high-performance steels.

\subsection{Review of Compactness Requirements for Beams}

The basic conundrums of plastic analysis and design have always been: what should be the unbraced length between lateral braces in the vicinity of a plastic hinge, and what is the limiting slendemess of the flange and the web of a compact cross section so that a full plastic mechanism can develop for the structure? At first only static load cases were considered, but since seismic design requires even more rotation capacity under repeated applications of earthquake shaking, the scope of the problem has expanded considerably.

The ductility behavior of structural members has two aspects: The rotation requirement and the rotation capacity. Historically the major research effort has gone into the determination of rotation capacity. Although many studies of the rotation requirements have been performed in the past forty or so years, definite answers have only been formalized for continuous composite beams (e.g., Kemp and Dekker, 1991). A generally accepted value of a rotation capacity requirement of three is implied for statically loaded structures in the AISC Specification (AISC, 1993) and seven or higher is implied for members in seismically designed structures (AISC, 1992). The former limit is based on research by Bansal (1971), and the latter is implicit in the requirements developed in the early plastic design work at Lehigh University. The reason for the relative dearth of explicit rotation requirements is due to the almost infinite structural combinations which should be considered. In the opinion of the writers of this report, rotation requirements are 
structure-specific and are therefore best addressed in the structural analysis of the specific frames under design investigation. It is now possible to call on "advanced" analysis programs which can provide the needed answers (White and Chen, 1993).

The problem of rotation capacity has a long and interesting history, and despite the large amount of research which has been performed, there is no full consensus on the subject (Moller, 1995). Studies on subjects of plastic instability started at Lehigh University in the early 1950's. This work was based on the application of the Theory of Plasticity to the stability of plates by Bijlaard (1947), Ilyushin (1947), Handelmann and Prager (1948) and Stowell (1948). The first work at Lehigh was by Haaijer and White (Haaijer, 1959; Haaijer and Thurlimann, 1960; and White, 1956), and it was the source of the compactness criteria for the first plastic design rules promulgated by the AISC in 1959. A second level of research activity on this topic at Lehigh University was started in 1960 by Galambos, Lee, Lay and Adams (Lee and Galambos, 1962; Lay, 1965 a and b, 1966; Lay and Galambos, 1965 a and b, 1966, 1967; Adams, 1965; Adams et al., 1965). A continuation of this work was carried on at the University of Alberta at Edmonton by Lukey and Adams (1969). This research was summarized and evaluated by Galambos (1968). The motivation for this second research activity was the availability of competitively priced high-strength steels up to $345 \mathrm{MPa}(50 \mathrm{ksi})$ yield stress in the early 1960 's. The major concern was whether these steels had the properties required for plastic design, and thus also seismic design. This research resulted in the compactness rules which are used throughout the world today in structural design specifications. The criteria for flange local buckling and laterally unbraced length in the AISC Specification are listed in Appendix 2, which gives formulas defining the compactness of the compression flange and spacing requirements for lateral bracing in the vicinity of a plastic hinge. Theoretically, the work rests on a plastic buckling model proposed by Lay and modified by experimental observations about inelastic behavior, including extensive tests on beams under uniform moment and under moment gradient. Lay's research will be further examined later in this report because it is based on the principles of mechanics and, therefore, can potentially be used to extrapolate to new steels with different properties than those of the steels in the original research, thus affording a degree of generality. First, however, other research will be briefly reviewed.

While Lay's buckling approach employs a bifurcation buckling model with stiffness values obtained from an assumed discontinuous yielding of the plate material, an entirely different approach was taken by Kato at Tokyo University in Japan. Kato considered the failure of flanges as being caused by a plastic plate mechanism. He published many papers on his work; the papers in 1989 and 1990 give a full summary of his life's work on this subject.

Studies that extended the Lehigh research were done by Kemp and his associates at the Witwatersrand University in South Africa (Kemp, 1986 a and b, 1984, 1990 and 1996; Kemp and Dekker, 1991). This work is semi-analytical, based on a reworking of Lay's buckling theory and on the assumption that, for a simply-supported beam under a central concentrated load, the sequence of failure is lateral-torsional buckling followed by local flange buckling. It was observed in the experiments that unloading below the maximum moment starts when the strain in the buckled compression flange equals the yield strain in the outer flange tip away from the local buckle. Lateral bracing exists at the ends and under the load point. For this same case Lay 
assumes that the sequence of failure is reversed: first local buckling, then lateral-torsional buckling. The reason for the different approaches between the two researchers is a matter of interpretation of test observations. Kemp's research involved an extensive re-analysis of the experiments performed at Lehigh and at Alberta, as well as a large number of new tests. The development of design criteria involved a number of numerical studies which are not general enough to give reliable answers for the new high-performance materials. For the traditional structural carbon steels, however, the predictions of the experimental rotation capacities by the semi-empirical equations are very good. For 44 tests, the mean test-to-prediction ratio of the rotation capacity is 1.05 , with a 0.32 standard deviation. Further details of Kemp's conclusions, including formulas and example calculations, are provided in Appendix 3. The example shows that for a simply-supported W16X26 beam with a central load, the rotation capacity is about 2.8 if $F_{y}=345 \mathrm{MPa}(50 \mathrm{ksi})$ and 1.0 if $F_{y}=552 \mathrm{MPa}(80 \mathrm{ksi})$. The rotation capacity is defined in Fig. 19 as the ratio of the rotation at the point where the unloading part of the curve crosses $M_{p}\left(\theta_{2}\right)$ less the elastic rotation at $M_{p}\left(\theta_{1}\right)$, to the elastic rotation at $M_{p}\left(\theta_{1}\right)$. The unbraced length in both instances is $50 r_{y}$, where $y$ is the minor axis radius of gyration. There is thus a substantial reduction of the rotation capacity for a steel with a higher yield stress according to this theory. It should be noted that the theory assumes the length of the plastic plateau equal to $s=10$, and a ratio of the elastic modulus-to-strain hardening modulus of $h=50$. This ratio is representative of the traditional steels but not of some high-performance steels (see Table 5).

Lay, Kemp and Kato attempted to use direct mechanistic models employing basic principles, combined with empirical observations and radical simplifications, to solve some very complex problems. This methodology has resulted in usable design rules, but their generality is limited by the material properties inherent in the model. Since the late 1970's problems of plastic buckling have also been solved by numerical techniques such as the finite strip method and the finite element method. The most extensive finite element studies were made by Dawe and Kulak at the University of Alberta in the 1980's, with the work carried on later by Dawe at the University of New Brunswick (Dawe and Kulak, 1984 a and b, 1986; Dawe and Grodin, 1985). This work resulted in new design criteria for the plastic local buckling of the webs of beams and beam-columns which were adopted in the Canadian specification. Numerical and experimental work at the University of Texas at Austin by Bansal (1971) gave the current rule for the plastic lateral bracing and the flange local buckling criteria in the AISC Specification. Numerical and experimental research germane to the definition of compactness was also conducted by Kuhlmann (1989) and Spangenmacher (1992) in Germany and by Murray and Khoo (1981), Bradford (1987), Hancock (1978) and Rasmussen and Hancock (1992) in Australia. The significance of the numerical work will be discussed later in the report.

The latest, but surely not the last, research on the subject of plastic local buckling is summarized in a doctoral dissertation by Moller at the Lulea Institute of Technology in Sweden. This thesis refutes Lay's theory by arguing that it contains a mistake relating to force equilibrium. To quote from Moller: "By this error, the whole theory of Lay falls, and it is hereby declared invalid." Moller then goes on to formulate a new plasticity model, not too dissimilar from Lay's model, which is then used in a numerical buckling analysis of a cruciform stub-column, failing by torsional buckling, which has two components: a) an incremental load-deformation model for an inelastic plate with initial imperfections for the early portion of the inelastic behavior, and b) a 
yield-line rigid-plastic mechanism for the post-buckling part of the load-deformation curve. Moller finds excellent agreement with his tests performed on cruciform-shaped stub-columns made with steels of around $345 \mathrm{MPa}(50 \mathrm{ksi})$ and $827 \mathrm{MPa}(120 \mathrm{ksi})$ yield stress. In conclusion, Moller made this statement: "Conclusively, in the comparison of equally slender flanges made of steels with different strengths, the higher strength flange seems to resist buckling better, in terms of higher ductility and higher strength" (emphasis by the authors of this report). Looking at the data presented by Moller, one has difficulty seeing where he got this conclusion. However, Moller may have stumbled upon a point that needs further study, namely, will extrapolation of current theories and specification rules indeed lead to compactness limits for high-performance steels that are too conservative? This question will be addressed next.

\subsection{Extension of Current Compactness Criteria for High-Performance Steels}

In this part of the report, the possibility of extending current knowledge to the development of compactness criteria for high-performance steels will be examined. First the AISC (1993) compactness nules will be discussed. The following two conditions will be addressed: a) flange local buckling criteria (AISC Table B.5) and b) spacing requirements for lateral bracing in the vicinity of a plastic hinge (AISC Eq. F1.7). These rules are listed in Appendix 2. The corresponding recommendations from Lay's theory are presented in Appendix 4. The web local buckling criteria will not be examined here, because the specification equations are empirically derived from a combination of finite element studies and experimental observations.

Flange local buckling: The AISC Specification defines the flange local buckling slenderness parameter as the ratio

$$
\lambda=\frac{b_{f}}{2 t_{f}}
$$

where $b_{f}$ is the flange width of the wide-flange section and $t_{f}$ is the flange thickness. The compactness limit is defined by the equation:

$$
\lambda_{p}=C \sqrt{\frac{E}{F_{y}}}
$$

where $C$ is a coefficient equal to 0.38 for an implied rotation capacity of three and is equal to 0.31 for an implied rotation capacity of seven or more. This latter rule applies to seismic design. The effect of material properties is thus represented simply by the inverse of the square root of the yield stress, $\mathrm{C}$ and $\mathrm{E}$ being the same for all steels. The corresponding equation from Lay's theory is: 


$$
\lambda_{\mathrm{Lay}}=\sqrt{\frac{4.1}{3+\frac{F_{u}}{F_{y}}} \sqrt{\frac{0.77 E}{F_{y}\left(1+\frac{h}{5.2}\right)}}}
$$

This is a more complicated relationship than the AISC formula involving the strain-hardening ratio, $h$, and the tensile strength of the steel, $F_{u}$, in addition to the yield stress, $F_{y}$. Comparisons between Eqs. 9 and 10 are given in Appendix 4. For example, the two AISC compactness limits are 9.34 and 7.62, respectively, for the modern A36 steels (steel C in Table 5), while the Lay equation gives 8.00. The comparison should be made for the seismic number which was adopted from the AISC rules for plastic design. As can be seen, the comparison is not too far off. This is as expected since the theory was developed for this type of steel. The comparison for A514 steel (Steel B in Table 5) is not as favorable: The AISC slenderness limits are 5.93 and 4.84, while Lay's equation gives 2.74 . Thus, as the strain-hardening modulus goes down, the theory predicts lower limits than the AISC rule. For this steel there is a direct comparison to experiment: McDermott (1969 a and b) tested beams rolled from this specific steel, and his conclusion from the experiments was that the limit should be 5.0. This result exceeds both the AISC seismic limits and the Lay criterion.

Plastic unbraced length limits: The AISC unbraced length limit equation for plastic design is a function of the moment gradient, and it is also inversely proportional to the yield stress (not the square root of this value). The equation is reproduced in Appendix 2 where a table with the unbraced length limits is also given for the four representative steels of Table 5. For the cases of uniform moment and one end-moment only, the minor-axis slenderness ratio limits are 12 and 30, respectively, for McDermott's A514 steel (Steel B in Table 5). Based on experiments, McDermott found that he could recommend limits of 21 and 36, respectively. The formulas for Lay's theory are listed in Appendix 4, and they are again strongly dependent on the plastic plateau-length ratio, $s$, and the strain-hardening ratio, $h$. The value of the limiting slenderness ratio for steel B for the case of uniform moment from Lay's equations is 11, nearly equal to the AISC value. Here again, the experiment appears to be less severe than the extrapolated rules based on Lay's theory.

Comments on the applicability of current rules and theories: The design rules for compactness in modern structural specifications are essentially the same in all steel design standards worldwide, and they all define the compactness and the lateral support spacing limits only as a function of the inverse of the yield stress without involving strain-hardening parameters or the yield stress-totensile strength ratio. The method which gives explicit formulas based on theoretical and empirical grounds is Lay's theory. Lay's formulas and the design rules give fairly consistent answers for steels with yield stress values at or below about $345 \mathrm{MPa}(50 \mathrm{ksi})$. This is as it should be, since the design rules were calibrated on Lay's predictions and were tested experimentally for steels with a yield stress ranging from $248 \mathrm{MPa}$ to $345 \mathrm{MPa}$ (36 ksi to $50 \mathrm{ksi}$ ). There are two reasons why the extension of current criteria to steels with higher strength is suspect:

1. The experimental evidence which exists (McDermott, 1969 a; Ricles, Sause and Green, 1996) indicates that predictions based on the extensions of existing theory and design 
criteria give unconservative answers for the compactness limits of the high-performance steels.

2. The theories which have been presented are semi-empirical, depending on test observations and on theory which is still being contested. Both Kemp's and Lay's theories depend very heavily on the extent of the plastic plateau and on the initial strain-hardening ratio ( $\mathrm{s}$ and $h$ on the stress-strain curve of Fig. 5). A typical experimental stress-strain curve for a high-performance steel (HSLA80) is shown in Fig. 1. It is very hard to really define either $s$ or $h$ on such a curve. Thus, in the current theory, too much emphasis is placed on quantities which are difficult to obtain and which may not be the relevant parameters anyway.

What can be done?: Many researchers have attempted to develop new theories based on a mechanistic approach. The phenomena of yielding, strain-hardening, plate buckling of the web and the compression flange acting independently or in concert, lateral buckling, twisting and cross-sectional distortion all occurring more-or-less at once may be just too complex to confine to an all-encompassing theoretical construct. One solution is finite element analysis, combined with carefully conducted selected physical experiments. This is perhaps not the most intellectually satisfying solution, but it will have to suffice as the best method to obtain the needed answers, at least for the time being. However, to quote again the doctoral thesis of Moller: "Finally, the finite element simulation offers [sic] little physical understanding of the problem since all the work is done by the computer and the guy that programmed the code." This is a rather cynical view, and it need not deter from the work that needs to be done. At this time, the finite element approach holds out the best path toward developing usable and reliable compactness limits for the new high-performance steels. The following section of this report will review what has been done and what still needs to be done to define the compactness criteria for high-performance steels.

\section{Establishing Compactness Requirements for High-Performance Steels}

In the previous section of this report it was pointed out that the solution to the compactness problem will need to progress along two avenues of attack: the experimental front and the finite element computational front. Before outlining what should be done in the future, it will be valuable to examine what work has already been done or is now in progress, again using research on compactness criteria of beams as an example of the type of research required.

\subsection{Experimental Results}

Experiments designed to study beam compactness limits and the associated issue of inelastic rotation capacity for traditional steels (i.e., steels with a yield stress of $345 \mathrm{MPa}(50 \mathrm{ksi})$ or less), have gone on for more than forty years. A considerable experimental data set exists to buttress the explicit and implicit requirements of the design specifications. These tests are reported in the following references: White 1956; Lee and Galambos 1962; Adams et al., 1965; Bansal 1971; 
Kato 1989 and 1990; Kemp and Dekker 1991; Kuhlmann 1989; Lukey and Adams 1969; Sawyer 1961; Spangenmacher 1992.

There are relatively few beam tests for high-performance steels. Two sets of tests will be examined in more detail in this report: a) the tests on A514 steel beams (Steel B in Table 5), performed at the US Steel research laboratory (McDermott, $1969 \mathrm{a}$ and b), and b) the experiments conducted at the ATLSS Center at Lehigh University as part of a current research project on HSLA80 steel, which is Steel D in Table 5 (Green, 1995; Green et al., 1995; Ricles et al., 1996; Sause et al., 1996). All of the test sets referred to above were conducted under static monotonic loading. Dynamic and cyclic effects were not studied, although the current program at Lehigh includes plans to test beams under cyclic loading. The pertinent results of the US Steel and the Lehigh tests are summarized in Tables 7, 8 and 9.

Table 7: The top part of this table lists the flange slenderness and the unbraced length slenderness ratios for five A514 beams which were tested under uniform moment (4-point loading: two symmetrically spaced concentrated loads on a simply-supported beam) by McDermott (1969 a). Lateral bracing was provided at the two load points and the two end-supports. The first three tests had closely spaced lateral braces in the constant moment region of the beam $\left(\mathrm{L}_{\mathrm{b}}\right.$ less than $\left.10 \mathrm{r}_{y}\right)$ and the compression flange width-thickness ratio ranged between 4 and 6 . Failure was by local buckling of the flange plate. The next two beams listed in the table had an unbraced slenderness ratio of around 25 and flange slenderness ratios of approximately 3 and 5 . Failure was by combined flange local buckling and lateral buckling in the region of uniform moment. The experimental rotation capacities are listed in the last column of the table at the top of Table 7. Test 4 is the only member which exhibited a larger rotation capacity, 8.4 , than the $R=7$ required by the AISC seismic criteria. (Rotation capacity is defined in Fig. 19.) Test 6 , with $R=2.4$, did not quite achieve the AISC requirement of $\mathrm{R}=3$ for compactness in non-seismic structures. In order to put the test results in perspective, the bottom listing in Table 7 gives the compactness requirements of the AISC Specification and of Lay's theory, as well as the limits recommended by McDermott in his paper. The flange width-thickness ratios of all the test specimens exceeded Lay's criterion; Test 3 and 4 exceeded the AISC seismic requirement, and Test 4 exceeds both the AISC and McDermott's limits. The test beams which came close to satisfying the AISC flange slenderness and lateral bracing requirements (Tests 3,4 and 5) demonstrated reasonable rotation capacity although Test 3 , with a high flange slenderness ratio, was marginal. The remaining two test beams ( 6 and 7 ), which were inadequately laterally braced by AISC's requirements, performed rather poorly as might be expected.

Table 8: Two additional beam experiments by McDermott (1969 a) are listed in this tabulation. The beams were under moment gradient, e.g., 3-point loading, with a central concentrated load applied to a simply-supported beam. Lateral bracing was provided at the two end supports and at the center of the beam at the load point. The unbraced length was in excess of the AISC criteria (slenderness ratio of 35 and 38 versus 30 ). The flange slendernesses were within the AISC seismic limits, but did not meet the Lay recommendation. The specimens deformed by combined local flange buckling and lateral-torsional buckling, but final failure was by the tensile fracture of the tension flange. The reported rotation capacities of 2.9 and 3.0 are marginally acceptable for the AISC non-seismic conditions. 
Table 9: Six tests performed on HSLA80 beams are listed in this table. Test 7 was a beam under uniform moment, and the others were under moment gradient. Except for Test 6, with a flange slenderness ratio of 9 , the flanges almost satisfied the AISC seismic compactness rule. The webs all had slenderness ratios below the AISC seismic criteria. The same is true for the unbraced slenderness ratios. The specimen of Test No. 1 finally failed by fracture of the tension flange, while the others all failed by combined flange and web local buckling. None of the beams achieved a rotation capacity of 7 but only Tests 2 and 7 had $R<3$.

\subsection{Finite Element Computation Results}

The finite element computations which will be discussed here were performed using the ABAQUS commercial software package. Two studies were available: the analyses performed by Green at Lehigh University (reported in Green et al., 1994; Green, 1995; Ricles et al., 1996) and those made by Earls at the University of Minnesota as part of this project. The results are presented in Tables 10, 11 and 12 .

Table 10: Ten beams were modeled for this finite element analysis (Ricles et al., 1996). Excellent correlation was achieved in predicting the complete moment-end rotation curve for Specimen 3 in Table 9 (see Fig. 18 in Ricles et al., 1996). The following description of the analysis is taken from the paper by Ricles et al. (1996):

"To extend the experimental data-base, analysis of HSLA80 steel beams were conducted, in which the geometric parameters for web and flange slenderness were systematically varied. This analytical parametric study involved a finite element model of a simply supported beam under a moment gradient. Initial imperfections and residual stresses due to welding were not included, while material nonlinearities were included. The von Mises yield criterion was used in an elastic-plastic material model that included isotropic strain hardening. The HSLA80 steel material characteristics were based on average properties, namely: yield stress of $\sigma_{y}=600 \mathrm{MPa}$; Young's modulus $E=206.9 \mathrm{GPa}$; Poisson's ratio of $v=0.3$; and strain-hardening modulus of $E_{x}=1034 \mathrm{MPa}$, which began immediately after the yield strain $\varepsilon_{y}=0.0029 \mathrm{~mm} / \mathrm{mm}$ was reached. An updated Lagrangian formulation, Green's strain and second Piola-Kirchoff stress were used to account for the effects of large displacements and finite strain. The Rik's method was utilized in the solution scheme to enable the post-ultimate strength behavior of the specimen to be determined. Lateral-torsional buckling was restrained in the models."

The beams analyzed were loaded by a three-point load system. The results in Table 10 show that there is a definite interaction between compression flange and web local buckling. The flange slenderness ratios 3,6 and 9, where the ratio of 6 is between the AISC requirements of 7 and 5.6 for seismic and non-seismic design, respectively. The web slenderness varied from 77.0 to 29.3. Two members exceeded the AISC seismic limit of 55.7 (Model Nos. 3 and 4). Only half of the beams exhibited a rotation capacity of 3 or more. Further numerical studies of this kind are 
needed to define an empirical relationship for the limiting flange and web slenderness ratios to achieve seismic and non-seismic compactness, i.e., $R=7$ and $R=3$, respectively.

Table 11: Tables 11 and 12 present the results of the analyses performed by Earls. These tables represent analyses performed on a W8X31 cross-section made from the four representative steels whose properties are listed in Table 5. The ABAQUS finite element program was checked against a beam-test performed under a three-point load arrangement and reported by Adams et al. (1965). The comparison of the moment-rotation relationship is shown in Fig. 20. The steel in this beam had essentially the same mechanical properties as Material $C$ in Table 5. The correlation is satisfactory, although the physical test showed a somewhat better ductility than the numerical test. Following is a description of the details of the computing method.

The ABAQUS Shell finite elements, designated in the program documentation as S9R5, were used to construct the W8X31 cross section of the beam members under consideration. The S9R5 is a 9-noded, 5 degrees-of-freedom per node, reduced integrated Mindlin-type non-linear shell finite element. The S9R5 element formulation addresses issues of element shear-locking through the use of a discrete Kirchoff method imposed by way of penalty functions. These elements use a $2 \times 2$ Gaussian quadrature scheme in-plane, and default 5-point Simpson's rule integration scheme through the thickness. In this research, the 5-point default was modified to a 9-point Simpson's rule integration, based on results of previous numerical experiments. This increase in the through-thickness integration order was found to improve the convergence characteristics of the models.

As a complement to the non-linear shell finite element formulations, the modified Riks-Wempner solution algorithm is used so that geometric non-linearities are considered in the modeling. Material non-linearities are incorporated into the models through the use of the ABAQUS Von Mises metal plasticity feature. The necessary constitutive data is included by specifying uniaxial tension stress-strain relations in terms of engineering stress and engineering strain. The stress-strain curve definitions of Fig. 3 are used. These are then converted to true stress and log-strain, respectively by a manually-entered sub-routine. The transformed material response parameters are then used by ABAQUS to extrapolate a failure surface in the three-dimensional stress space. The traditional classification of large-deflection small-strain would best describe the level of non-linearity of the models in this study.

The beam corresponding to the data in Table 11 is subjected to three-point loading where lateral support is provided under the load-point at the beam center and at the two end-supports. There is, therefore, interaction between flange and web local buckling and lateral-torsional buckling. The slenderness ratios for the flange, the web and the unbraced length are 7.8, 29.9 and 71, respectively. The corresponding AISC non-seismic and seismic limits, as well as Lay's recommendations, for each of the four materials are listed in Table 11. Only two of the four beams had a deformation capacity which exceeded $R=3$, namely, those made from the materials with low yield stress-to-tensile strength ratios of 0.74 and 0.71 . These were Steel A (Japanese steel) and Steel C (A36 steel), respectively. The other two tests did not perform in an acceptable manner, with deformation capacities of 0.3 and 1.3 , respectively. The individual 
load-versus-deflection curves generated by computer are shown in Fig. 21, while all four curves are compared in Fig. 22.

Table 12: The difference between the data in this table and that in previous one is that the beam is subjected to four-point loading, which puts the central unbraced segment under uniform moment. The side-spans are one-half the length of the unbraced center span and are rigid compared to the stiffness of the center span. Except for an unbraced slenderness ratio of 30 for the $A 36$ beams, the other beams have an unbraced slenderness ratio of 20 . The rotation capacities are quite high except for the $A 514$ beam ( $R=2.5$ as compared to 10,17 and 4, respectively, for the other beams). The moment-rotation curves are shown in Fig. 23. It should be realized that for these tests the rigid ends give an artificially high lateral restraint. This, combined with the relatively low unbraced length in the center and low web slenderness, make these tests useful for the study of the effect of flange local-buckling in the case of uniform bending. Indeed failure was observed due to flange buckling.

\section{Summary of the finite element analysis results:}

- There are reliable numerical tools available in commercial finite element software to solve inelastic beam problems in an efficient manner at a cost much less than the expense of the physical tests. Even so, the computation cost is not negligible since a super computer may be required. It also takes a considerable amount of time for the accumulation of experience by the analyst to intelligently input the correct material characterization and to display and interpret the results obtained from the computer.

- The physics of the problem is very complex: there is interaction between local flange and web-buckling and lateral-torsional buckling, and the shape of the stress-strain curve has a significant effect on the outcome, especially the behavior beyond the start of strain-hardening. Considerable numerical experimentation is needed to define limits of acceptable post-yield behavior. However, the fact that this can be accomplished has already been demonstrated on the much less complex problem of the bending of single-angle beams (Earls, 1995).

\section{Summary of Research Needs Workshop}

The previous sections of this report focused on several issues relating mainly to the questions of compactness and rotation capacity of statically loaded flexural members. A much broader set of issues was discussed at a workshop held at the University of Minnesota on June 1, 1996. The purpose of the workshop was to convene a group of experts on the design and analysis of steel structures to discuss the research which would be needed to incorporate new high-performance steels into structural steel design specifications. As expected of such a gathering, the topics discussed were wide-ranging and many of the research needs do not only pertain to the high-performance steels, but also to steel structures in general.

The discussions of research needs were organized on the basis of the following topical areas:

- Material properties 
- Cross section characteristics

- Connections

- Members

- Structural systems

Results of discussions in these topical areas are presented below.

\subsection{Material Properties}

It was noted in the beginning of the workshop that there is an ongoing initiative in the steel bridge engineering community to utilize high-performance steels for innovative new bridge design. The following improvements in the currently available steel inventory array were desired:

- Higher strength

- Improved fracture toughness

- Improved weldability

- Improved ductility

- Improved corrosion resistance and corrosion fatigue resistance.

The following challenges were posed to the steel-making industry by the bridge designers:

- Overcome the high yield stress-to-tensile strength ratio of current very-high-strength steels.

- Eliminate preheat and interpass temperature requirements in welding.

- Eliminate the wide variability of toughness resulting from some steel-making techniques.

- Provide adequate plate length and thickness ranges for use in plate-girder fabrication for bridges.

- Provide custom-rolled capabilities.

In the ensuing discussion many points related to material properties were brought up. The message was clearly expressed that desirable material properties for high-performance steels did not only include the optimal shape of the stress-strain curve, but also improved weldability, better corrosion and corrosion fatigue resistance, as well as reliable and high toughness. The term high-performance steel was defined as a steel that has qualities which are an improvement over those of existing steels, be that in strength, ductility, durability, weldabilty or toughness, and that these qualities be attained through new steel making technology. 
The following specific research needs were enumerated:

- Desirable stress-strain curves for different applications, such as bridge design, seismic design, plastic design, and "elastic" design, need to be defined and agreed upon by the specification-writing and steel-using community. The associated production costs should be developed by the steel-making community. Such information is necessary to decide on the course of action in future design specification modifications.

- Stress-strain curves should be characterized by a standard method, with consideration of expected variability. Methods should be recommended for the generation of statistical data so that resistance factors based on probabilistic criteria can be reliably determined.

- Steels should be produced to acceptable variabilities of the properties appropriate to the application, so that the designer can count on getting the type of behavior that is assumed in the design specification (see also Kuwamura, 1988; Kuwamura and Sasaki, 1990).

- Extensive work is needed for all new steels to assemble statistically convincing data for cyclic behavior, strain-rate effects, and performance in high and low temperature under both static and dynamic loading. This is a formidable task, and it would have to be attacked by stages, starting with the generation of stress-strain data for static applications.

- Design engineers and specification writers should more thoroughly understand the stress-strain curves of the various steels available for design, and specifications should provide more data on the material properties. This is especially important for the creative use of high-performance and other steels in seismic design applications.

- Variabilities of the yield stress and the tensile strength need to be reduced to acceptable values.

- Variabilities in hardness across the cross section are of concern, as well as the control of the martensitic layer on gas-cut edges.

The material problem with all steels, but especially with new high-performance steels, is very much a "chicken-and-egg" conundrum: much of the research needed to define the type of steel properties for different applications, such as, for example seismic design, involves physical tests on steel that has actually been made and is available for research. The evolution of the optimal high-performance steels will have to involve the creative cooperation between steel-makers and steel users. The key research issues on materials can be summarized as being the following:

\section{For the steel maker:}

- Develop cost figures for the feasible types of steels so that consequences of design requirements can be economically evaluated. (It is assumed that steel can be made for any requirement, but the greater the severity of the requirements, the greater the cost). 
- Generate statistical data on the material properties of the currently available high-performance steels, including stress-strain curves under static, dynamic, and cyclic loads, as well as information on toughness, weldability, corrosion resistance, and high and low temperature performance.

- Produce steels with properties which lie reliably within reasonable variations, so that the designer can count on the reproducibility of the design assumptions in the actual structure, in, say a severe earthquake.

\section{For the steel user:}

- Develop specific, and preferably numeric, desired criteria for corrosion resistance, overall and local ductility, toughness, weldability and high and low temperature performance.

- Develop the desired shape of the stress-strain curve, especially the post-yielding characteristics such as the strain-hardening modulus, the extent of the plastic plateau and the ratio of the yield stress-to-tensile strength for different applications, e.g., "elastic", plastic, seismic, and bridge design. Such information will have to be developed from systems, member and connection research (to be discussed later in this report).

- Develop a suitable testing technology which will give the material properties required by the specification writing bodies and the advanced designers the ability to evaluate the suitability of the steel for a given design condition.

It was understood by the participants of the workshop that it will not be possible to come up with one "super" material which has all of the desired qualities, but that a number of steel types would evolve, as discussed by Kuwamura (1992):

"The high-performance steels for earthquake resistant design are classified into the following three types of steels. The first one is a high strength steel of heavy section with good weldability, represented by TMCP (Thermo-Mechanical Control Process) steel. The second one is an extra-high strength steel providing satisfactory ductility when used in structural members, represented by low yield stress-totensile strength ratio steel. The third one is a stable quality steel characterized by little variation in its mechanical properties which may assure a stable ultimate behavior of a structural system such as a weak-beam strong column structure, represented by narrow yield-point range steel."

The search for a better steel must continue, perhaps finding the type of steel which is "just right" for the earthquake problem! 


\subsection{Cross Section Characteristics}

The following desires for new structural products were brought forward by the participants of the workshop:

- Creation of rolled shapes of high-performance steels for use by bridge and building designers.

- Application-specific optimal shapes, including tubular flanges, corrugated webs and sandwich panel webs, utilizing the advantage of the new steels creatively. Examples of such shapes for bridge structures were shown at the workshop. Further information on modern shapes were also given in the paper by Fisher and Dexter (1994).

- Use of high-performance steels in cold-formed profiles.

- Development of an efficient and reliable rolling procedure to limit the variation of hardness in the cross section, especially in the flange-to-web junction area.

- Develop statistics on the variation of material properties across rolled sections.

Opinions were expressed at the workshop that the likelihood of the availability of a wide range of rolled shapes is not probable in the near future, and that a better use of research would be to concentrate on shapes fabricated from plates by welding or cold-forming. This would involve a statistical study of the magnitude and distribution of residual stresses in various types of shapes made from high-performance steel.

The highest priority of research is the development of optimal shapes for applications in bridges and other structures.

\subsection{Connections}

It was emphasized during the discussion that joints in bridges tend to be larger than in buildings, with large moments to support. Transfer of research results from building-oriented studies to connections in bridges is often suspect. The following areas of future research on bridge connections were recommended:

- Fracture behavior of high-performance steel bolted connections and splices.

- Experiments on large splice and other connection plates to understand the effect of size on performance.

- Perform fatigue studies on appropriate weld details. 
The sub-group in the workshop that discussed connection behavior had the following contributions to make:

- Traditional connection design depends on a reserve of ductility and toughness in the material to complement design rules that often have been simplified or are based on limited test data. The new high-performance steels must be examined in particular to determine whether the current rules are still applicable. Products should be examined for toughness and ductility throughout the cross section, not just at arbitrary locations. The applicability of the rules to existing steels as they are currently produced should also be re-examined if the opportunity is available.

- Buckling issues in connections (e.g., web crippling, web yielding) are not expected to present any new problems if high-performance steels are used.

- It is obvious that the introduction of holes into a member with bolted connections will have the potential for presenting special problems when high-performance steels are used. This will be of particular concern for all steels in which the yield stress-to-ultimate strength ratio is significantly greater than the value for which the current design rules were promulgated. These issues are particularly related to the desire that fracture on the net cross section be preceded by yielding on the gross cross section. Flange fractures in beams should be avoided. The group felt that the investigation of the effect of holes in flanges of high-performance steel is a research need of high priority. It was also noted that the method of hole formation (drilled, punched, or sub-punched and reamed) could be of importance in high-performance steel members.

- Many aspects of connection design come from investigations that used monotonic loading. Cyclic loading studies for such topics as prying action, end-plate behavior, etc. are appropriate when high-performance steels are examined. Rate of loading should also be considered.

Research on connections made from high-performance steels was thought to be of major importance by the panelists. The following research needs can be identified for connections:

- Effect of the yield stress-to-tensile strength ratio on the behavior of tension connections, and tension components of bending connections, with bolt holes.

- The strength of tension connections under static and cyclic loads when prying action is present.

- The ability of the high-performance steel material to undergo large local strains under repetitive applications of load (see also Kuwamura and Yamamoto, 1995; Kuwamura, 1995).

- The complete reworking of all design specification criteria where fracture plays a role in the failure mechanism. 


\subsection{Members}

The behavior of members is closely linked to the problems resulting from their becoming unstable under load. The panelists felt that given the basic building blocks, e.g., the stress-versus strain characteristics of the steel, residual stress patterns, member initial out-of-straightness, and so on, the strength and ductility investigations for members made from high-performance steels is not too different philosophically than it is for the usual strength grades. These aspects include member capacity and ductility as well as local and lateral-torsional buckling. The following research needs were enumerated:

- In the range of elastic buckling, no new research is needed for the new steel grades. In the inelastic range (defined in Fig. 16 as the range where part of the cross section is yielded at buckling, but the full cross section strength is not yet attained) the current design criteria will have to be re-examined in the light of the residual stresses and initial deformations which exist. Column design curves and beam-column interaction equations will need to be developed if the actual behavior of high-performance steel members do not fit the design rules for conventional steel members. Statistical data on residual stresses and initial imperfections will have to be generated in order to perform the numerical analyses for developing column, beam and beam-column strength curves. However, no new theoretical insights are required to solve the inelastic buckling problems with the new steels.

- In the previous part of this report considerable attention was paid to the behavior of beams in the plastic range, where the full plastic moment must be maintained through a certain amount of rotation. The theoretical and experimental bases of the current design rules were shown to be inadequate to predict the behavior of beams of high-performance steels. Also, the available experimental and numerical studies were found to be insufficient for the promulgation of better limits for compactness of the members. Further numerical work with finite element methods is needed to obtain load-deformation data for the development of empirical equations for specification use. The emphasis must be on "system buckling" which explores the interaction between web local buckling and flange local buckling on the one hand, and member lateral-torsional buckling combined with cross-sectional distortion on the other hand. The workshop panelists felt that there may be a combination of large distortions which interact in complex ways in a rather localized portion of the member, resulting not only in loss of strength and ductility in an overall sense, but also in large local strains which could lead to fracture. This was believed to be especially so when the loads are applied cyclically.

- From a monotonic loading point of view the research needs are: more finite element studies to permit the development of slenderness criteria for given desired deformation capacities, i.e., the definition of rules for compactness for "elastic" design, plastic design and seismic design. Further laboratory experiments would be desirable, especially for steels newly arriving on the scene. From such work it will also be possible to define the kind of stress-strain curve that a high-performance steel must minimally possess to be considered for applications requiring large inelastic energy absorption. 
- The most pressing problem to be solved, not only for high-performance steels, but also for conventional steels, is the behavior of members under large inelastic cyclic loading. Work on this topic has been initiated at the State University of New York at Buffalo, and results have been presented by Lee et al. (1992), Sugiura et al. (1992), and Yang et al. (1995). In this research comparison was made between the cyclic buckling of tubular stub-columns made from mild carbon steel with a pronounced yield plateau, and similar specimens made from aluminum and from stainless steel with a rounded type of stress-strain curve. The mild steel stub column experienced a quickly deteriorating and complex behavior "Because of the presence of a plastic plateau of structural steel..." (Sugiura, 1992), while the other materials performed in a stable manner in the post-buckling cyclic range. The new high-performance steels, such as the HSLA80 steel do not have a pronounced plastic plateau (see Fig. 1 for the stress-strain curve), and so they may perhaps have an advantage over conventional steels.

\subsection{Structural Systems}

The research needs of structural systems evoked the largest amount of discussion, and it was dominated by the recent Northridge and Kobe earthquakes in 1994 and 1995, respectively. Following is a summary of the ideas presented by the participants:

Structural systems designed by "elastic" design:

- Determine the stiffness, strength, and ductility required of connections for the implied redistribution of forces in the "elastic" design method (which is the most used method of building design in non-seismic areas of the world).

- Investigate what detrimental influence, if any, second-order effects have on highperformance steel frames.

- Will it be necessary to revise the serviceability requirements for buildings made from the new steels?

- Develop an optimal balance between design for serviceability and strength.

- Develop possible new structural forms to utilize high-performance steels efficiently.

Available theory and tools are adequate to deal with the problems posed by "elastic" design for the new materials.

\section{Structural systems designed by plastic design for static loads}

The research needs for plastic design for the most part coincide with those given next by the needs for seismic design. The following specific ideas were brought up for plastic design for monotonic loading: 
- Using "advanced" methods of analysis, study the inelastic rotation requirements of representative frames (White and Chen, 1993).

- Develop simpler "macro" non-linear finite element models so that designers will have their own tools to calculate the rotation requirements of their individual structures under investigation.

\section{Structural systems designed for seismic loads}

The following research needs were presented by the participants of the workshop:

- System ductility is necessary to survive a severe earthquake. System ductility is governed by the type of framing of the structure (e.g., moment-resisting frame, braced frame, etc.). For each system, the ductility comes from member ductility and the connection strength in the yielding part of the system. Designer's wish to control the failure mechanism to identify the yielded part of the structure. This yield location in the design concept must actually be the same as the part actually yielding in a severe earthquake. Therefore, the yield stress of the steel must be well controlled, and the yielded member must have adequate rotation capacity. The connection must have adequate strength, and premature connection fracture must be avoided. From these viewpoints the major requirements for steels for use in seismic design are, in order of priority: (1) a narrow range in the variation of the yield stress; (2) a low yield stress-to-tensile strength ratio; (3) large ductility, i.e., a high ultimate strain-to-yield strain ratio; (4) a fracture toughness appropriate to the dynamic nature of the earthquake force.

- The effect of the whole stress-strain curve on the seismic performance of frames should be evaluated.

- The idea of the "weak-beam strong-column" should be studied in the context of the high-performance steels. Will the overall ductility demand be reduced?

- Optimization studies aimed at balancing the strength, ductility demand, and stiffness to develop higher R-values for seismic design. High-performance steels may be helpful in this context.

- General systems studies should be performed for seismic demands to investigate the following issues (with decreasing levels of importance) as they are influenced by the new types of steel: re-calibration of the R-factor; insuring survival of the building in a large earthquake; the effects of "fuses"; base isolators; the role of damping; active control devices.

- Check the feasibility of an entirely elastic path to resisting earthquake forces, not relying on redistribution. 
- Studies to determine the required rotation capacity for typical structures in earthquakes.

- Investigate if the second-order amplification factors in the specifications are still appropriate for the high-performance steel members.

- Perform extensive Monte-Carlo simulation studies of frame behavior with the higher strength steels. Perhaps less ductility is required than for conventional steels.

It should be remarked here again that many of the seismic system issues are common for all types of steel, and that many of the problems enumerated above are being actively investigated currently (time-period 1996 - 2000) by research groups at various laboratories in the country and by the SAC Joint Venture, under the sponsorship of the Federal Emergency Management Agency (FEMA).

\section{Bridge systems}

The problems of bridge systems are often quite different from those of buildings, except for the seismic considerations in steel frame and tower structures. The following research recommendations were discussed by the members of the workshop panel:

- Evaluate how much rotation capacity is actually needed for steel plate-girder bridges.

- Determine the effect of the high-performance steels on friction-bolted connections.

- Is mechanism-based plastic design viable for bridges made from high-performance steels? If the answer is "yes", then a different set of compactness criteria will be required than if the answer is "no". More stringent, and possibly prohibitive, criteria could result if the option of mechanism-based design is retained for continuous steel or composite steel and concrete girders. Steels such as HSLA80 might well be acceptable if design is based on no plastic mechanism formation. Design based on shake-down will also require less plastic deformation than the plastic mechanism.

- Cyclic and low-cycle fatigue behavior of members, especially beam-columns, used in bascule structures and tower legs should be investigated.

\section{Composite steel-concrete systems}

Very little explicit mention of composite structures and members was made in the workshop. However almost all the issues that were discussed are relevant for such structures also. A particularly challenging and timely topic is the inelastic behavior of high-strength steel tubes filled with high-strength concrete (Ricles et al., 1996).

A comment on the general tone of the work-shop: 
It appeared to the writers of this summary that the arrival of the new high-performance steels provides an excellent opportunity to re-examine the premises of the rules in the current design standards for steel structures design, using modern tools and high-technology methods. Many of the present criteria are 30 to 40 years old, and they were promulgated on research which was performed on steels no longer in use today.

\section{Summary and Recommendations}

The contents of this report derive from the following sources:

- Work performed specifically on studies of high-performance steel structures.

- The relevant literature on the subject of inelastic structural behavior of steel structures in general, and of high-performance steel structures in particular.

- The discussion of a workshop convened on June 1, 1996 at the University of Minnesota.

The general conclusion from the evaluation of the existing information is that the application of new high-performance steels in the design of Civil Engineering structures is feasible, but that considerable data obtainable from steel mills, further research, combined with technical and economic studies, are needed before these steels can be confidently used in design.

The reader should bear in mind that the focus of the study reported herein was the technical feasibility of using high strength high-performance steels in the construction of building and bridge structures, and not the economic feasibility. While, presumably, less high strength steel than conventional steel would be required in a design (based on strength), this apparent advantage may be offset by stability and stiffness limitations. Further, the cost of producing structural shapes, of either conventional or innovative section profile, using high strength high-performance steel is an unknown at this time. So an economic justification for the introduction of high strength steels has not been attempted.

Many suggestions for future work are discussed throughout this report. Following is a concise condensation of the most important of these:

Information desired by the structural engineer from the steel producer about high-performance steels:

- Knowledge of the complete stress-strain curve of the high-performance steel, especially data on stain-hardening and ductility.

- Toughness, corrosion resistance, and weldability data of high-performance steels. 
Research to obtain needed data to certify acceptability of the high-performace steels in current structural design specifications:

- Define what inelastic material properties are needed for the specific design applications of "elastic" design, plastic design, seismic design, and bridge design. Especially important are the strain-hardening modulus, the ratio of the yield stress-to-tensile strength, and the strain at the tensile strength.

- Obtain sufficient statistical data on the yield stress and the tensile strength of the representative high-performance steels so that robust values of the mean and standard deviation can be evaluated for checking the applicability of the probabilistic resistance factors in current specifications for steel building and bridge design.

- Perform laboratory tests and finite element studies on wide-flange beams under uniform moment and moment gradient to establish compactness criteria (i.e., limits of flange and web slenderness, as well as unbraced length limits) and rotation capacities under static and cyclic loading. Additionally, other issues should be revisited in light of the stress-strain characteristics of high-performance steels including welded and bolted beam-to-column joints under cyclic loading, fracture of joints with holes and other discontinuities, and fatigue strength of typical welded details.

- Perform analytical studies, verified by experiments, to determine the effect of lateral-torsional buckling on the behavior of beam-columns, in-plane moment-rotation relationships for laterally braced W-shaped beam-columns (including the effect of local buckling, under both static and dynamic loading) and required rotation capacity of typical continuous beams and frames using "advanced" methods of analysis.

- Initiate development projects in such areas as cross-sectional shape optimization, design criteria for specifications, design and testing of weldments, and earthquake design examples, especially for connections. 


\section{References}

Adams, P. F., Lay, M. G. and Galambos, T. V. (1965), Experiments on High Strength Steel Members, Welding Research Council Bulletin, No. 110, Nov.

Adams, P. F. (1964), Determination of the Static Yield Level and the Strain-Hardening modulus, Fritz Engineering Laboratory Report 297.7, Lehigh University, Bethlehem, PA

Adams, P. F. (1966), Plastic Design in High Strength Steel, Ph. D. Dissertation, Lehigh Univ. Bethlehem, PA

Adams, P. F. and Galambos, T. V.(1969), Material Considerations in Plastic Design, IABSE Publications, Volume 29-II, p. 1-18

AISC (1992), Seismic Provisions for Structural Steel Buildings, American Inst. of Steel Construction, Chicago, IL

AISI (1996), Specification for Cold-Formed Steel Structural Members, American Iron and Steel Inst., Washington, D. C.

American Institute of Steel Construction (1989), Specification for Structural Steel Buildings, Allowable Stress Design and Plastic Design, AISC, June 1, Chicago, IL

American Association of Bridge and Highway Officials (1994), AASHTO LRFD Bridge Design Specifications, 1st ed., AASHTO, June, Washington, C.C.

American Institute of Steel Construction (1993), Load and Resistance Factor Design Specification for Structural Steel Buildings, 2nd ed., AISC, Dec. 1, 1993, Chicago, IL

Ang, A.-H. S. (1961), Analysis of Frames With Non-Linear Behavior, Transactions of ASCE, Vol. 126, Part I, p. 823

Bansal, J. P. (1971), The Lateral Instability of Continuous Steel Beams, Ph. D. Dissertation, UT Austin

Beg, D, and Hladnik, L. (1996), Slenderness Limits of Class 3 I Cross Sections Made of High Strength Steel, J. of Constr. Steel Research, Vol. 38, No. 3, July, pp. 201 - 213

Bijlaard, P. P. (1947), Some Contributions to the theory of Elastic and Plastic Stability, International Assoc. of Bridge and Struct. Engrg. Vol. VIII

Bradford, M. A. (1987), Inelastic Local Buckling of Fabricated I-Beams, J. of Constr. Steel Research, Vol. 7, pp. 317-334 
Cattan, J. (1995), Statistical Analysis of Charpy V-Notch Toughness For Steel Wide Flange Structural Shapes, AISC, July

Civil Engineering Research Foundation (1993), High-Performance Structural Materials and Systems, ASCE CERF Tech. Report 93-5011, April, Washington, D. C.

CSA (1994), Limit States Design of Steel Structures, Canadian Standards Assoc. Toronto, ON

Dawe, J. L. and Kulak, G. L. (1984 b), Plate Instability of W-Shapes, ASCE J. Struct. Engrg., Vol 110, No. 6, June, p. 1278-1291.

Dawe, J. L. and Kulak, G. L. (1984 a), Local Buckling of W-shaped Columns and Beams, ASCE J. Struct. Engrg., Vol 110, No. 6, June, p. 1292-1304

Dawe, J. L. and Kulak, G. L. (1986), Local Buckling of Beam-Columns, ASCE J. Struct. Engrg., Vol 112, No. 11, Nov., p. 2447-2461

Dawe, J. L. and Grondin, G. Y. (1985), Inelastic Buckling of Steel Plates, ASCE J. Struct. Engrg., Vol 111, No. 1, Jan., p. 95-107

Dhalla, A. K. and Winter, G.(1974), Suggested Steel Ductility Requirements, ASCE J. Struc. Div. Vol. 100, No. ST2, Feb. 1974, p. 445-464

Dhalla, A. K., Errera, S. J. and Winter, G. (1971), Connections in Thin Low-Ductility Steels, ASCE J. Struct. Div., Vol. 97, No. ST10, Oct., p. 2549-2566

Earls, C. J. (1995), On the Use of Finite Element Analysis Techniques to Model Structural Steel Angle Response, Ph.D. Thesis, University of Minnesota, Dec. 1995

Fisher, W. J. and Dexter, R. J. (1994), High Performance Steel for America's Bridges, Welding Journal, Jan., p. 35-43

Fukumoto, Y. (1994), New Constructional Steels and Structural Stability, Proc. 50th Anniv. Conf., Struct. Stab. Res. Counc., June 21-22, Bethlehem, PA, p. 211-225

Galambos, T. V. ed (1988), Structural Stability Research Council Guide to Stability Design Criteria For Metal Structures, John Wiley, New York

Galambos, T. V. (1968), Deformation and Energy Absorption Capacity of Steel Structures in the Inelastic Range, Bulletin No. 8, March 1968, American Iron and Steel Institute

Galambos, T. V. and Ravindra, M. K. (1978), Properties of Steel For Use in LRFD, ASCE J. Struct. Div., Vol. 104, No. ST9, Sep., p. 1459-1468 
Gerardy, J. C. (1996), ASTM A913/A913M "The Perfect Steel for Seismic Design", ASCE Proc. of the Structures Congress, Apr. 1996, Chicago, II

Green, P. S., Sooi, T. K., Ricles, J. M., Sause, R. and Kelly, T. (1994), Inelastic Behavior of Structural Members Fabricated From High Performance Steel, Struct. Stab. Res.

Counc., Ann. Tech. Session Proc., 1994, Lehigh Univ. Bethlehem, PA, p. 435-456

Green, P. S. (1995), Inelastic Behavior of Members and Frames Fabricated From High-Performance Steel, Proposed research program for the Ph.D. dissertation, Lehigh University, Bethlehem, PA, July (private communication to the authors)

Haaijer, G. and Thurlimann, B. (1960), On Inelastic Buckling in Steel, ASCE Trans. Vol. 125 , pp. $308-338$

Haaijer, G (1959), Plate Buckling in the Strain-Hardening Range, ASCE Transactions, Vol. 124 , p. $117-148$

Hancock, G. C. (1978), Local, Distortional and Lateral Buckling of I-Beams, ASCE J. Struct. Div., Vol. 104, No. ST 11, p. 1787-1798

Handelmann, G. H. and Prager, W. (1948), Plastic Buckling of Rectangular Plate Under Edge Thrusts, NACA TN-1530, August

Horne, M. R. (1951), The Effect of Strain-Hardening on the Equalization of Moments in the Simple Plastic Theory, Welding Research, 5, p. 147

Horne, M. R. and Medland, I. C. (1966), Collapse Loads of Steel Frameworks Allowing for the Effect of Strain-Hardening, Proc., Inst. of Civil Engrs., Vol. 33, March, p. 381.

Hrennikoff, A. P. (1965), Importance of Strain-Hardening in Plastic Design, ASCE J. Struct. Div., Vol. 91, No. ST4, August, p. 23-34

Illyushin, A. A. (1947), Stability of Plates and Shells Beyond the Proportional Limit, NACA TM-116, October

Kato, B. (1990), Deformation Capacity of Steel Structures, J. Constr. Steel Research, Vol. 17, p. 33-94

Kato, B. (1989), Rotation Capacity of H-section Members as Determined by Local Buckling, J. Constr. Steel Research, Vol. 13, p. 95-109

Kemp, A. R. (1984), Slenderness Limits Normal to Plane of Bending for Beam-Columns in Plastic Design, J. Constr. Steel Research, Vol. 4, No. 2, p. 135-150 
Kemp, A. R., Dekker, N. W. (1991) Available Rotation Capacity in Steel and Composite Beams, The Struct. Eng., 5 March, Vol. 69, No. 5, p. 88-97

Kemp, A. R. (1986 a); Interaction of Plastic Local and Lateral Buckling, ASCE J. Struct. Engrg, Vol 111, No. 4, April, p. 374-382

Kemp, A. R. (1986 b), Factors Affecting the Rotation Capacity of Plastically Designed Members, The Struct. Engr., Vol. 64B, No. 2, June, p 28-35

Kemp, A. R. (1996); Inelastic Local and Lateral Buckling in Design Codes, ASCE J. Struct. Engrg, Vol 122, No. 4, April, p. 374-382

Kemp, A. R.(1990); Quantifying Limit-States of Rotation Capacity in Flexural members, Proc. Instn. Civ. Engr.. Part 2, Vol. 89, Sept., p. 387-406

Kuhlmann, U. (1989), Definition of Flange Slenderness Limits on the Basis of Rotation Capacity Values, J. Constr. Steel Research, Vol. 14, No. 1, p. 21-40

Kuranishi, S. (1995), The Shortening Characteristics of Columns of Strain-Hardening Material, Prel. Rep., "Stability of Steel Structures", Budapest, Hungary, p. I/63-I/70

Kuwamura, H. and Sasaki, M. (1990), Control of Random-Yield Strength For Mechanism-Based Seismic Design, ASCE J. Struct. Engrg. Vol. 116, No.1, Jan., p. 98-110

Kuwamura, H. (1988), Effect of Yield Ratio On the Ductility of High Strength Steels Under Seismic Loading, Proc. Annual Techn. Session, Struct. Stab. Res. Counc., Minneapolis, MN, Apr. 26-27, p. 201-210

Kuwamura, H. (1992), High Performance Steels for Earthquake Resistant Building Structures in Japan, in "Stability and Ductility of Steel Structures Under Cyclic Loading" (ed. Fukumoto, Y. and Lee, G. C.), CRC Press, p. 49-60

Kuwamura, H. and Yamamoto, K.(1995), Ductile Crack As a Trigger of Brittle Fracture in Steel, Univ. of Tokyo, Dept. of Architecture

Kuwamura, H. (1995), Transition Between Fatigue and ductile Fracture in Steel, Univ. of Tokyo, Dept. of Architecture

Lay, M. G. and Galambos,, T. V. (1965 b), Inelastic Steel Beams Under Uniform Moment, ASCE J. Struct. Div., Vol. 91, No. ST6, Dec., p. 67-93

Lay, M. G. and Smith, P. D. (1965), Role of Strain-Hardening in Plastic Design, ASCE J. Struct. Div., Vol. 91, No. ST3, June, p. 25-43 
Lay, M. G. and Galambos,, T. V. (1966), Bracing Requirements for Inelastic Steel Beams, ASCE J. Struct. Div., Vol. 92, No. ST2, Apr., p. 207-228

Lay, M. G. and Galambos,, T. V. (1965 a), Studies of the Ductility of Steel Structures, ASCE J. Struct. Div., Vol. 91, No. ST4, Aug. 1965, p. 125-151

Lay, M. G. (1966), A New Approach to Inelastic Structural Design, Proc., Inst. of Civil Engr., Vol. 33, March, p.1

Lay, M. G. (1965 b), Flange Local Buckling in Wide-Flange Shapes, ASCE J. Struct. Div., Vol. 91, No. ST6, Dec., p. 95-117

Lay, M. G. and Galambos, T. V. (1967), Inelastic Steel Beams Under Moment Gradient, ASCE J. Struct. Div., Vol. 93, No. ST1, Feb., p. 381-399

Lay, M. G. (1965 a), Yielding of Uniformly Loaded Steel Members, ASCE J. Struct. Div., Vol. 91, No. ST6, Dec., p. 49-68

Lee, G. C. and Galambos, T. V. (1962), Post-Buckling Strength of Wide-Flange Beams, ASCE J. Engr. Mech. Div., Vol. 88, No. EM1, Jan., p. 59-72

Lee, G. C., Chang, K.-C. and Sugiura, K. (1992),The Experimental Basis of Material Constitutive Laws of Structural Steel Under Cyclic and Non-Proportional Loading, in "Stability and Ductility of Steel Structures Under Cyclic Loading" (ed. Fukumoto, Y. and Lee, G. C.), CRC Press, p. 3-14

Lukey, A. F. and Adams, P. F. (1969), Rotation Capacity of Beams Under Moment Gradient ASCE J. Struct. Div., Vol. 95, No. ST6, Jun., p. 1173-1188

Macadam, J. N. et al. (1988), Low-Strain-Hardening Ductile-Steel Cold-Formed Members, Proc. 9th Intl. Specialty Conf. on Cold-Formed Steel Struct., St. Louis, MO., p.459-487

Mazzolani, F. M., Mele, E. and Piluso, V., Statistical Characterization of Constructional Steels For Structural Ductility Control, Costruzioni Metalliche, Vol. 2, p. 89-101

McDermott, J. F. (1969 b), Local Plastic Buckling of A514 Steel Members, ASCE J. Struct. Div., Vol. 95, No. ST9, Sep., p. 1837-1850

McDermott, J. F. (1969 a), Plastic Bending of A514 Steel Beams, ASCE J. Struct. Div., Vol. 95, No. ST9, Sep., p. 1851-1871

Moller, M. (1995), On Inelastic Local Flange Buckling, Ph. D. Thesis, Lulea Institute of Technology, Sweden 
Murray, N. W. and Khoo, P. S. (1981), Some Basic Plastic Mechanisms in the Local Buckling of Thin-Walled Steel Structures, Intl. J. of Mechanical Sciences, Vol. 23, No. 12, pp. $703-713$

Ramberg, W. And Osgood, R. (1943), "Description of Stress-Strain Curves by Three Parameters," Tchnical Note 902, NACA, Washington, D.C.

Rasmussen, K. J. R. and Hancock, G. J. (1992), Plate Slenderness Limits For High Strength Steel Sections, J. Constr. Steel Research, Vol. 23, pp. 73 - 96

Ricles, J. M., Lu, L. W., Graham, W. W. Jr. and Vermaas, G. W. (1996), Seismic Performance of CFT Column-WF Beam Rigid Connection, Report from Civil Engr. Dept, Lehigh Univ., Bethlehem, PA 1996

Ricles, J. M., Sause, R. and Green, P. S. (1996), High-Strength Steel: Implications of Geometric and Material Characteristics On Rotation Capacity, NSF US/Japan Seminar "Innovations in Stability Concepts and Methods for Seismic Design in Structural Steel", Honolulu, HI, July 14-18

Sause, R. and Fisher, J. W. (1996), Application of High-Performance Steels in Highway Bridges, ATLSS Engineering Research Center, Lehigh Univ., Bethlehem, PA 1996

Sawyer, H. A. (1961), Post-Elastic Behavior of Wide-Flange Steel Beams, ASCE J. Struct. Div., Vol. 87, No. ST8, December, p. 43-72

Sooi, T. K., Green, P. S., Sause, R., and Ricles, J. M. (1995), Stress-Strain Properties of High-Performance Steel and the Implications for Civil-Structure Design, Proc. Intl. Symp. on High-Performance Steel for Structural Applications, 30 Oct. - 1 Nov., Cleveland, Oh, p. 35-43

Spangemacher, R. and Sedlacek, G (1992), To the Demonstration of Sufficient Rotation Capacity of Plastic Hinges in Plastic Design, (in German), Stahlbau, Vol. 61, p. 329 $-339$

SSPC (1993), Statistical Analysis of Tensile Data For Wide-Flange Structural Shapes, Structural Shapes Producers Council, AISI

Stowell, A. (1948), A Unified Theory of Plastic Buckling of Columns and Plates, NACA Report 898

Sugiura, K., Watanabe, E., Lee, G. C. and Chang, K.-C. (1992), Instability of Steel Short Column Under Cyclic Loading, in "Stability and Ductility of Steel Structures Under Cyclic Loading" (ed. Fukumoto, Y. and Lee, G. C.), CRC Press, p. 15-23 
Thurlimann, B. (1960), New Aspects Concerning the Inelastic Stability of Steel Structures, ASCE J. Struct. Div., Vol. 86, No. ST1, Jan., p. 99

Vickery, B. (1961), The Influence of Deformations and Strain-Hardening on the Collapse Load of Rigid Frame Structures, Transactions, Institution of Engineers, Australia, Vol. CE3, No.2, Sept., p 103

White, M. W.(1956), The Lateral-Torsional Buckling of Yielded Structural Members, Ph. D. Thesis, Lehigh University, June

White, D. W. and Chen, W. F. (1993), Plastic Hinge Based Methods For Advanced Analysis and Design of Steel Frames, Struc. Stab. Res. Counc., Bethlehem, PA

Yamao, T., Sakimoto, T. and Iwatubo, K. (1995), Strength and Behavior of Stub-Columns Made of High Strength Steel With Low Yield Ratio, Prel. Rep., "Stability of Steel Structures", Budapest, Hungary, p. I/95-I/101

Yang, C. F., Lee, E. T., Chang, K. C. and Lee, G. C. (1995), Inelastic Behavior of Steel Members Under Non-Proportional Loading, ASCE, J. Eng. Mech., Vol. 121, No.1, Jan. p. 131-141

Yura, J. A., Galambos, T. V. and Ravindra, M. K. (1978), The Bending Resistance of Steel Beams, ASCE J. Struct. Div., Vol. 104, No. ST9, Sep., p. 1355-1370 
Table 1 - Tensile Coupon Properties of Japanese Steels

\begin{tabular}{|c|c|c|c|c|c|c|c|c|}
\hline $\begin{array}{l}\text { Name } \\
\text { of } \\
\text { Steel }\end{array}$ & $\underset{\mathbf{( k s i )}}{\mathbf{E}}$ & $\underset{(\mathbf{k s i})}{\mathbf{M} \mathbf{y}}$ & $\begin{array}{l}\mathbf{F}_{\mathbf{z}} \\
\text { (ksi) }\end{array}$ & $F_{y} / F_{z}$ & $\varepsilon_{\mathrm{st}} / \varepsilon_{\mathrm{y}}$ & $\varepsilon_{b} / \varepsilon_{y}^{* *}$ & $\varepsilon_{\mathrm{u}} / \varepsilon_{\mathrm{y}}$ & Source \\
\hline $\mathbf{A}$ & $\begin{array}{c}200,000^{*} \\
(29000)\end{array}$ & $\begin{array}{c}506 \\
(73.4)\end{array}$ & $\begin{array}{c}683 \\
(99.0)\end{array}$ & 0.74 & 1 & 6 & 36 & $\# 1$ \\
\hline B & $\begin{array}{c}200,000 * \\
(29000)\end{array}$ & $\begin{array}{c}661 \\
(95.9)\end{array}$ & $\begin{array}{c}710 \\
(103)\end{array}$ & 0.93 & 9 & 12 & 27 & $\# 1$ \\
\hline$A^{\prime}$ & $\begin{array}{c}200,000 * \\
(29000)\end{array}$ & $\begin{array}{c}478 \\
(69.3)\end{array}$ & $\begin{array}{c}636 \\
(92.2)\end{array}$ & 0.75 & 3 & 10 & 50 & $\# 1$ \\
\hline SM58 & $\begin{array}{r}211,000 \\
(30600)\end{array}$ & $\begin{array}{c}523 \\
(75.8)\end{array}$ & $\begin{array}{c}609 \\
(88.3)\end{array}$ & 0.86 & 8 & 20 & 32 & $\# 2$ \\
\hline LYR & $\begin{array}{r}208,000 \\
(30200)\end{array}$ & $\begin{array}{c}485 \\
(70.3)\end{array}$ & $\begin{array}{c}644 \\
(93.4)\end{array}$ & 0.75 & 1 & 9 & 52 & $\# 2$ \\
\hline B1 & $\begin{array}{c}200,000 * \\
(29000)\end{array}$ & $\begin{array}{l}593 \\
(86)\end{array}$ & $\begin{array}{l}676 \\
(98)\end{array}$ & 0.88 & 5 & 8 & 40 & $\# 3$ \\
\hline A2 & $\begin{array}{c}200,000^{*} \\
(29000)\end{array}$ & $\begin{array}{l}421 \\
(61)\end{array}$ & $\begin{array}{l}600 \\
(87)\end{array}$ & 0.70 & 2 & 9 & 57 & $\# 3$ \\
\hline A3 & $\begin{array}{c}200,000 * \\
(29000)\end{array}$ & $\begin{array}{l}448 \\
(65)\end{array}$ & $\begin{array}{l}586 \\
(85)\end{array}$ & 0.76 & 4 & 13 & 60 & $\# 3$ \\
\hline \multicolumn{9}{|c|}{$\begin{array}{l}\text { \#1 Kuwamura, } 1988 \\
\text { \#2 Yamao, 1995 } \\
\text { \#3 Fukumoto, } 1994\end{array}$} \\
\hline \multicolumn{9}{|c|}{$\begin{array}{l}* \text { nominal value } \\
* * \text { scaled from small graph in paper } \\
\varepsilon_{y}=F_{y} / E\end{array}$} \\
\hline
\end{tabular}


Table 2 - Tensile Coupon Properties of A514 Steel (McDermott, 1969 a)

\begin{tabular}{cccc} 
Property & Mean * & Standard deviation & Coeff. of Variation \\
\hline $\mathrm{F}_{\mathrm{y}}, \mathrm{MPa}(\mathrm{ksi})$ & $821(119)$ & $30(4.4)$ & 0.037 \\
$\mathrm{~F}_{\mathrm{u}}, \mathrm{MPa}(\mathrm{ksi})$ & $889(129)$ & $31(4.5)$ & 0.035 \\
$\varepsilon_{\mathrm{u}}$ & 0.07 & 0.013 & 0.19 \\
$\mathrm{E}_{\mathrm{st}}, \mathrm{MPa}(\mathrm{ksi})$ & $1,696(246)$ & $142(20.6)$ & 0.08 \\
$\varepsilon_{\mathrm{y}}=\mathrm{F}_{\mathrm{y}} / 29000$ & 0.0041 & & \\
$\mathrm{E} / \mathrm{E}_{\mathrm{st}}$ & 118 & & \\
$\mathrm{~F}_{\mathrm{u}} / \mathrm{F}_{\mathrm{y}}$ & 1.08 & \\
$\varepsilon_{\mathrm{st}} / \varepsilon_{\mathrm{y}}$ & 2 & & \\
$\varepsilon_{\mathrm{b}} / \varepsilon_{\mathrm{y}}$ & 7 & & \\
$\varepsilon_{\mathrm{u}} / \varepsilon_{\mathrm{y}}$ & 17 & & \\
$* 12$ tests & & & \\
\end{tabular}


Table 3 - Tensile Coupon Properties of HSLA80 Steel (Sooi et al., 1995)

\begin{tabular}{cccc} 
Property & Mean * & Standard Deviation & Coeff. of Variation \\
\hline $\mathrm{F}_{\mathrm{y}}, \mathrm{MPa}(\mathrm{ksi})$ & $585(84.9)$ & $26(3.8)$ & 0.045 \\
$\mathrm{~F}_{\mathrm{u}}, \mathrm{MPa}(\mathrm{ksi})$ & $665(96.5)$ & $28(4.1)$ & 0.042 \\
$\varepsilon_{\mathrm{u}}$ & 0.0816 & 0.00139 & 0.169 \\
$\mathrm{E}_{\mathrm{st}}, \mathrm{MPa}(\mathrm{ksi})$ & $1,524(221)$ & $352(51)$ & 0.233 \\
$\varepsilon_{\mathrm{y}}=\mathrm{F}_{\mathrm{y}} / 207,700$ & 0.00282 & & \\
$\mathrm{E} / \mathrm{E}_{\mathrm{st}}$ & 136 & & \\
$\mathrm{~F}_{\mathrm{u}} / \mathrm{F}_{\mathrm{y}}$ & 1.14 & & \\
$\varepsilon_{\mathrm{st}} / \varepsilon_{\mathrm{y}}$ & 2 & & \\
$\varepsilon_{\mathrm{b}} / \varepsilon_{\mathrm{y}}$ & 19 & & \\
$\varepsilon_{\mathrm{u}} / \varepsilon_{\mathrm{y}}$ & 29 & &
\end{tabular}

* 33 tests

Additional data from Green (1995) for A36 steel (one test):

$\mathrm{F}_{\mathrm{y}}=328 \mathrm{MPa}(47.5 \mathrm{ksi})$

$\mathrm{F}_{\mathrm{u}}=462 \mathrm{MPa}(67.0 \mathrm{ksi})$

$\varepsilon_{y}=0.00154$ (note: Fig. 1 gives the $0.2 \%$ offset yield strain)

$F_{\mathrm{u}} / \mathrm{F}_{\mathrm{y}}=1.41$

$\varepsilon_{\mathrm{st}} / \varepsilon_{\mathrm{y}}=11$

$\varepsilon_{\mathrm{b}} / \varepsilon_{\mathrm{y}}=25$

$\varepsilon_{\mathrm{u}} / \varepsilon_{\mathrm{y}}=136$ 
Table 4 - Tensile Coupon Properties from Trade Arbed Co. (Gerardy 1996)

\begin{tabular}{cccc} 
Material & ASTM A36 & ASTM A572 & ASTM A913* $^{*}$ \\
\hline $\begin{array}{c}\text { Nominal yield } \\
\text { stress }\end{array}$ & $36 \mathrm{ksi}$ & $50 \mathrm{ksi}$ & $65 \mathrm{ksi}$ \\
Mean yield stress & $49.2 \mathrm{ksi}$ & $57.6 \mathrm{ksi}$ & $75.3 \mathrm{ksi}$ \\
Standard deviation & $4.9 \mathrm{ksi}$ & $5.1 \mathrm{ksi}$ & $4.0 \mathrm{ksi}$ \\
Coeff. of Variation & 0.10 & 0.09 & 0.05 \\
Tensile strength & $68.5 \mathrm{ksi}$ & $75.6 \mathrm{ksi}$ & $89.7 \mathrm{ksi}$ \\
Standard deviation & $4.6 \mathrm{ksi}$ & $6.2 \mathrm{ksi}$ & $3.5 \mathrm{ksi}$ \\
Coeff. of Variation & 0.07 & 0.08 & 0.04 \\
$\mathrm{~F}_{\mathrm{u}} / \mathrm{F}_{\mathrm{y}}$ & 1.39 & 1.49 & 1.19
\end{tabular}

* ASTM 490: High-Strength Low-Alloy Steel Shapes of Structural Quality Produced by a Quenching and Self-Tempering Process 
Table 5 - Representative Material Properties for Analysis

\begin{tabular}{ccccccc} 
Property & $\begin{array}{c}\mathbf{F}_{\mathbf{y}} \\
\mathbf{M P a}(\mathbf{k s i})\end{array}$ & $\mathbf{F}_{\mathbf{y}} / \mathbf{F}_{\mathbf{u}}$ & $\varepsilon_{\mathbf{s t}} / \varepsilon_{\mathbf{y}}$ & $\varepsilon_{\mathrm{b}} / \varepsilon_{\mathbf{y}}$ & $\varepsilon_{\mathbf{z}} / \varepsilon_{\mathbf{y}}$ & $\mathbf{E} / \mathbf{E}_{\mathbf{s t}}$ \\
\hline $\begin{array}{c}\text { Steel A } \\
\text { Japanese }\end{array}$ & $483(70)$ & 0.74 & 2 & 10 & 50 & 46 \\
$\begin{array}{c}\text { Steel B } \\
\text { A514 }\end{array}$ & $821(119)$ & 0.93 & 2 & 7 & 17 & 118 \\
$\begin{array}{c}\text { Steel C } \\
\text { A36 }\end{array}$ & $331(48)$ & 0.71 & 10 & 25 & 136 & 30 \\
$\begin{array}{c}\text { Steel D } \\
\text { HSLA80 }\end{array}$ & $586(85)$ & 0.87 & 2 & 19 & 29 & 136
\end{tabular}


Table 6 - Coordinates for the Elastic-Plastic Analysis of the Three-Span Beam

\begin{tabular}{ccc}
$\mathbf{w} \mathbf{L}^{2} / \mathbf{M}_{\mathbf{y}}$ & $\Delta \mathrm{EI} / \mathbf{M}_{\mathbf{y}} \mathbf{L}^{2}$ & $\begin{array}{c}\text { Domain of } \\
\text { Applicability }\end{array}$ \\
\hline 0 & 0 & $\alpha<=1 / 2$ \\
$6(2 \alpha+3)$ & $(10 \alpha+3) / 64$ & $\alpha<=1 / 2$ \\
24 & $1 / 8$ & $\alpha<=1 / 2$ \\
\hline 0 & 0 & $\alpha>=1 / 2$ \\
$12(2 \alpha+3) /(2 \alpha+1)$ & $(10 \alpha+3) /(64 \alpha+32)$ & $\alpha>=1 / 2$ \\
24 & $\alpha / 4<=1.0$ & $\alpha>=1 / 2$ \\
\hline
\end{tabular}


Table 7 - Results of Tests on A514 Beams (McDermott 1969 a) Uniform Moment Case

\begin{tabular}{cccc} 
Test No. & $\mathbf{b}_{\mathbf{f}} / \mathbf{2 \mathbf { t } _ { \mathbf { f } }}$ & $\mathbf{L}_{\mathbf{b}} / \mathbf{r}_{\mathbf{y}}$ & $\begin{array}{c}\text { Rotation } \\
\text { Capacity } \\
\text { (Fig. 19) }\end{array}$ \\
\hline 3 & 6.05 & 7.3 & 4.8 \\
4 & 5.03 & 6.0 & 8.4 \\
5 & 4.03 & 5.4 & 6.3 \\
6 & 3.18 & 24.9 & 2.4 \\
7 & 4.80 & 23.9 & 3.6
\end{tabular}

Recommended compactness values:

\begin{tabular}{ccc} 
& {$\left[\mathbf{b}_{\mathbf{f}} / 2 \mathbf{t}_{\mathbf{f}}\right]_{\mathbf{p}}$} & $\mathbf{L}_{\mathbf{p d}} / \mathbf{r}_{\mathbf{y}}$ \\
\hline McDermott (1969) & 5.0 & 21 \\
AISC & 5.9 & 12 \\
AISC seismic & 4.8 & 12 \\
Lay & 2.8 & 11
\end{tabular}

Note: This is Steel B in Table 5. The cross sections are wide-flange shapes Loading: 4-point loading 


\section{Table 8 - Results of Tests on A514 Beams (McDermott 1969 a) Moment Gradient Case}

\begin{tabular}{cccc} 
Test No. & $\mathbf{b}_{\mathrm{f}} / \mathbf{2 \mathbf { t } _ { \mathrm { f } }}$ & $\mathbf{L}_{\mathrm{b}} / \mathbf{r}_{\mathbf{y}}$ & $\begin{array}{c}\text { Rotation } \\
\text { Capacity } \\
\text { (Fig. 19) }\end{array}$ \\
\hline A & 3.23 & 37.5 & 2.9 \\
B & 4.82 & 35.4 & 3.0
\end{tabular}

Recommended compactness values:

\begin{tabular}{ccc} 
& {$\left[\mathbf{b}_{\varepsilon} / 2 \mathbf{t}_{\mathrm{f}}\right]_{\mathrm{p}}$} & $\mathbf{L}_{\mathrm{pd}} / \mathbf{r}_{\mathrm{y}}$ \\
\hline McDermott (1969 a) & 5.0 & 36 \\
AISC & 5.9 & 30 \\
AISC seismic & 4.8 & 30 \\
Lay & 2.8 &
\end{tabular}

Note: This is Steel $B$ in Table 5. The cross sections are wide-flange shapes.

Loading: 3-point loading 
Table 9 - Results of Tests on HSLA80 Wide-Flange Beams (Ricles et al., 1996)

\begin{tabular}{cccccc}
$\begin{array}{c}\text { Test } \\
\text { No. }\end{array}$ & $\mathbf{b}_{\mathbf{f}} / \mathbf{2} \mathbf{t}_{\mathbf{f}}$ & $\mathbf{h} / \mathbf{t}_{\mathbf{w}}$ & $\mathbf{L}_{\mathbf{b}} / \mathbf{r}_{\mathbf{y}}$ & $\begin{array}{c}\text { Rotation } \\
\text { Capacity }\end{array}$ & $\begin{array}{c}\text { Loading } \\
\text { Type }\end{array}$ \\
\hline 1 & 3.0 & 28.75 & 26 & 4.2 & 3-point \\
2 & 6.0 & 45.92 & 26 & 1.3 & 3-point \\
3 & 6.0 & 29.33 & 27 & 5.8 & 3-point \\
$4 \mathrm{~A}$ & 6.0 & 53.33 & 31 & 3.2 & 3-point \\
6 & 9.0 & 29.33 & 17 & 3.5 & 3-point \\
7 & 6.0 & 53.33 & 14 & 2.6 & 4-point
\end{tabular}

Recommended compactness values:

\begin{tabular}{ccccc} 
& {$\left[\mathbf{b}_{\mathbf{f}} / 2 \mathbf{t}_{\mathbf{f}}\right]_{\mathbf{p}}$} & {$\left[\mathbf{h} / \mathbf{t}_{\mathbf{w}}\right]_{\mathbf{p}}$} & {$\left[\mathbf{L}_{\mathbf{p d}} / \mathbf{r}_{\mathbf{y}}\right]_{\text {3point }}$} & {$\left[\mathrm{L}_{\mathbf{p d}} / \mathbf{r}_{\mathbf{y}}\right]_{\text {hpoint }}$} \\
\hline AISC & 7.0 & 69.4 & 42 & 17 \\
$\begin{array}{c}\text { AISC } \\
\text { seismic } \\
\text { Lay }\end{array}$ & 5.7 & 56.0 & 42 & 17
\end{tabular}

Note: This is Steel $D$ in Table 5 
Table - 10 Results of Finite Element Studies (Ricles et al., 1996)

\begin{tabular}{lcccc} 
& $\begin{array}{c}\text { FEM } \\
\text { Model No. }\end{array}$ & $\mathbf{b}_{\mathbf{f}} / \mathbf{2 \mathbf { t } _ { \mathbf { f } }}$ & $\mathbf{h} / \mathbf{t}_{\mathbf{w}}$ & $\begin{array}{c}\text { Rotation } \\
\text { Capacity }\end{array}$ \\
\hline 1 & 6.0 & 29.3 & 4.7 \\
2 & 6.0 & 38.0 & 4.5 \\
3 & 6.0 & 77.0 & 2.0 \\
& 4 & 6.0 & 61.3 & 1.9 \\
& 5 & 6.0 & 58.7 & 2.6 \\
& 6 & 6.0 & 53.3 & 3.0 \\
& 7 & 9.0 & 53.3 & 2.5 \\
& 8 & 3.0 & 53.3 & 2.8 \\
Compactness & 9 & 9.0 & 29.3 & 3.6 \\
Criteria: & AISC & 7.0 & 68.6 & \\
\cline { 2 - 5 } & AISC seismic & 5.6 & 55.7 & \\
& Lay & 2.6 & & \\
\cline { 2 - 5 } & & 3.0 & 29.3 & 5.6 \\
\cline { 2 - 5 } & & & &
\end{tabular}

Notes:

3-point loading

$\mathrm{F}_{\mathrm{y}}=600 \mathrm{MPa}(87.0 \mathrm{ksi})$

$\mathrm{E}=206,900 \mathrm{MPa}(30,000 \mathrm{ksi})$

$\mathrm{E}_{\mathrm{s}}=1034 \mathrm{MPa}(150 \mathrm{ksi})$

$\mathrm{h}=200$

lateral-torsional buckling is prevented

$s=1$; no plastic plateau 


\section{Table 11 - Results of Finite Element Studies Performed by C. Earls}

For This Project

\begin{tabular}{cccccccc}
$\begin{array}{c}\text { Type of } \\
\text { Steel } \\
\text { Table 5) }\end{array}$ & $\begin{array}{c}{\left[\mathbf{b}_{\mathbf{f}} / 2 \mathbf{t}_{\mathbf{f}}\right]_{\mathbf{p}}} \\
\text { AISC }\end{array}$ & $\begin{array}{c}{\left[\mathbf{b}_{\mathbf{f}} / 2 \mathbf{t}_{\mathbf{f}}\right]_{\mathbf{p}}} \\
\text { AISC } \\
\text { seismic }\end{array}$ & $\begin{array}{c}\left.\mathbf{b}_{\mathbf{f}} / 2 \mathbf{t}_{\mathbf{f}}\right]_{\mathbf{p}} \\
\mathbf{L a y}\end{array}$ & $\begin{array}{c}{\left[\mathbf{h} / \mathbf{t}_{\mathbf{w}}\right]_{\mathbf{p}}} \\
\text { AISC }\end{array}$ & $\begin{array}{c}{\left[\mathbf{h} / \mathbf{t}_{\mathrm{w}}\right]_{\mathbf{p}}} \\
\text { AISCC } \\
\text { seismic }\end{array}$ & $\mathbf{L}_{\mathbf{p d}} / \mathbf{r}_{\mathbf{y}}$ & $\begin{array}{c}\text { Rotation } \\
\text { Capacity }\end{array}$ \\
\hline A & 7.7 & 6.3 & 5.5 & 77 & 62 & 51 & 4.6 \\
B & 5.9 & 4.8 & 2.8 & 59 & 48 & 30 & 0.3 \\
C & 9.3 & 7.6 & 8.0 & 92 & 75 & 75 & 5.2 \\
D & 7.0 & 5.7 & 3.1 & 69 & 56 & 42 & 1.3
\end{tabular}

Notes:

Three-point loading, with lateral braces at the supports and under the load point Cross section used in these analyses: W8X13

Flange slenderness ratio, $b_{\mathrm{f}} / 2 \mathrm{t}_{\mathrm{f}}=7.8$

Web slenderness ratio, $h / t_{w}=29.9$

Unbraced length slenderness ratio, $\mathrm{L}_{\mathrm{b}} / \mathrm{r}_{\mathrm{y}}=71$ 
Table 12 - Results of Finite Element Studies Performed by C. Earls For This Project

\begin{tabular}{|c|c|c|c|c|c|c|c|c|c|}
\hline $\begin{array}{l}\text { Type of } \\
\text { Steel } \\
\text { (Table 5) }\end{array}$ & $\mathbf{L}_{\mathbf{b}} / \mathbf{r}_{\mathbf{y}}$ & $\begin{array}{c}{\left[\mathbf{b}_{\mathrm{f}} / 2 \mathrm{t}_{\mathrm{t}}\right]_{\mathrm{p}}} \\
\text { AISC }\end{array}$ & $\begin{array}{c}{\left[b_{r} / 2 t_{t}\right]_{p}} \\
\text { AISC } \\
\text { seismic }\end{array}$ & $\begin{array}{c}{\left[\mathbf{b}_{\mathbf{r}} / 2 \mathbf{t}_{\mathbf{t}}\right]_{\mathbf{p}}} \\
\text { Lay }\end{array}$ & $\begin{array}{c}{\left[\mathbf{h} / \mathbf{t}_{\mathbf{w}}\right]_{\mathrm{p}}} \\
\mathbf{A I S C}\end{array}$ & $\begin{array}{c}{\left[\mathbf{h} / \mathrm{t}_{\mathrm{m}}\right]_{\mathrm{p}}} \\
\text { AISC } \\
\text { seismic }\end{array}$ & $\begin{array}{l}\mathbf{L}_{\mathrm{pd}} / \mathbf{r}_{\mathrm{y}} \\
\text { AISC }\end{array}$ & $\begin{array}{c}\mathbf{L}_{\mathbf{p d}} / \mathbf{r}_{\mathbf{y}} \\
\mathbf{L a y}\end{array}$ & $\begin{array}{l}\text { Rotation } \\
\text { Capacity }\end{array}$ \\
\hline A & 20 & 7.7 & 6.3 & 5.5 & 77 & 62 & 20 & 23 & 10 \\
\hline B & 20 & 5.9 & 4.8 & 2.8 & 59 & 48 & 12 & 11 & 2.5 \\
\hline C & 30 & 9.3 & 7.6 & 8.0 & 92 & 75 & 27 & 34 & 17 \\
\hline D & 20 & 7.0 & 5.7 & 3.1 & 69 & 56 & 17 & 13 & 4 \\
\hline
\end{tabular}

Notes:

Four-point loading, with lateral braces at the supports and under the load points

Cross section used in these analyses: W8X13

Flange slenderness ratio, $b_{\mathrm{f}} / 2 \mathrm{t}_{\mathrm{f}}=7.8$

Web slenderness ratio, $\mathrm{h} / \mathrm{t}_{\mathrm{w}}=29.9$

The length of the lateral restraining span is $\mathrm{L}_{b} / 2$

The stiffness of the laterally restaining span is very large compared to the stiffness of the W8X13 segment in the ceter segment, which is under uniform moment. 


\section{STRESS VS. STRAIN RELATIONSHIP}

\section{HSLA80 vs. A36 STEEL}

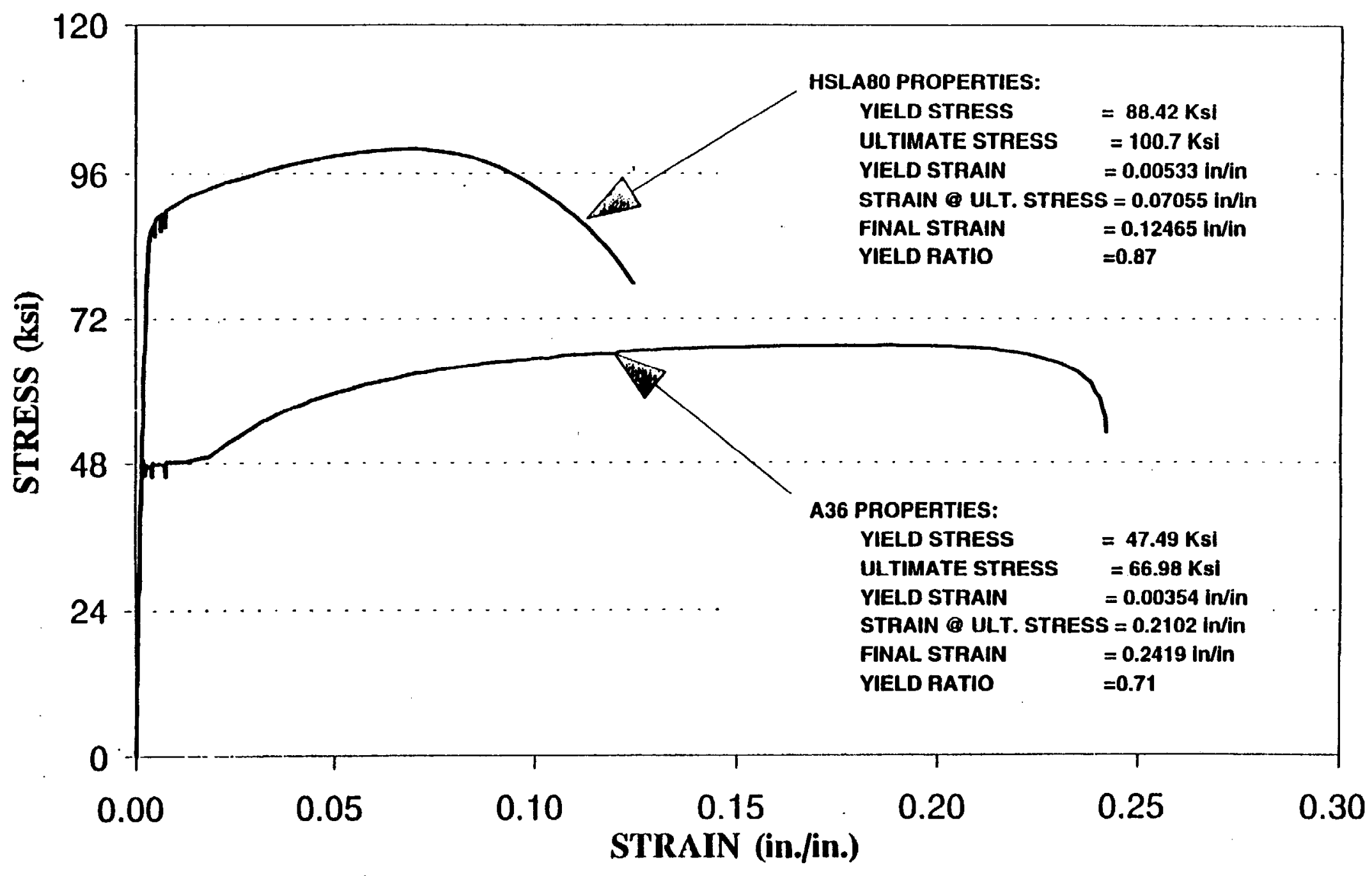

Figure 1 Comparison of HSLA80 and A36 Stress-Strain Relationships 
Fig. 2 Stress-Strain Curve Model No. 1

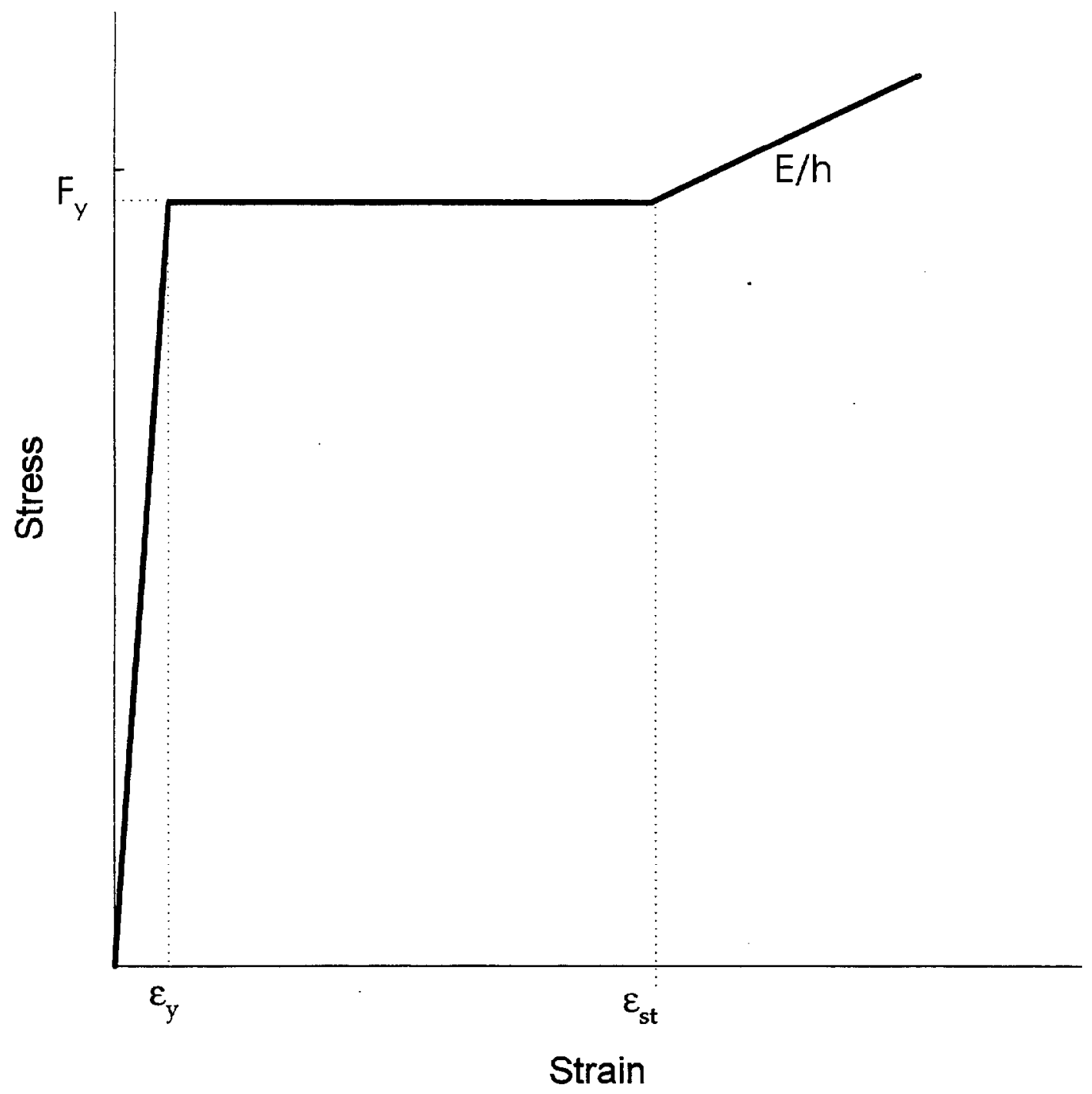


Fig. 3 Stress-Strain Curve Model No. 2

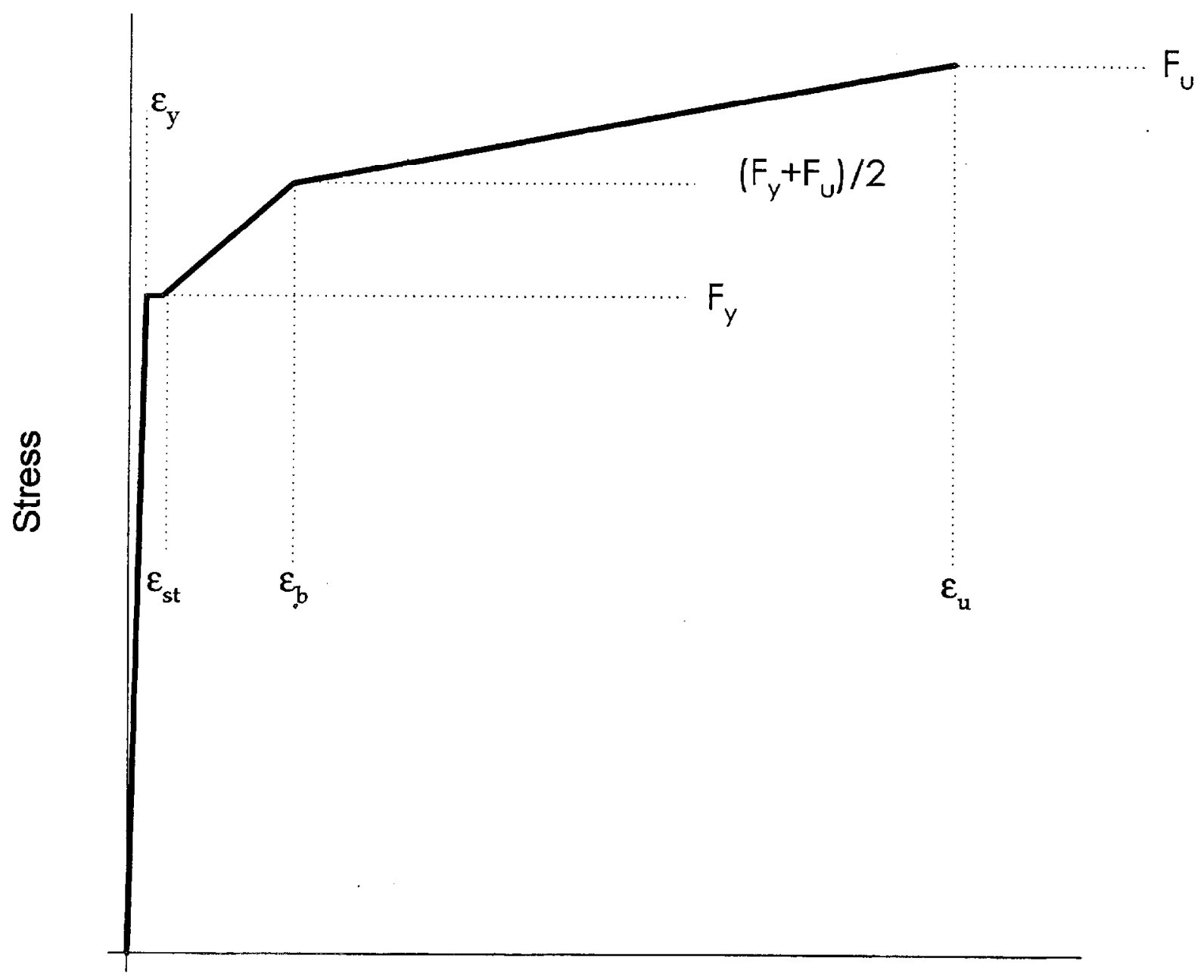

Strain 
Fig. 4 Stress-Strain Curve Model No.3

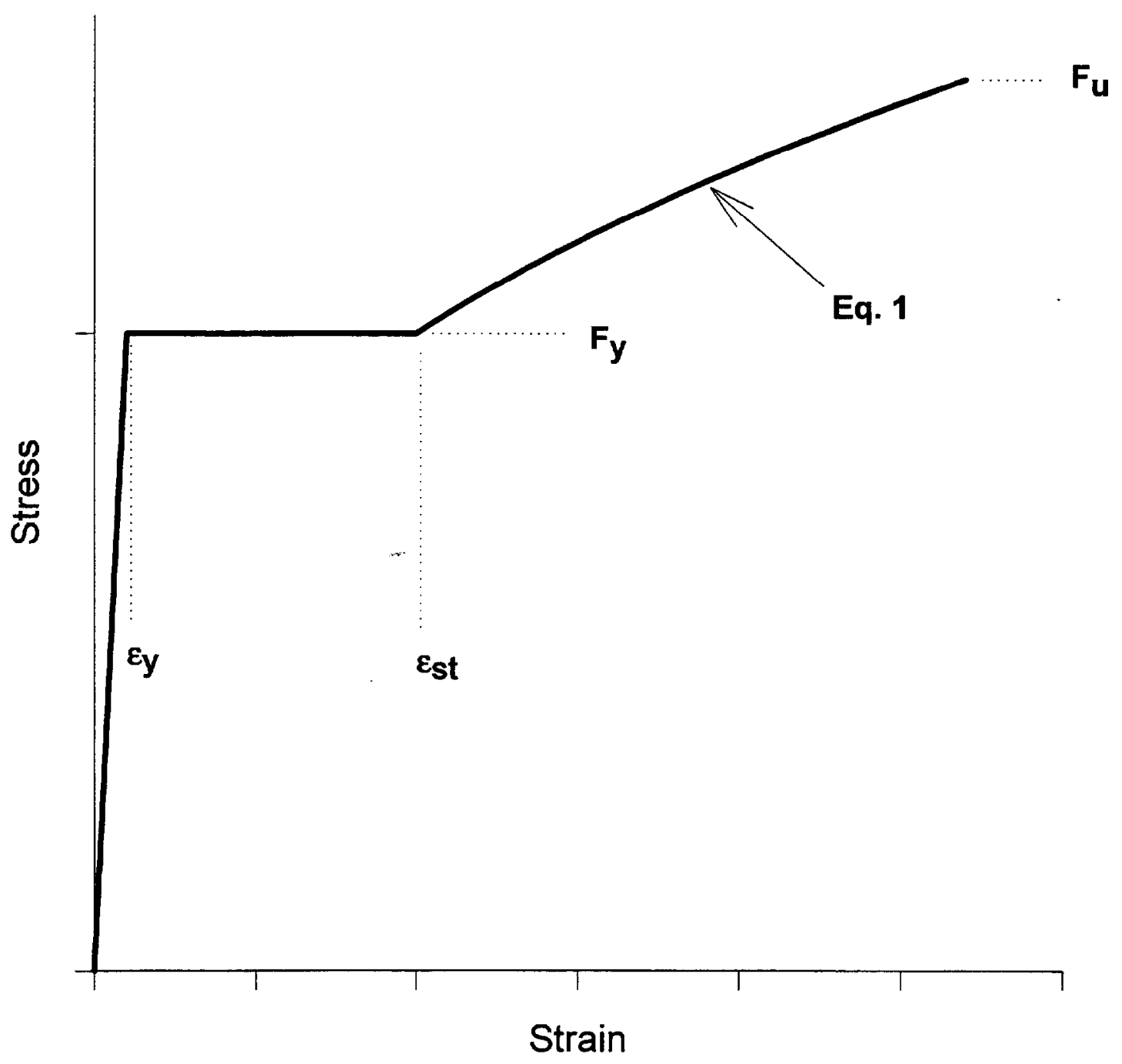


Fig 5 Effect of Stress-Strain Curve on load-deflection relations of rectangular indeterminate beams

\section{LOADING AND BEAM GEOMETRY}

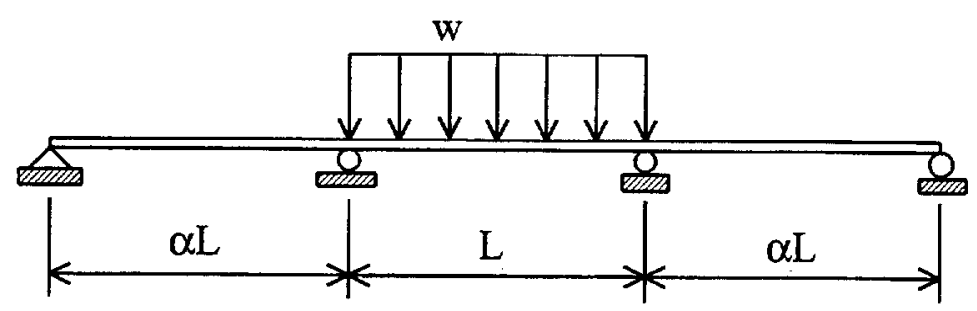

\section{STRESS-STRAIN CURVE}

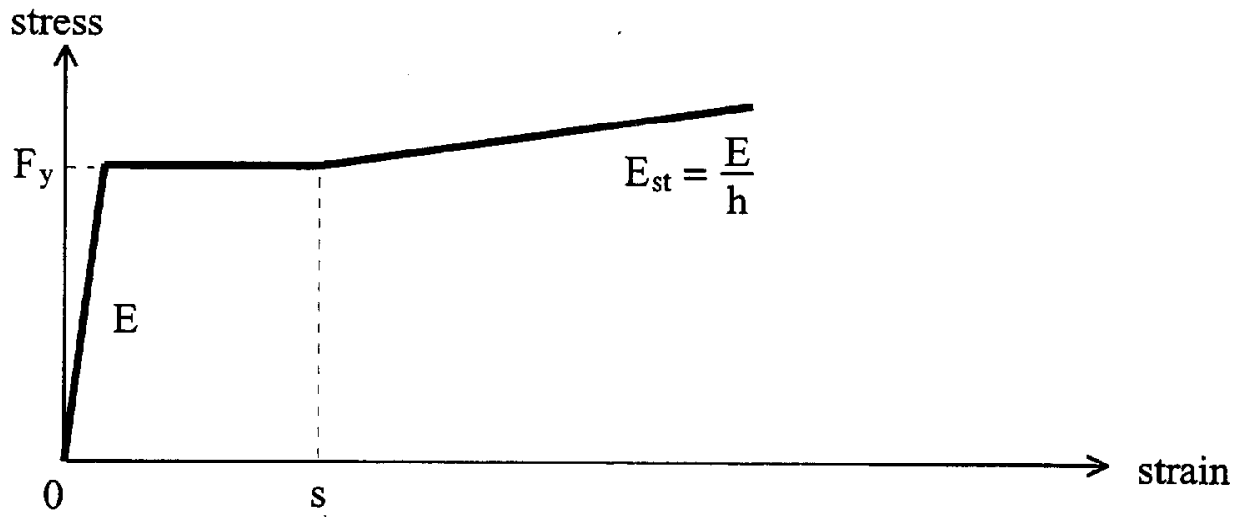


Fig. 6 Effect of end restraint, rectangular shape

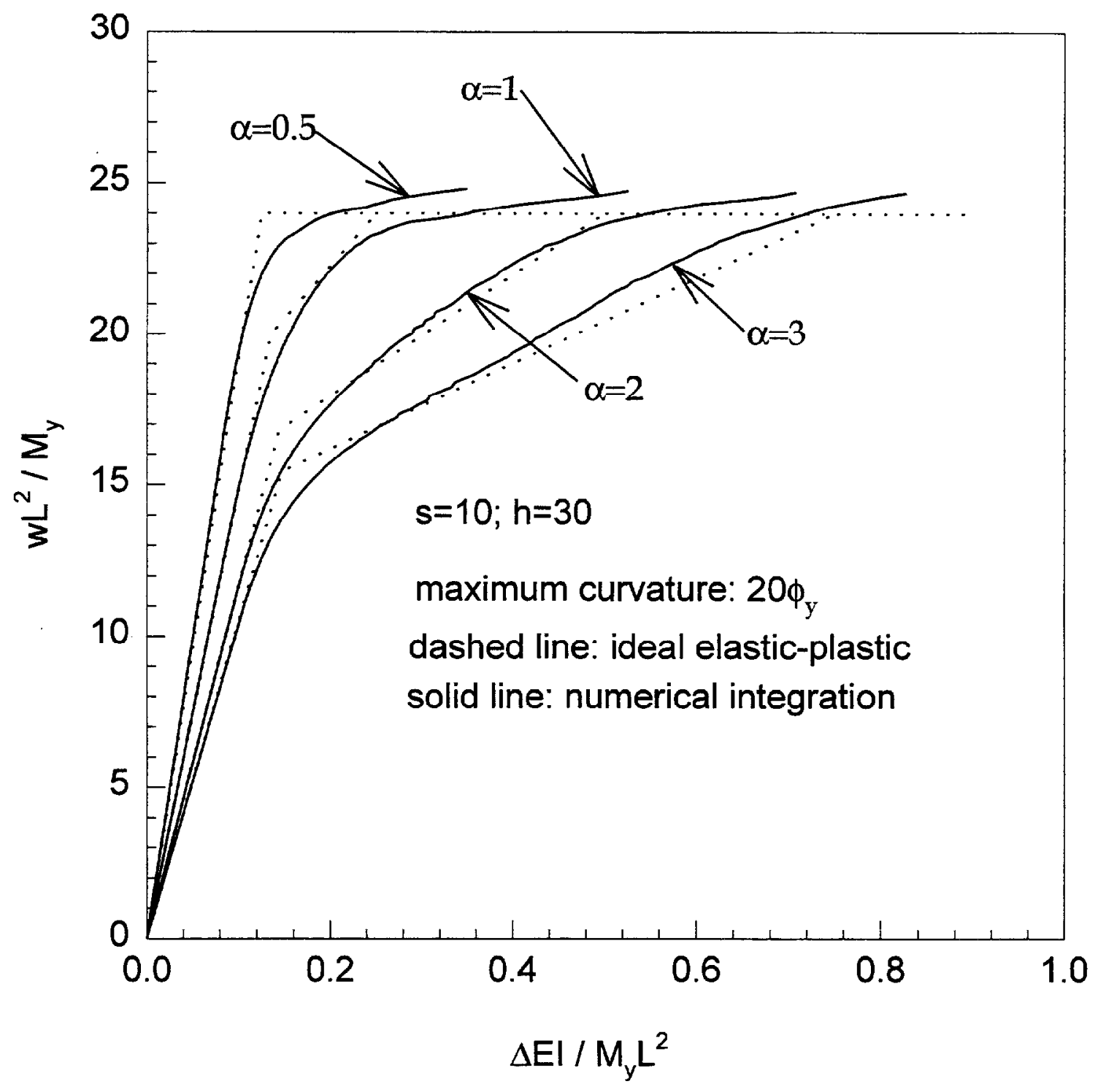


Fig. 7 Effect of end restraint, rectangular shape

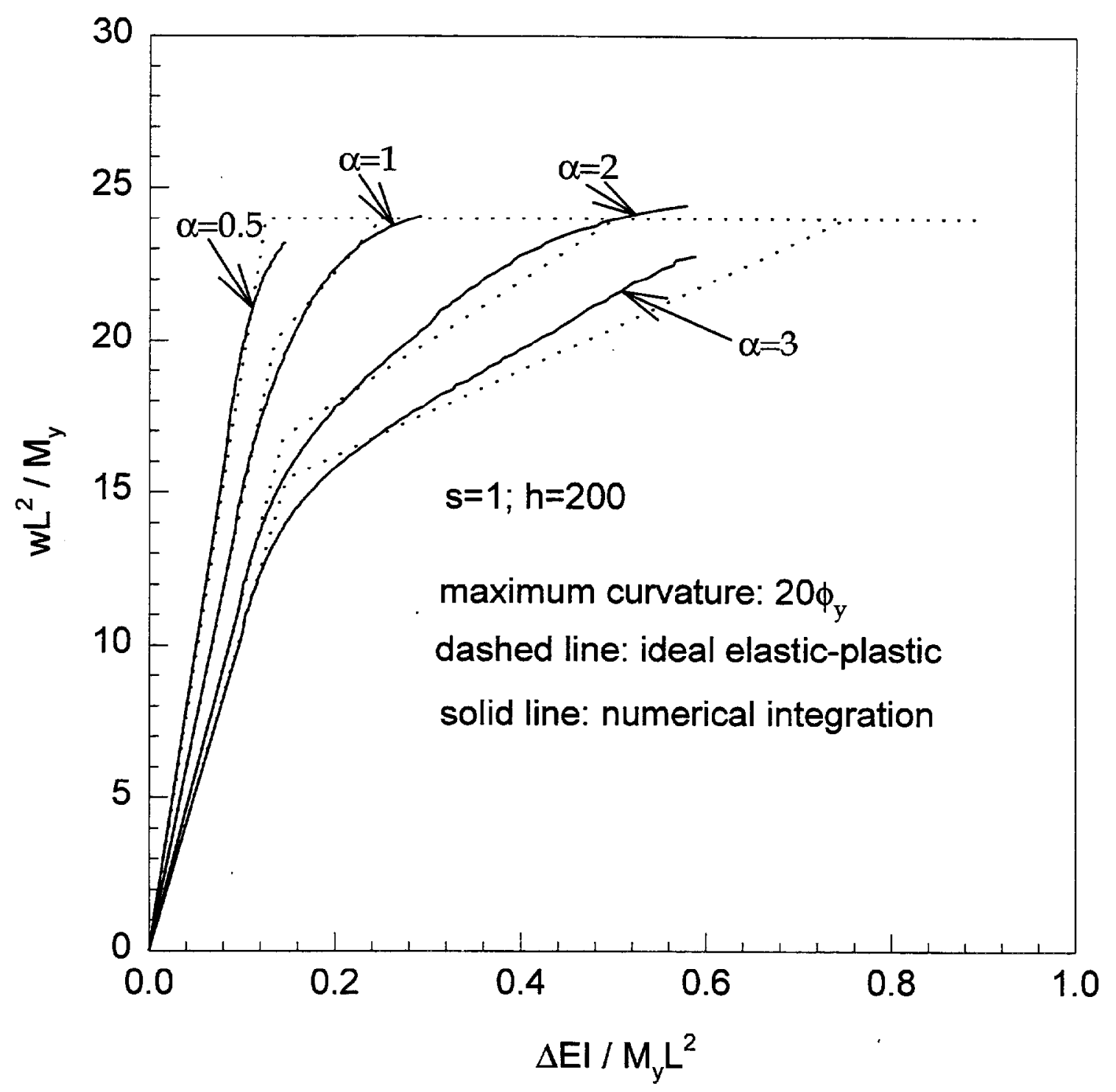


Fig. 8 Effect of $E / E_{s t}$, rectangular cross section

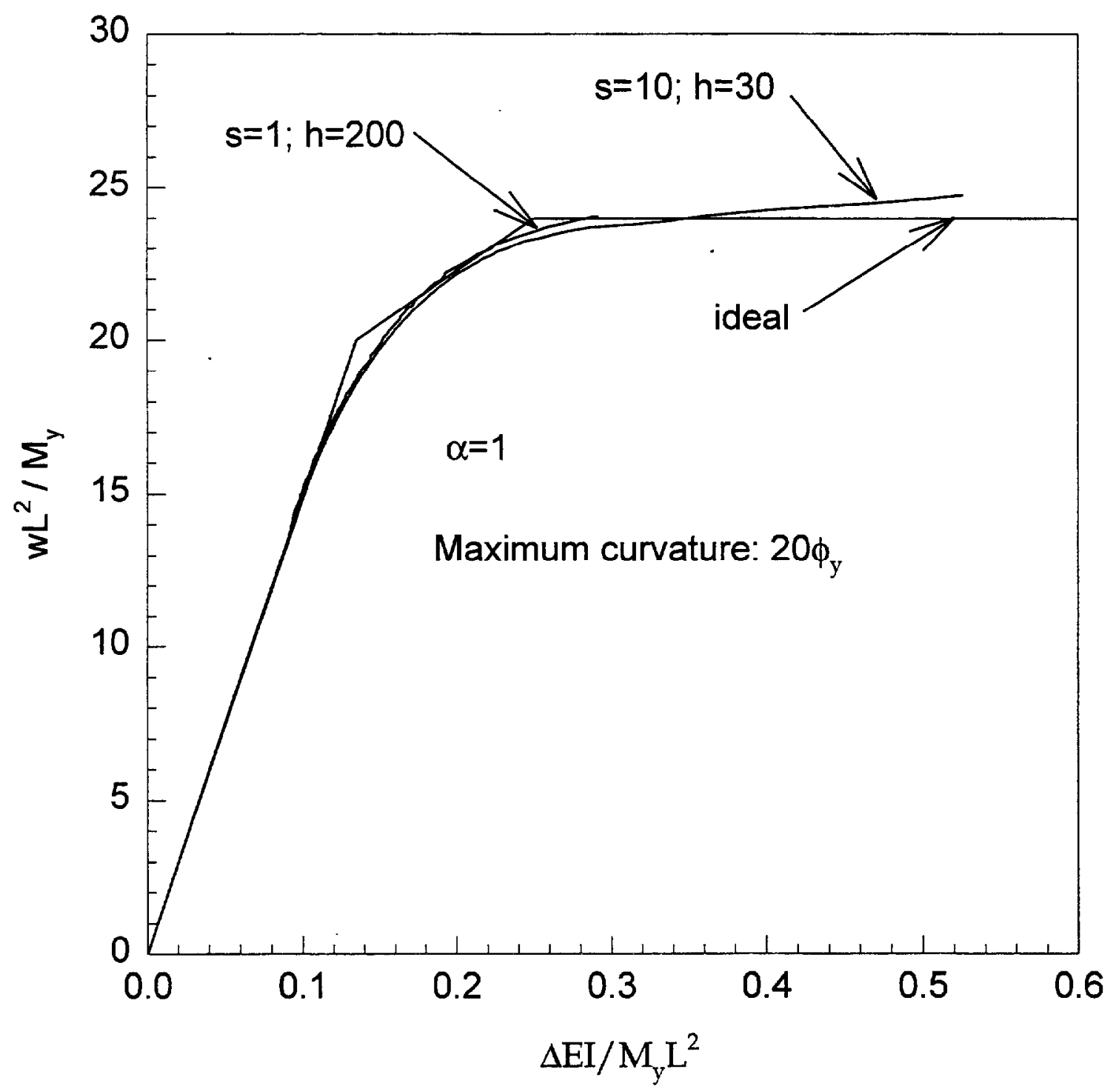


Fig. 9 Materials A, B, C, D; rectangular shape

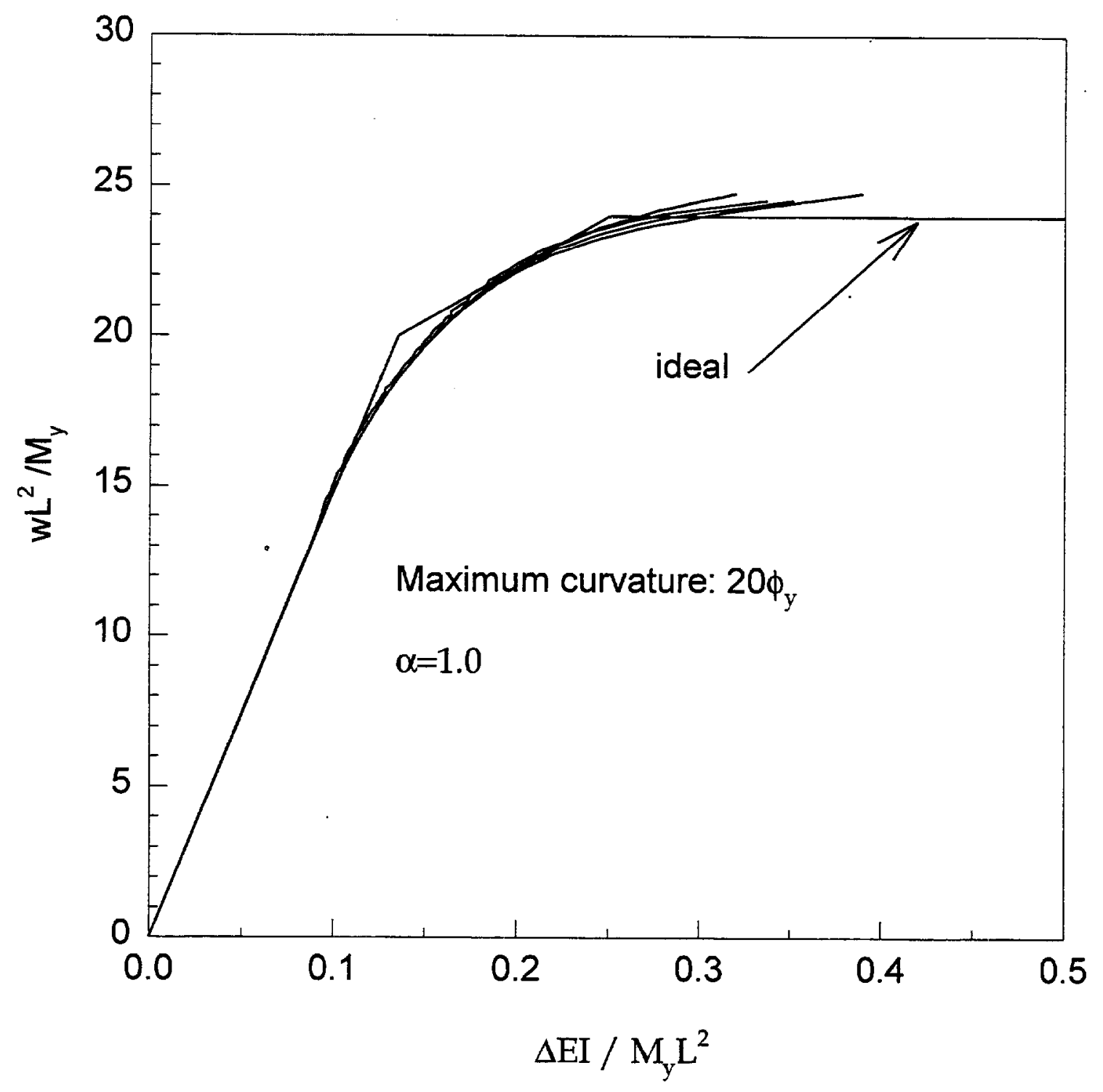


Fig. 10 Moment-Curvature Curves

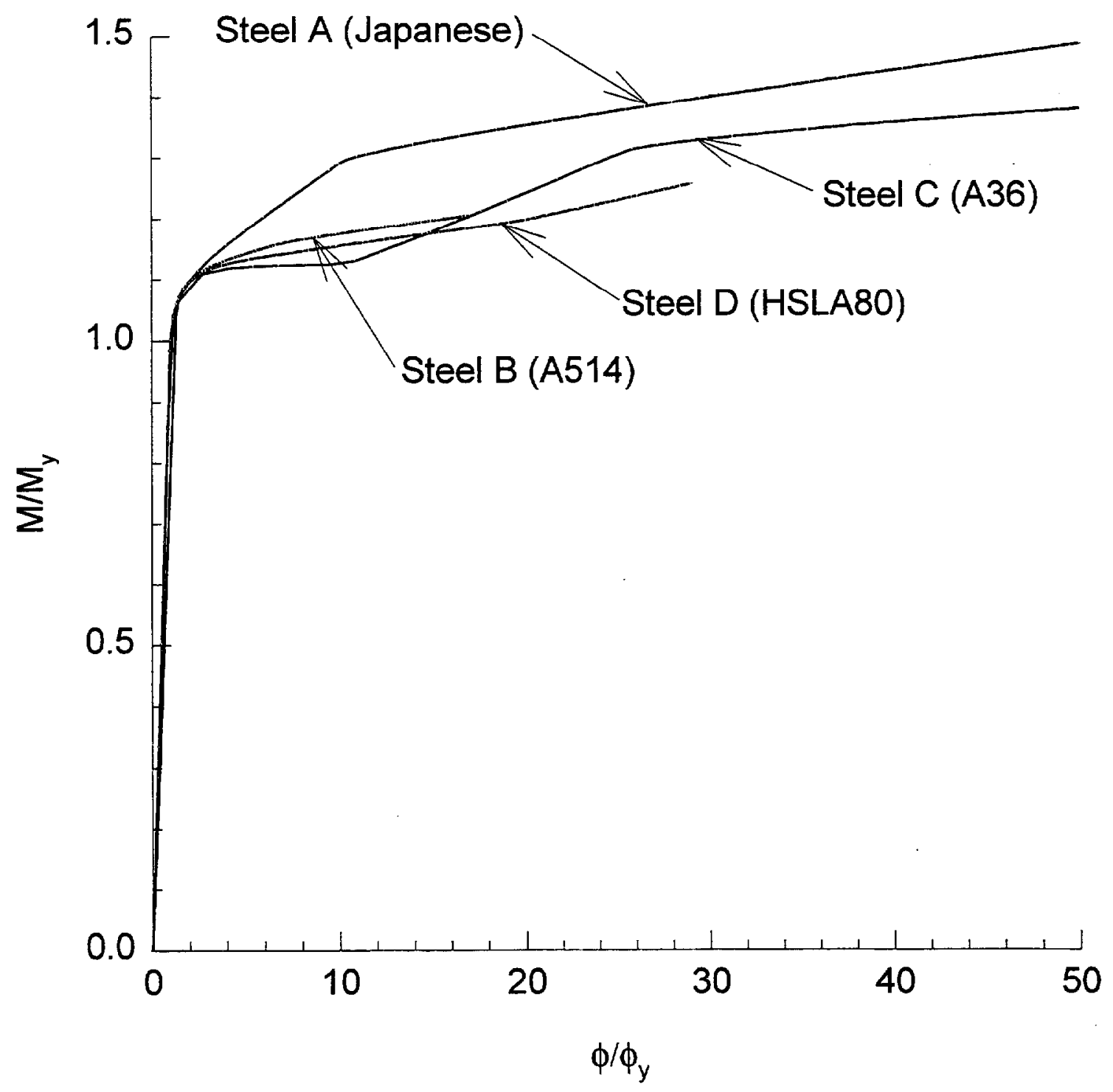


Steel A (Japanese)

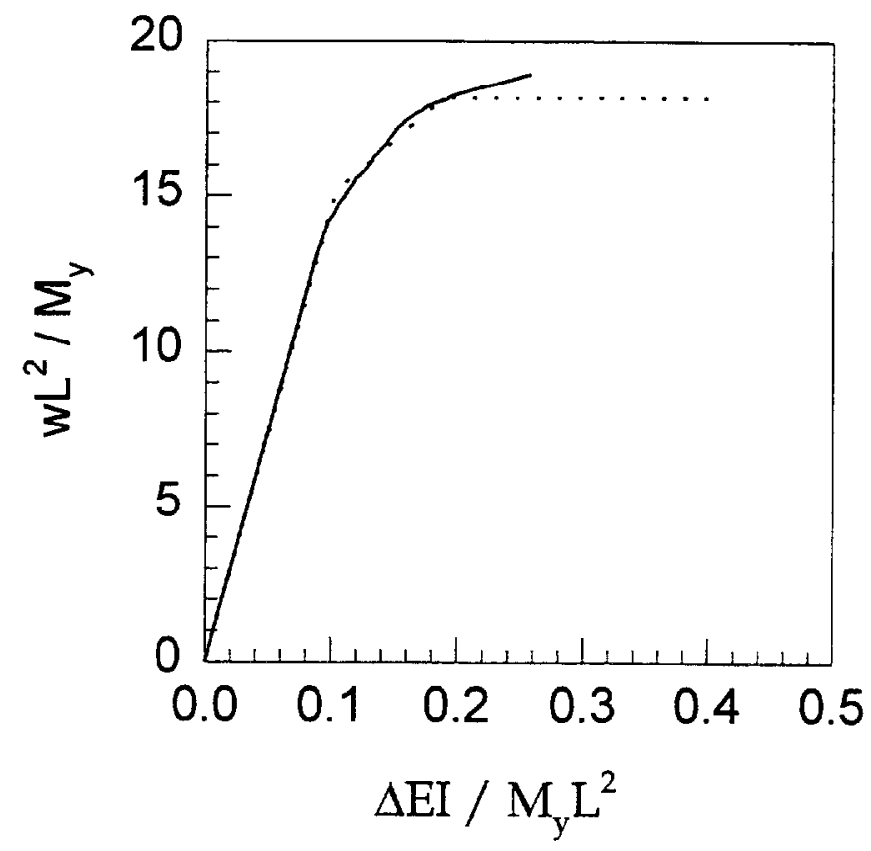

Steel B (A514)

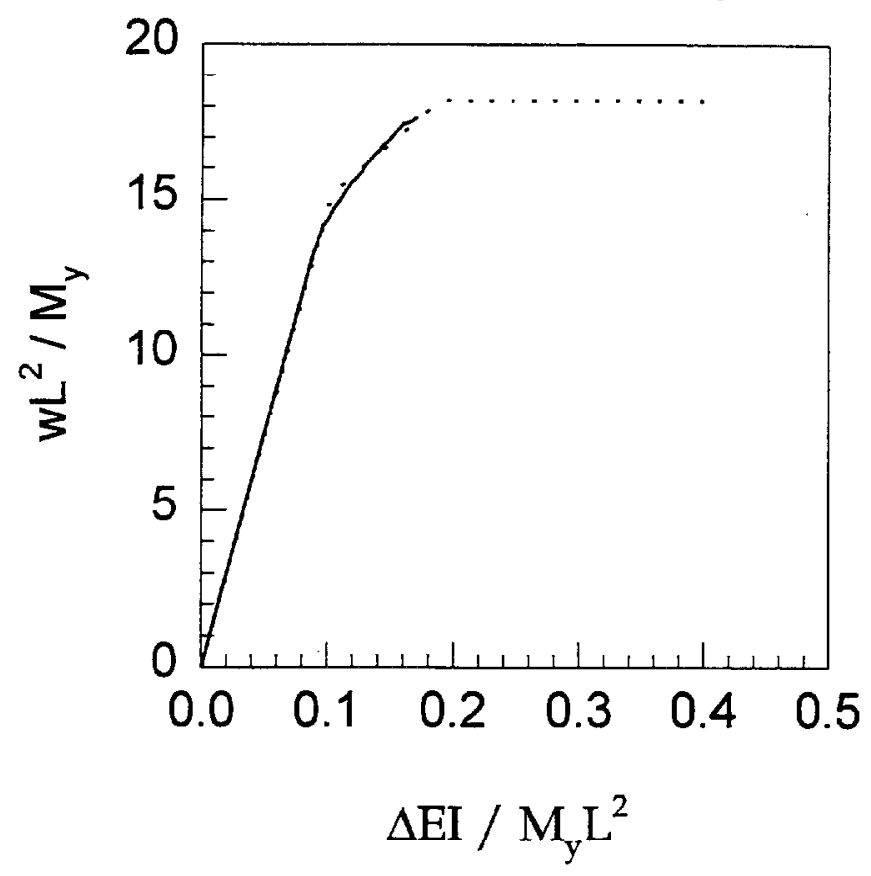

Steel C (A36)

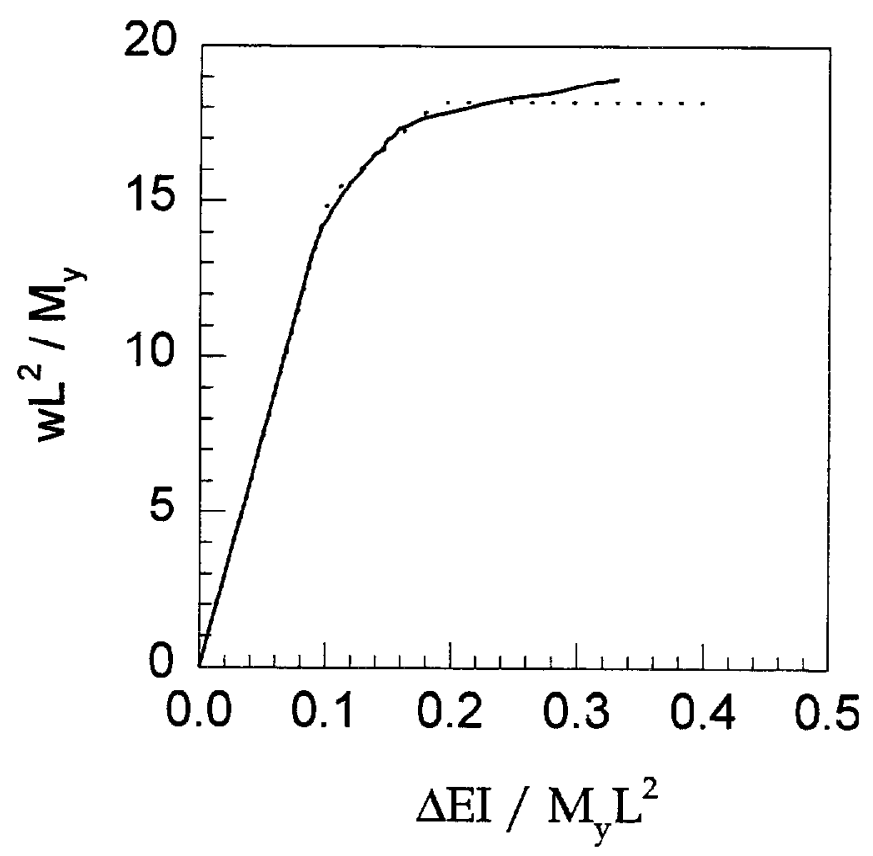

Steel D (HSLA80)

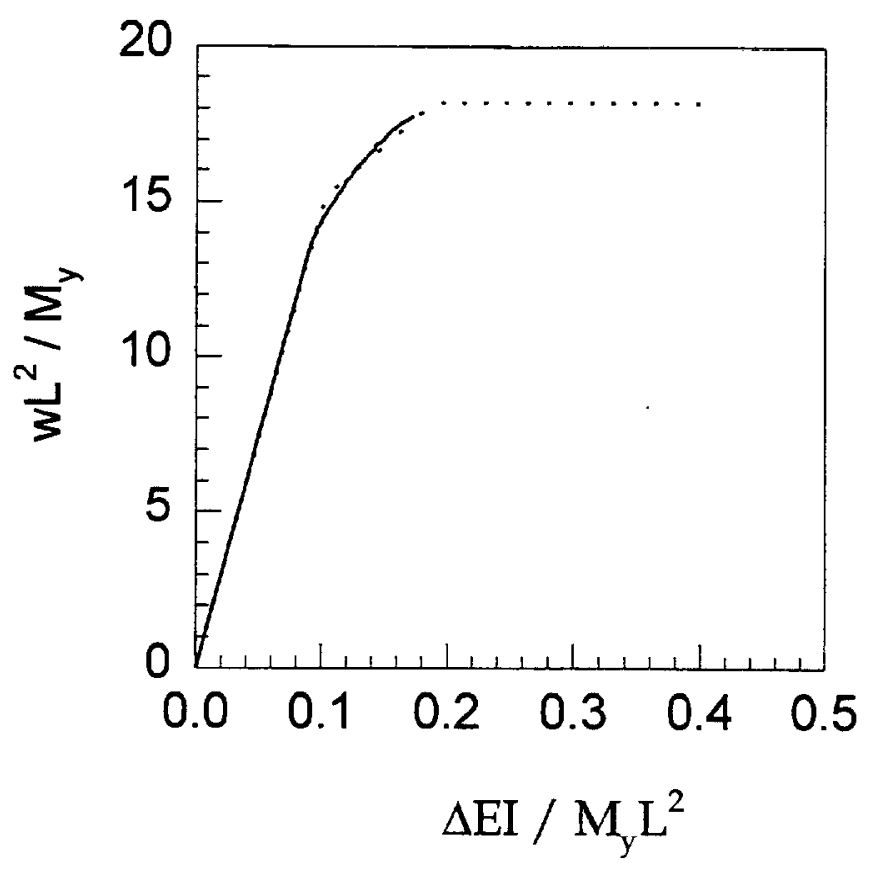

Fig. 11 Load-Deflection Curves for $\alpha=1.0$; maximum curvature: $10 \phi_{y}$ 


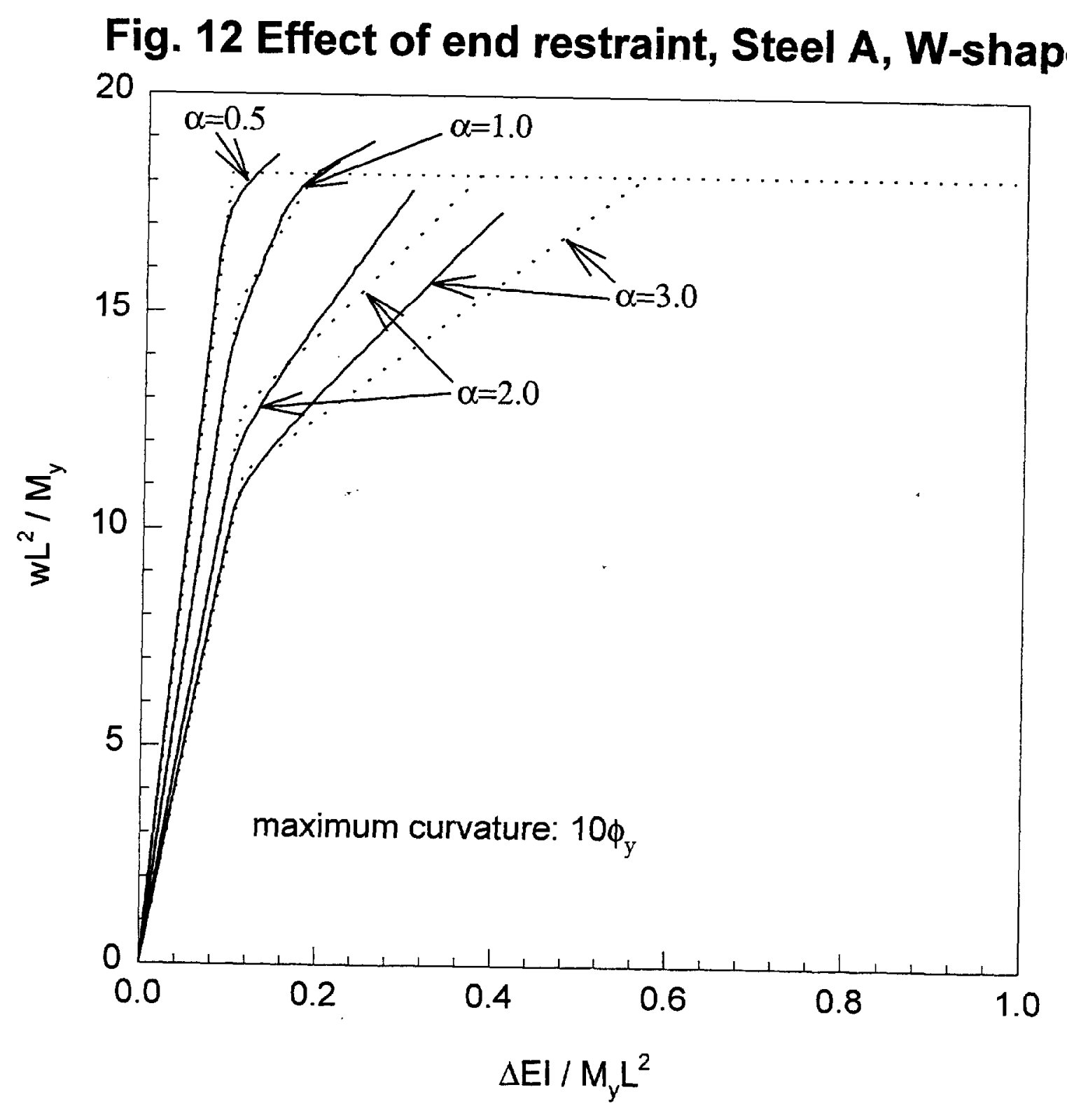


Steel A (Japanese)

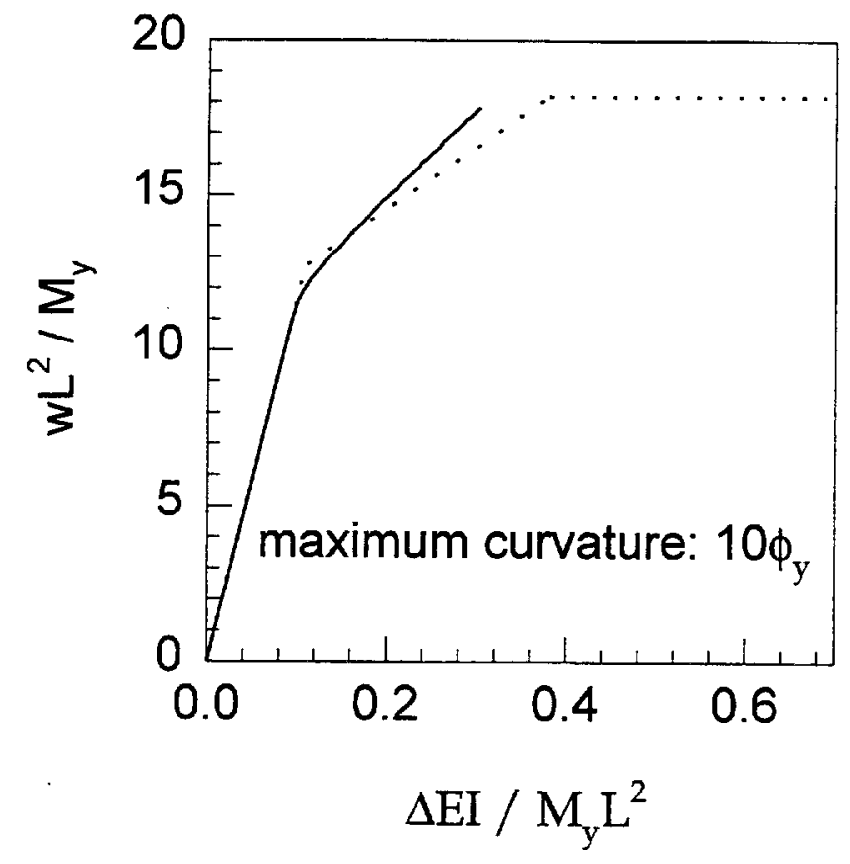

Steel C (A36)

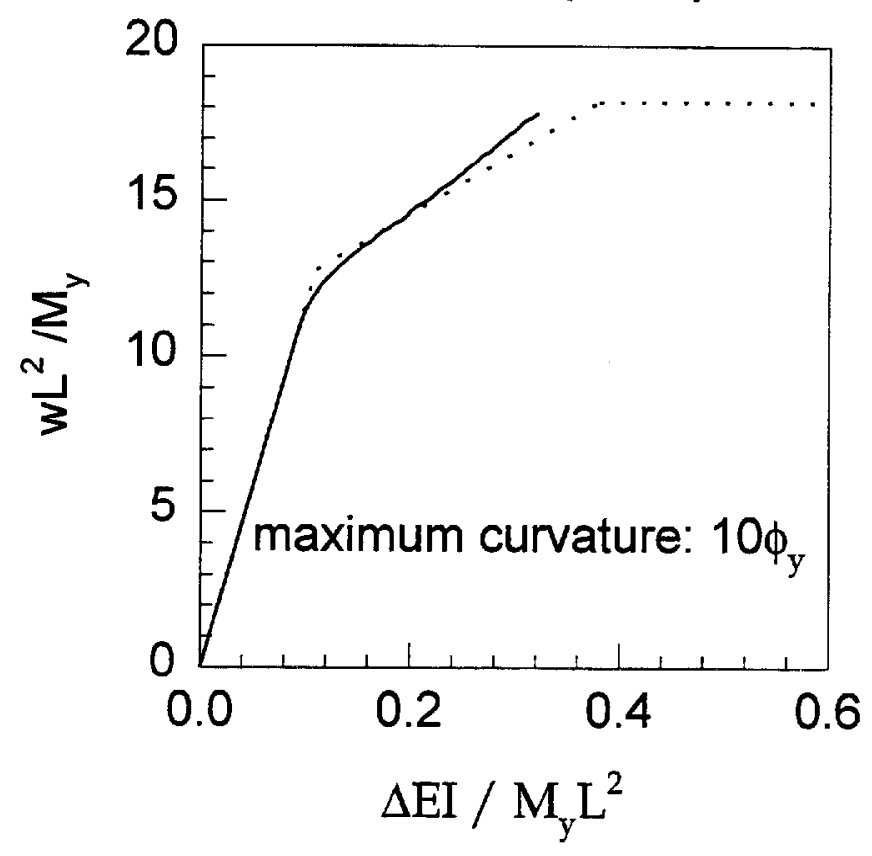

Steel D (HSLA80)

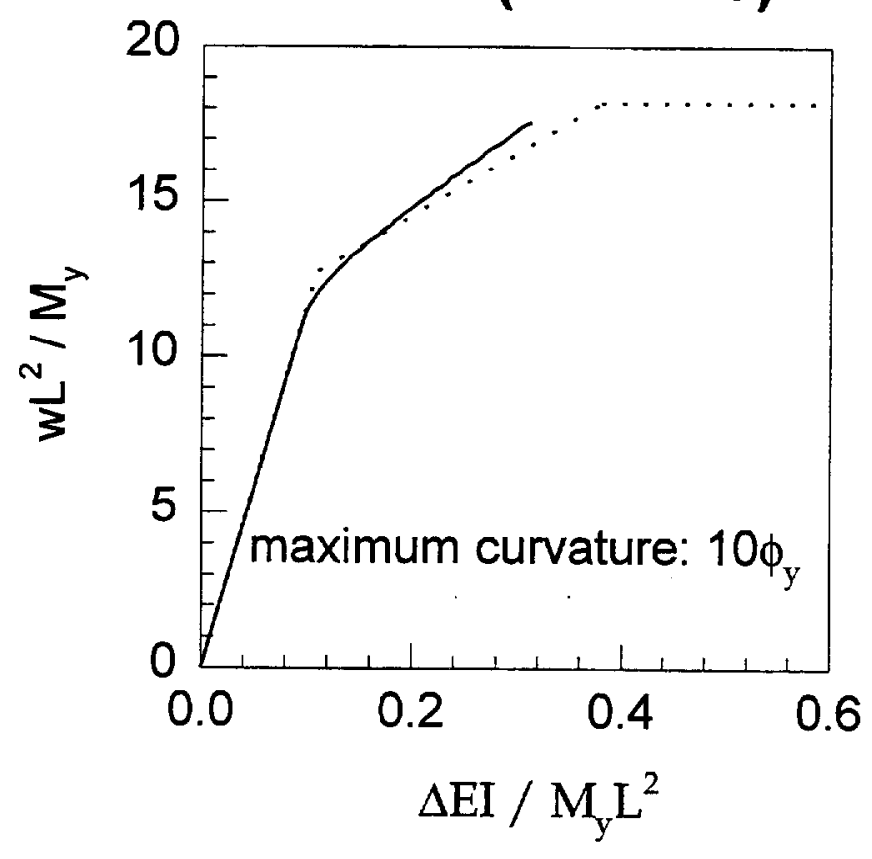

Steel D (HSLA80)

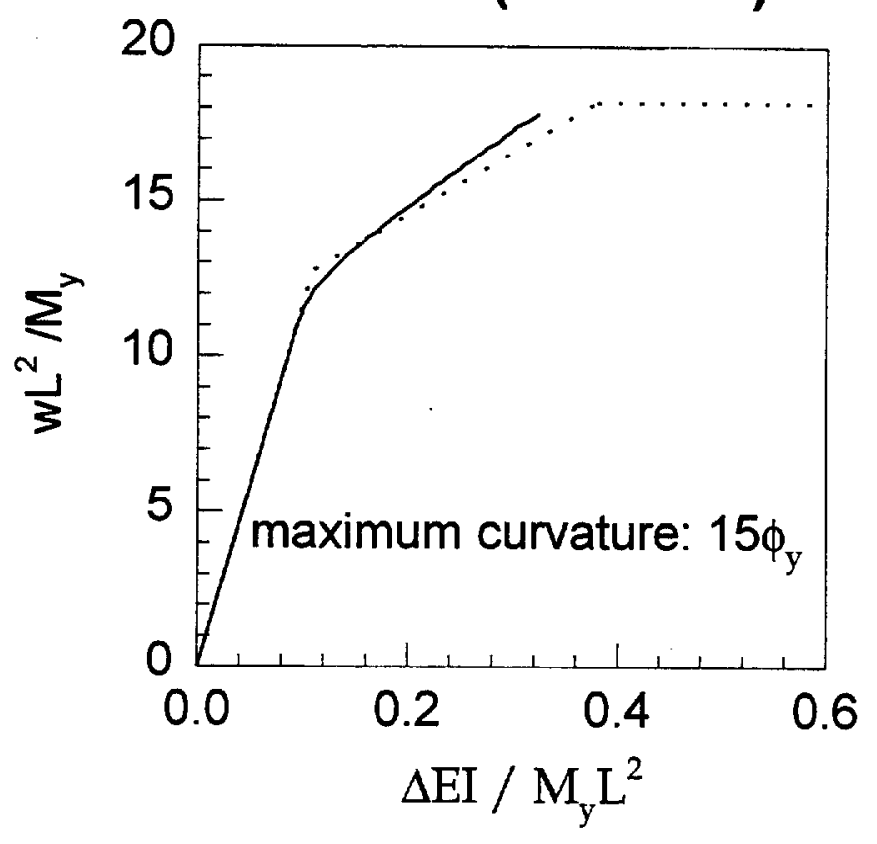

Fig. 13 Load-Deflection Curves for $\alpha=2$ 

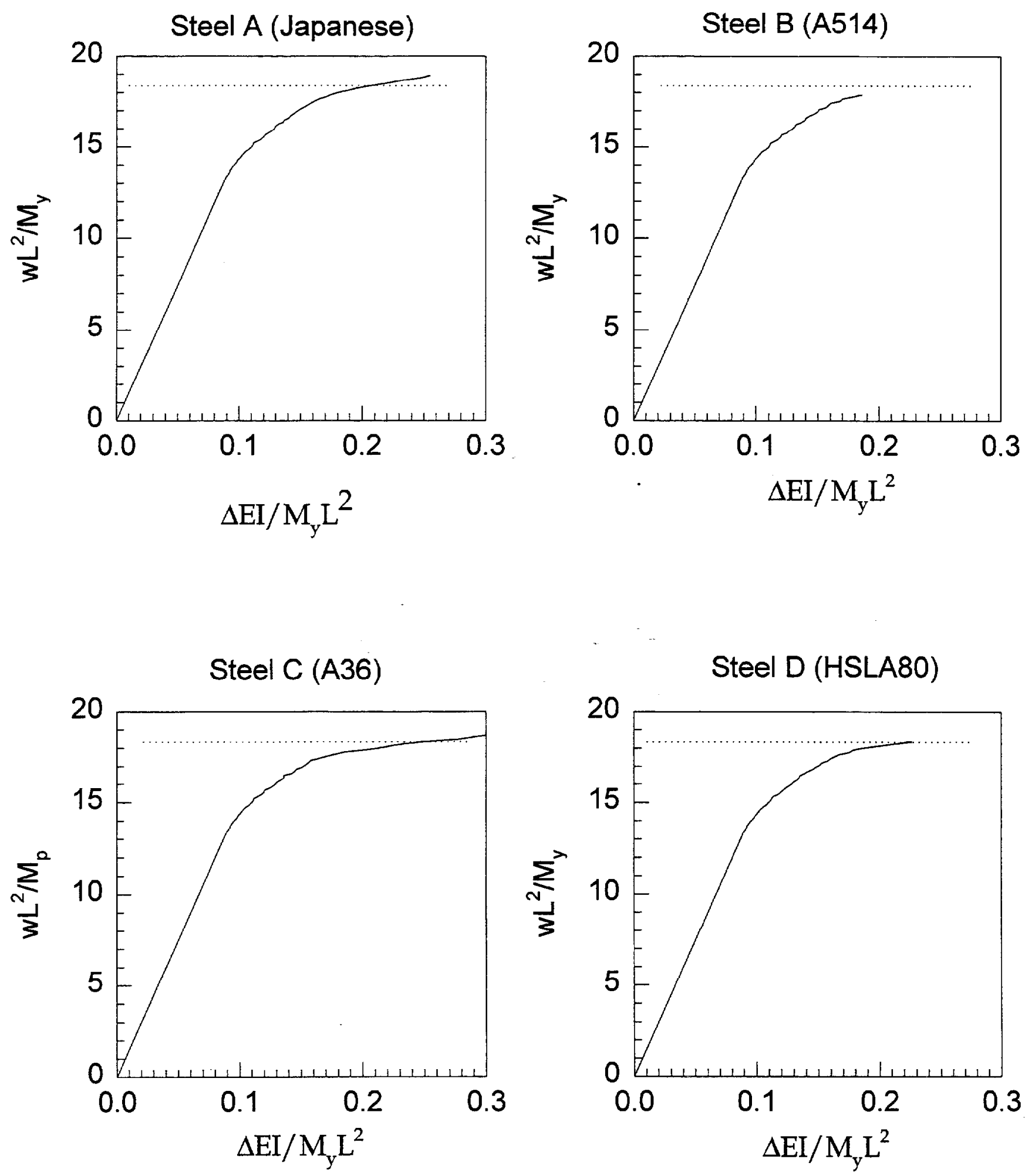

Fig. 14 Load-Deflection Curves for maximum curvature $=15 \phi_{\mathrm{y}}$ 

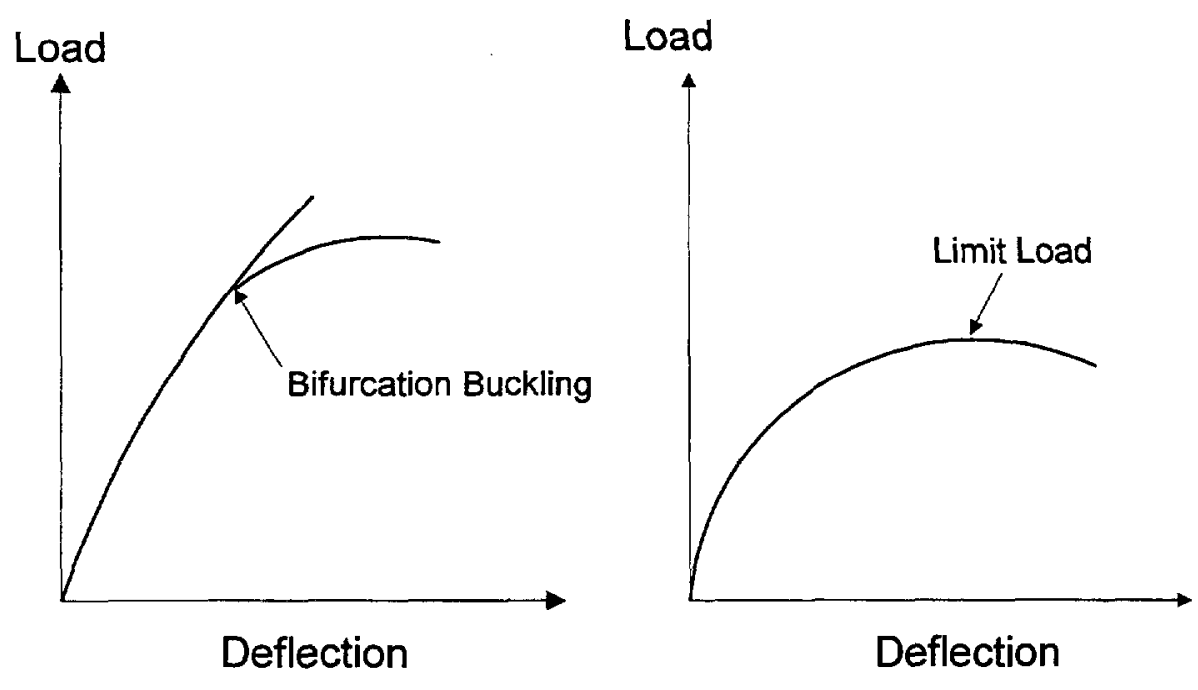

Fig. 15 Types of Buckling 


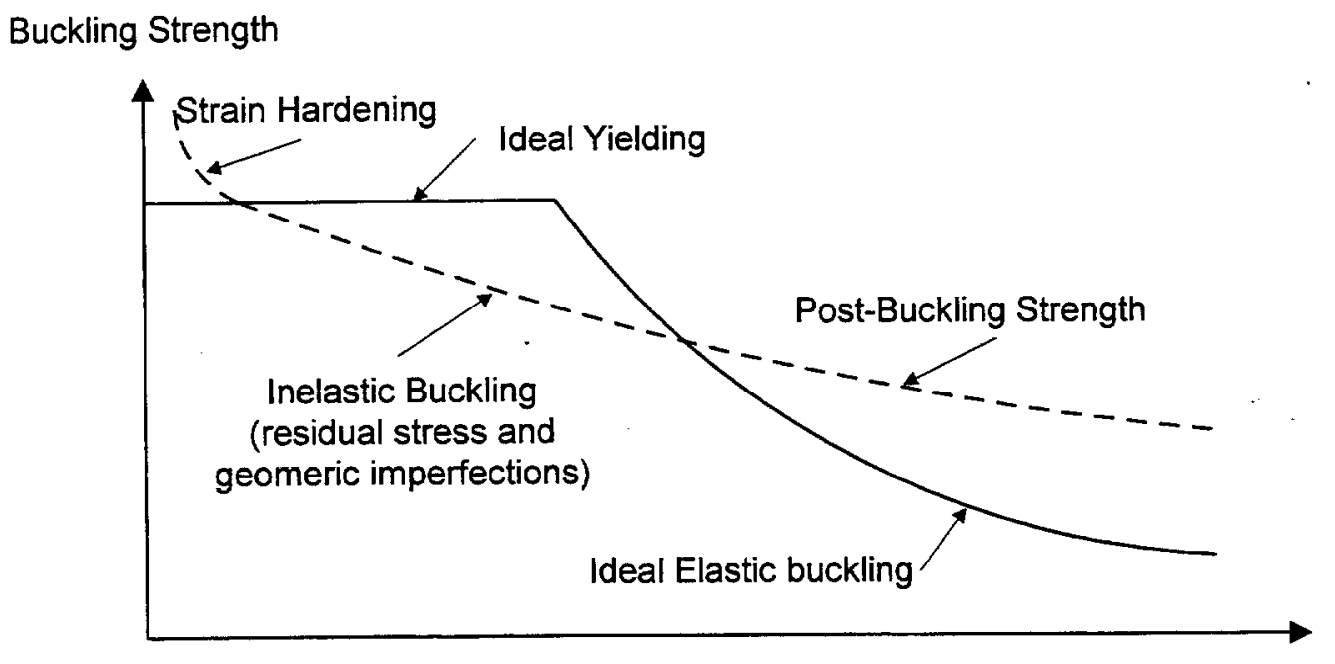

Slenderness Ratio

Fig. 16 Schematic Drawing of Buckling Domains 

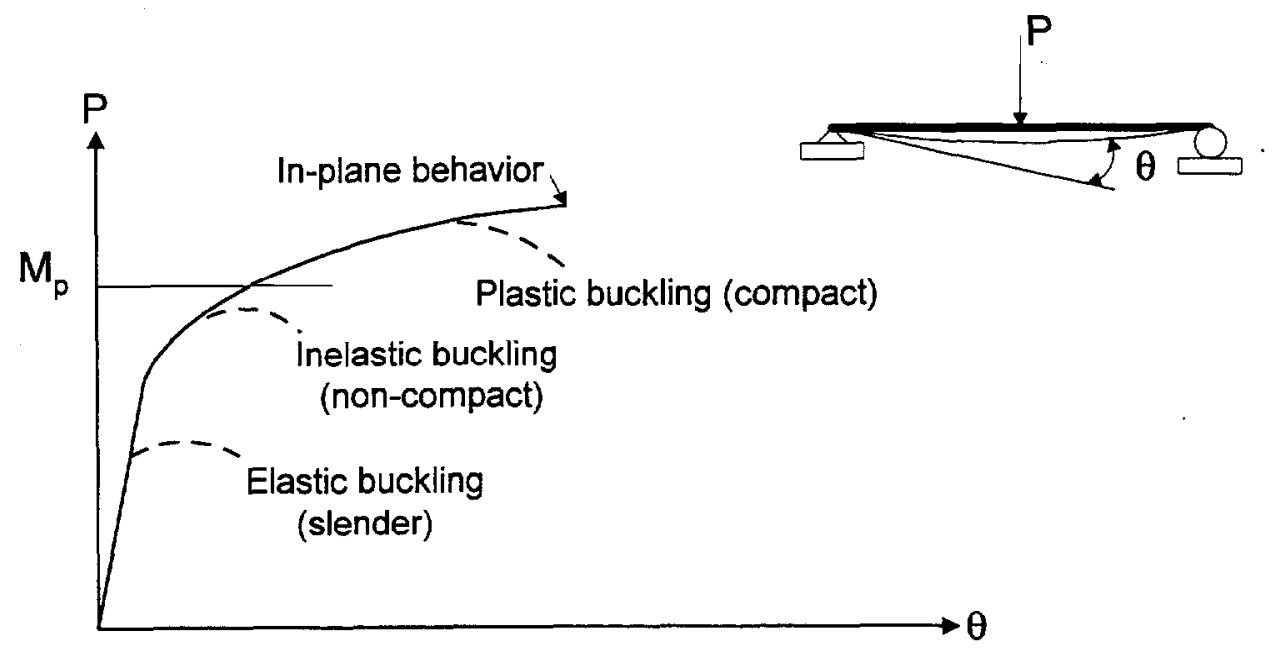

Fig. 17 Load-Deformation Curves With And Without Buckling 


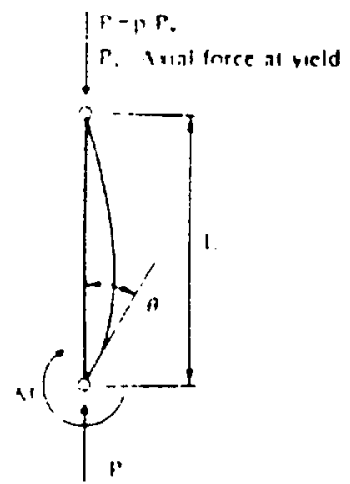

(1) Loading condition

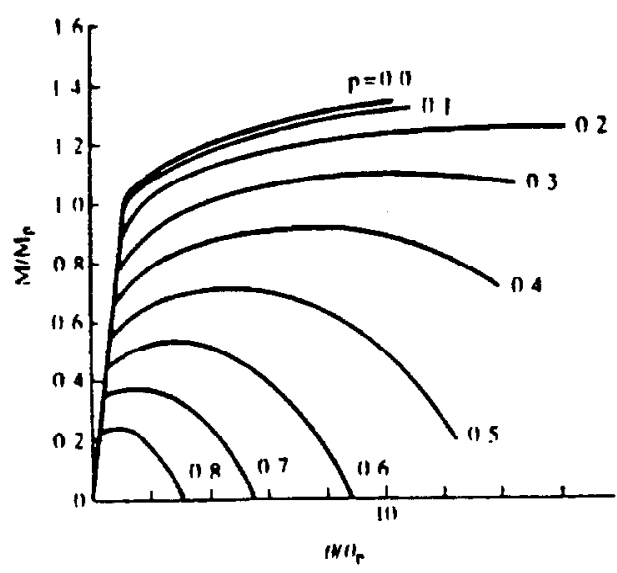

(2) Low yield-ratio steel $A, Y=75 \%$

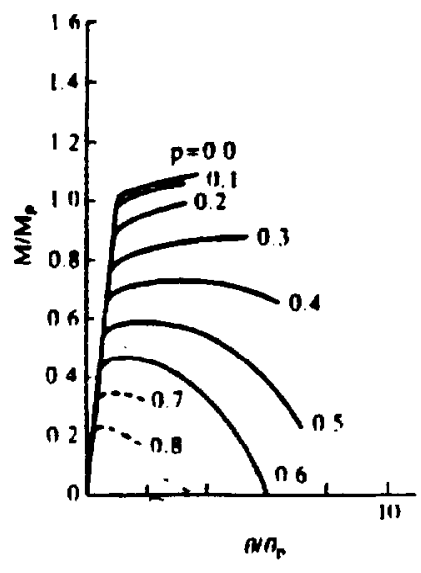

(3) High yield-ratio steel B, $Y=93 \%$

Fig.7 In-plane behaviors of beams and beam-columns made of different yield-ratio steels of a $600-\mathrm{MPa}$ tensile strength grade (4).

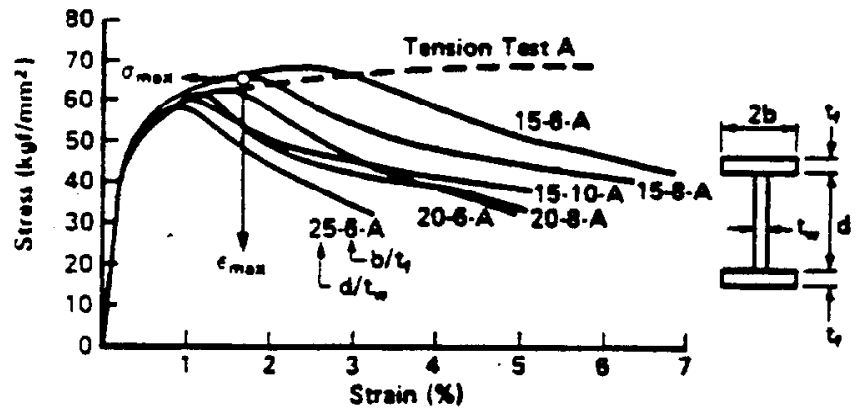

(a) Steel A with a low yield-racio, $Y=74 \%$

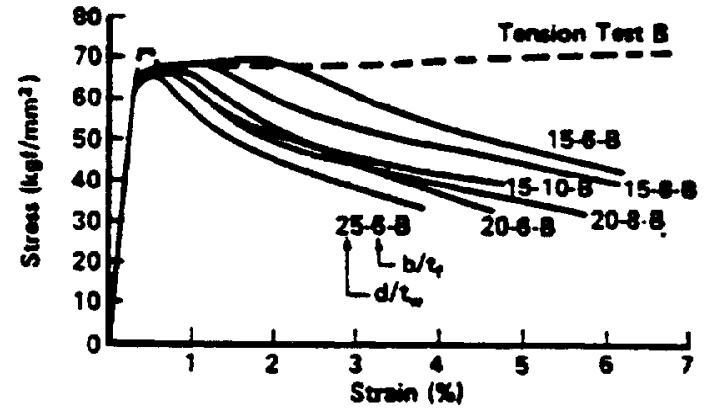

(b) Steel B with a high yield-ratio, $Y=93 \%$

Fig. 8 Stress-strain curves in compression obtained from stub-column testing of different yield-ratio steels of a $600-\mathrm{MPa}$ tensile strength grade (9).

\begin{tabular}{|l|l|l|}
\multicolumn{1}{l}{ Steel } & A & \multicolumn{1}{l}{ B } \\
\hline Yield Stress & $73.4 \mathrm{ksi}$ & $95.9 \mathrm{ksi}$ \\
Tensile Strength & $99.0 \mathrm{ksi}$ & $103.0 \mathrm{ksi}$ \\
$\mathrm{F}_{\mathrm{y}} / \mathrm{F}_{\mathrm{u}}$ & 0.74 & 0.93
\end{tabular}

Fig. 18. Figs. 7 and 8 from Kuwamura (1992). 


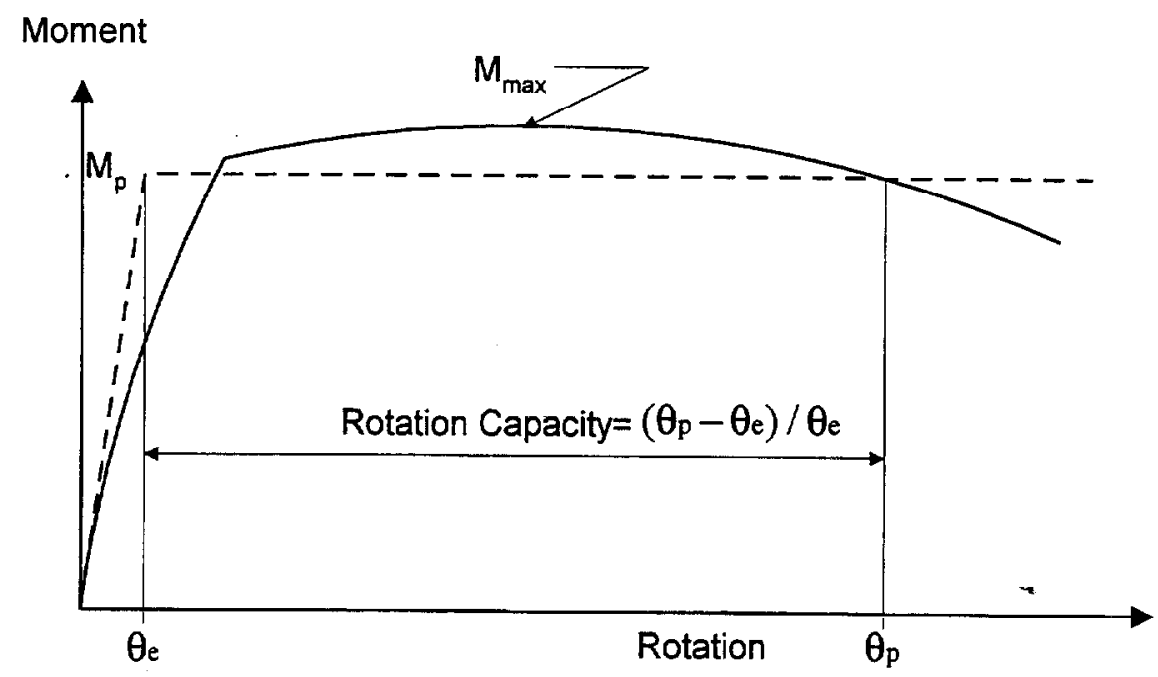

Fig. 19 Definition of Rotation Capacity 


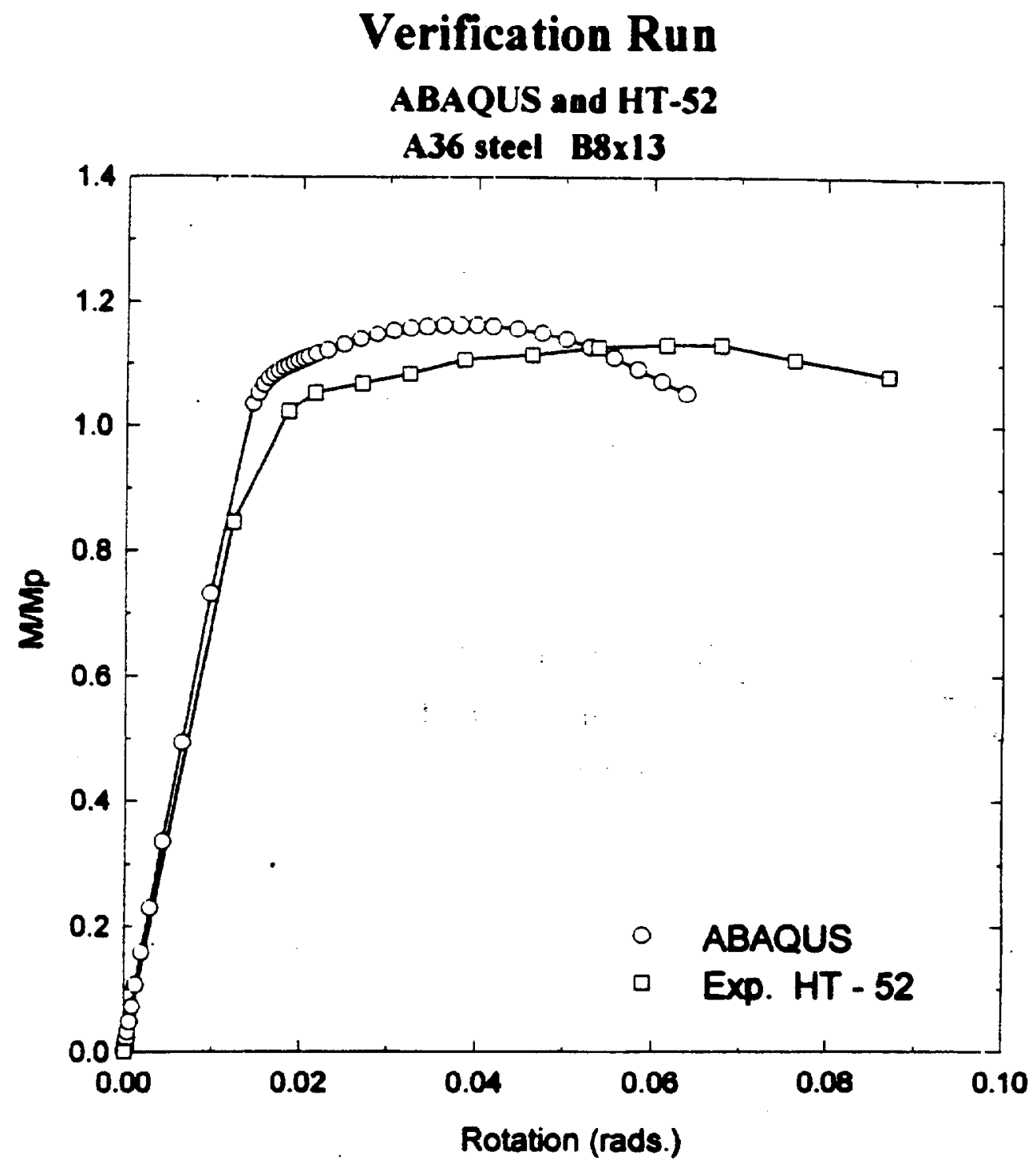

Fig. 20 Comparison of ABAQUS Prediction With Test HT-52 from Adams et. al. (1965) 
New Japanese Steel (A)

A36 Steel (C)

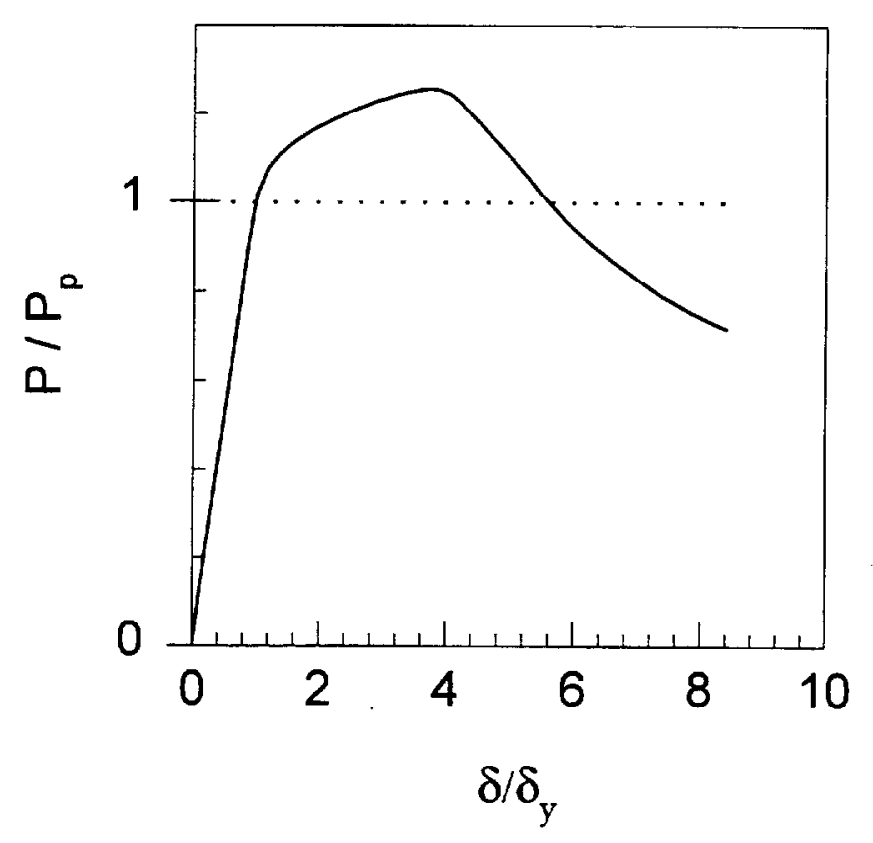

A514 Steel (B)

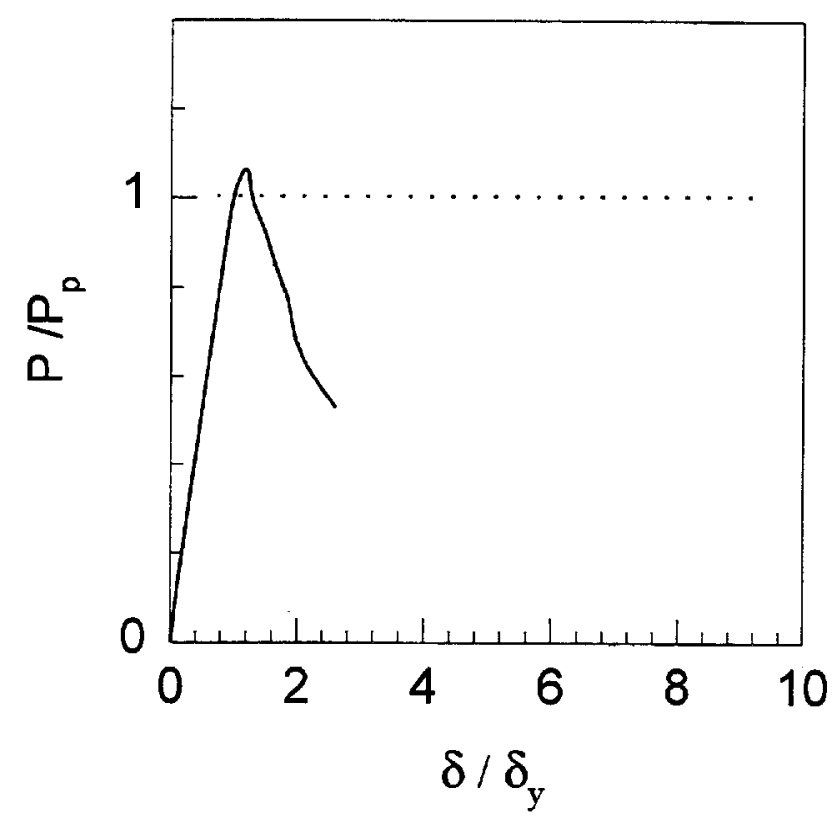

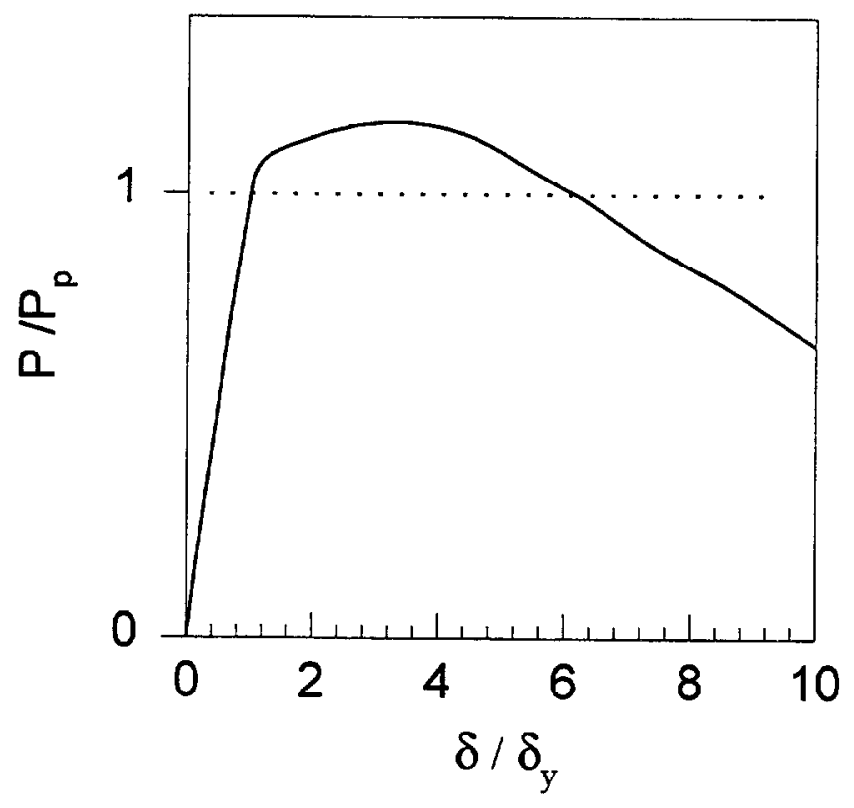

HSLA80 Steel (D)

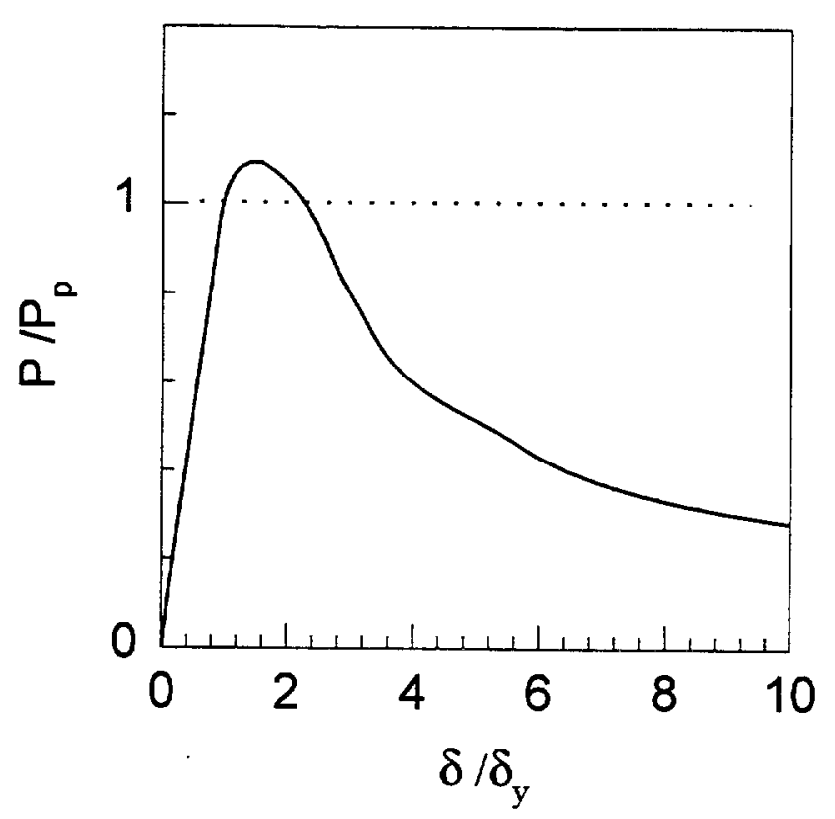

Fig. 21 Load-Deflection Curves From ABAQUS (3-point loading) 


\section{Load-deflection Curves}

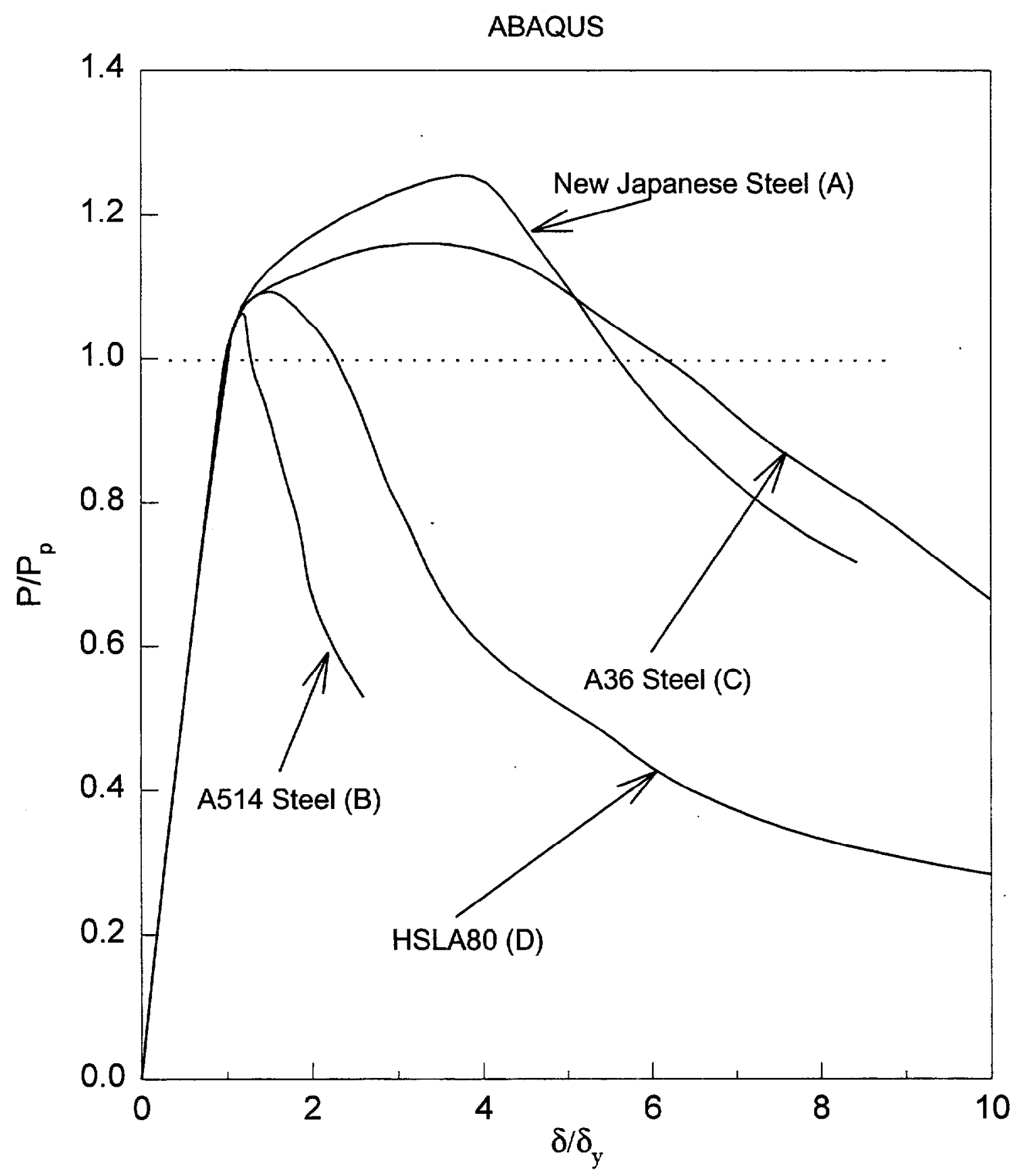

Fig. 22 Load-Deflections Curves From ABAQUS Compared To Each Other (3-point Loading) 

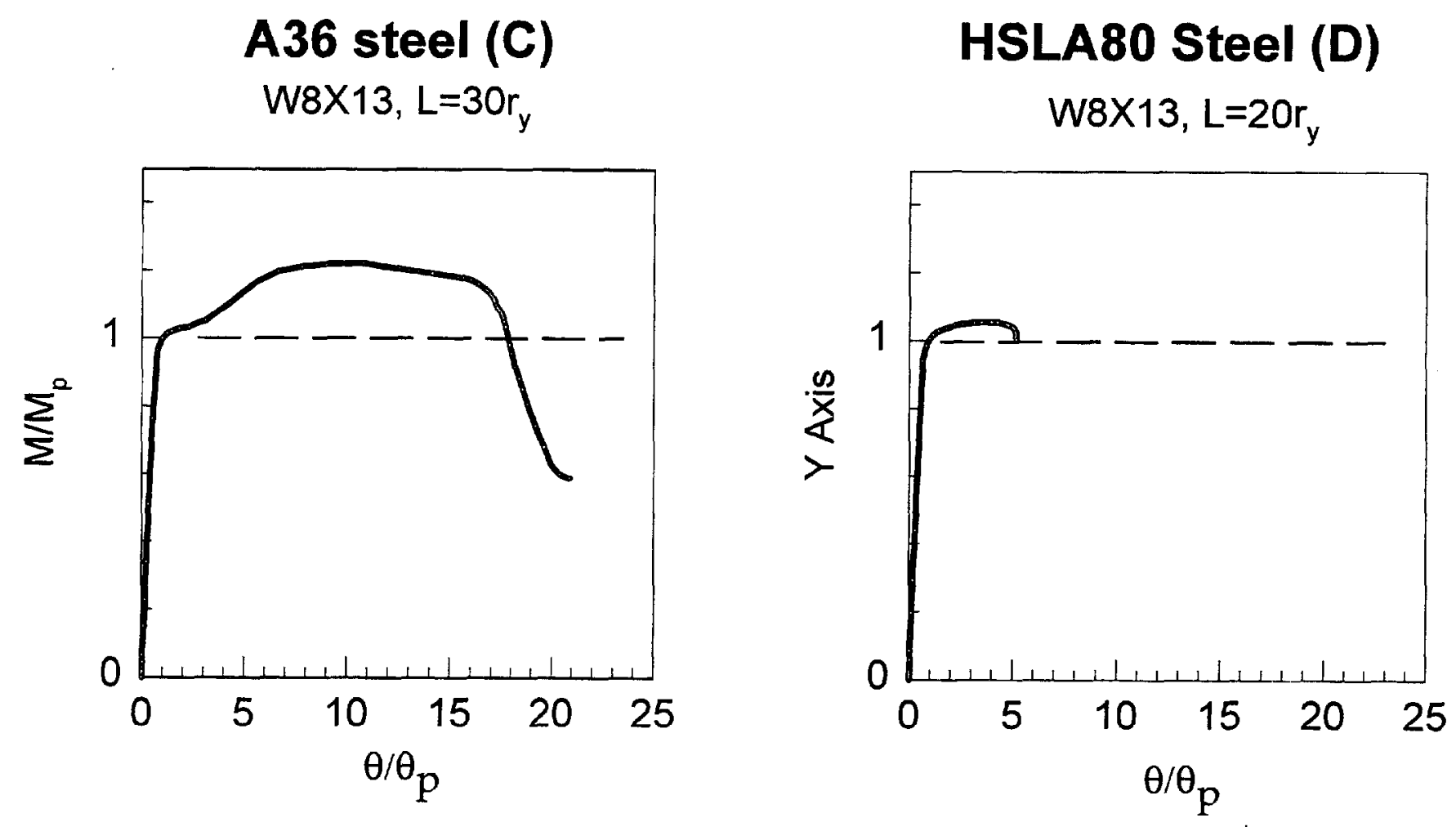

New Japanese Steel (A)

W8X13, L=20r

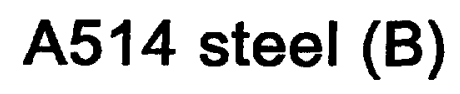

W8X13, L=20r
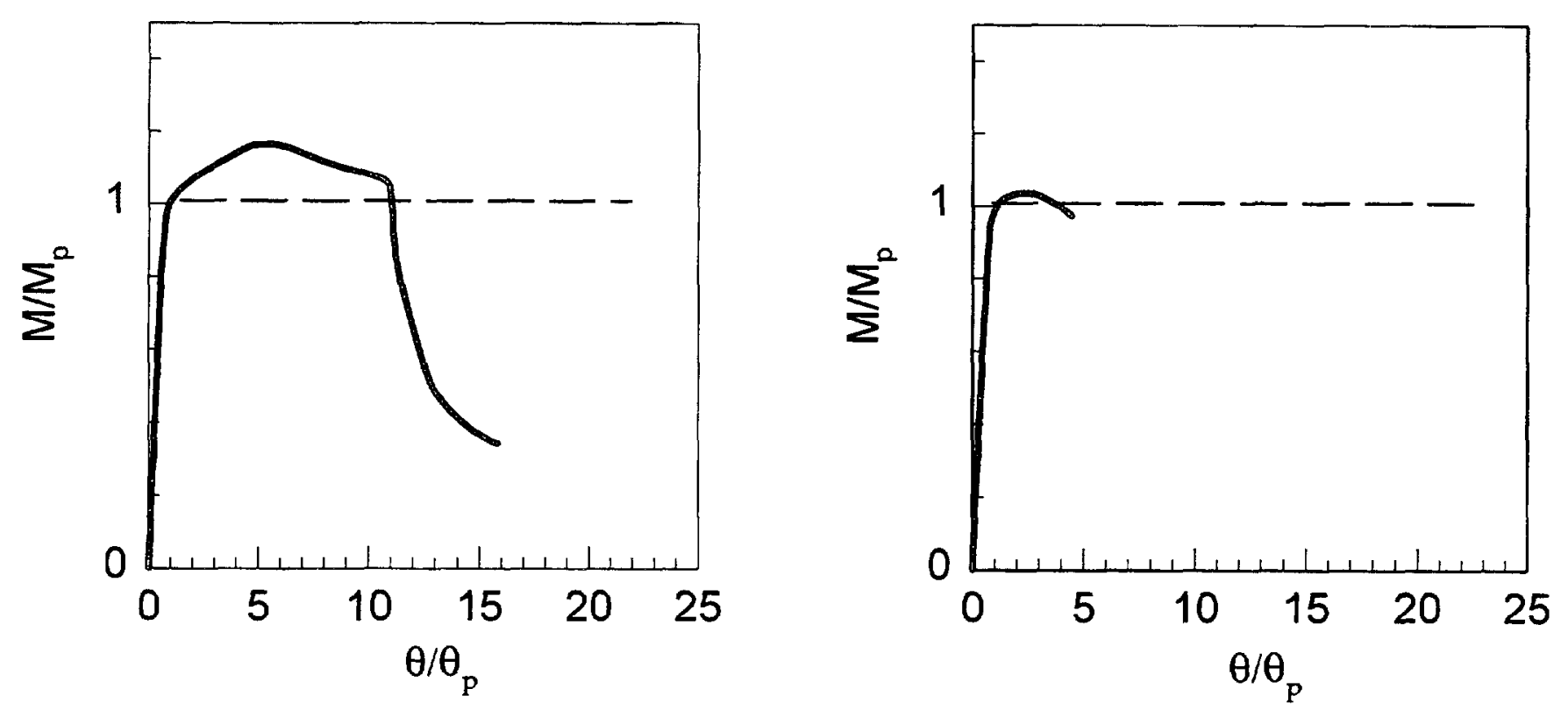

Fig. 23 Load-Deflection Curves From ABAQUS (4-point loading) 


\section{Appendix 1 - Workshop Participants}

Workshop held at the University of Minnesota, June 1, 1996

- Roger L. Brockenbrough, consulting engineer, Pittsburgh

- Christopher J. Earls, University of Minnesota

- Theodore V. Galambos, University of Minnesota

- John L. Gross, National Institute of Standards in Technology (NIST)

- Jerome F. Hajjar, University of Minnesota

- Geoff L. Kulak, University of Alberta

- John M. Kulicki, Modjeski and Masters

- Hitoshi Kuwamura, University of Tokyo

- George C. Lee, State University of New York at Buffalo

- James M. Ricles, Lehigh University

- Richard Sause, Lehigh University

- Thomas J. Schlafly, AISC

- Joseph A. Yura, University of Texas at Austin 


\section{Appendix 2 AISC-LRFD Stability Requirements}

Local Buckling Compactness Definition: (Table B.5)

$$
\lambda=\frac{b_{f}}{2 t_{f}} \text { for flange buckling }
$$

- for general building structures

$$
\lambda_{p}=0.38 \sqrt{\frac{E}{F_{y}}}
$$

- for seismic structures

$$
\lambda_{\mathrm{ps}}=0.31 \sqrt{\frac{E}{F_{y}}}
$$

$\begin{array}{lll}F_{y} & \lambda_{p} & \lambda_{\text {ps }} \\ 248 \mathrm{MPa}(36 \mathrm{ksi}) & 10.79 & 8.80 \\ 345 \mathrm{MPa}(50 \mathrm{ksi}) & 9.15 & 7.47 \\ 448 \mathrm{MPa}(65 \mathrm{ksi}) & 8.35 & 6.55 \\ 483 \mathrm{MPa}(70 \mathrm{ksi}) & 7.74 & 6.31 \\ 552 \mathrm{MPa}(80 \mathrm{ksi}) & 7.23 & 5.90 \\ 621 \mathrm{MPa}(90 \mathrm{ks}) & 6.82 & 5.57 \\ 689 \mathrm{MPa}(100 \mathrm{ksi}) & 6.47 & 5.28\end{array}$


Lateral Buckling of Wide-Flange Beams, Plastic Design (Eq. F1-17)

$$
L_{p d}=\left[0.12+0.076\left(\frac{M_{1}}{M_{2}}\right)\right]\left[\frac{E}{F_{y}}\right] r_{y}
$$

For uniform moment, $\frac{M_{1}}{M_{2}}=-1$ and for one end-moment only $\frac{M_{1}}{M_{2}}=$

Steel $F_{y}$

A $\quad 483 \mathrm{MPa}(70 \mathrm{ksi}) \quad 20 \quad 51$

B $\quad 820 \mathrm{MPa}(119 \mathrm{ksi}) \quad 12(21)^{*}$

C $\quad 331 \mathrm{MPa}(48 \mathrm{ksi}) \quad 29$

D $\quad 586 \mathrm{MPa}(85 \mathrm{ksi}) \quad 17$
$\left[\frac{L_{p d}}{r_{y}}\right]_{U M} \quad\left[\frac{L_{p d}}{r_{y}}\right]_{M G}$

$30(36)^{*}$

75

42

* recommended by McDermott in 1969 for A514 steel

subscript UM : uniform moment

subscript MG : moment gradient 


\section{Appendix 3 Work of Alan Kemp and his associates in South Africa}

\section{Relevant References}

- Kemp, A. R. (1996); Inelastic Local and Lateral Buckling in Design Codes, ASCE J. of Sruct. Engrg, Vol 122, No. 4, April, 1996, p. 374-382

- Kemp, A. R., Dekker, N. W. (1991) Available Rotation Capacity in Steel and Composite Beams, The Structural Engineer, 5 March 1991, Vol. 69, No. 5, p. 88-97

- Kemp, A. R.(1990); Quantifying limit-States of Rotation Capacity in Flexural members, Proc. Instn. Civ. Engrs. Part 2, 1990, Vol. 89, Sept., p. 387-406

- Kemp, A. R. (1986); Interaction of Plastic Local and Lateral Buckling,ASCE J. of Sruct. Engrg, Vol 111, No. 4, April, 1996, p. 374-382

In addition Kemp and his co-workers have a number of references on the ductility and local buckling of composite beams. 
Comments on Kemp's work:

- Time period of this work 1980 - 1996 (current)

- Research is extension of the earlier work at Lehigh (Thurlimann White - Kusuda - Galambos - Lee - Lay - Adams), 1954 -1966

- Semi-analytical work, based on plasticity concepts, assumptions regarding causes of reduction of force level in the inelastic range, and on old and new experimental work

- The research includes an extensive re--analysis of previous tests at Lehigh, Alberta and Witwatersrand Universities.

- Most of Kemp's work is on the case of the beam subjected to a central concentrated load, with extensions to other moment ratios

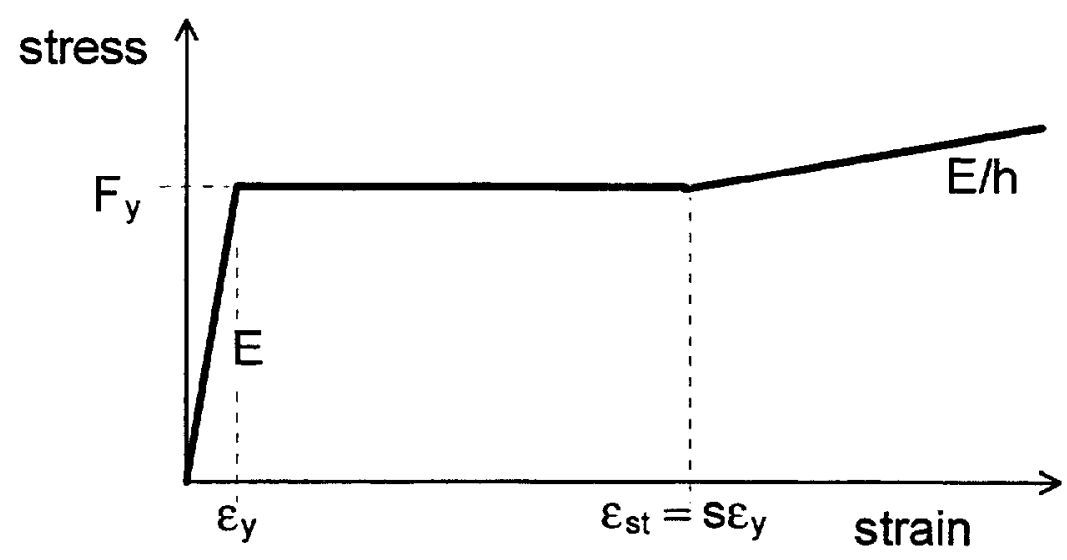

- Stress-strain curve: 
Geometry, loading, bracing, moment diagram and curvature diagram
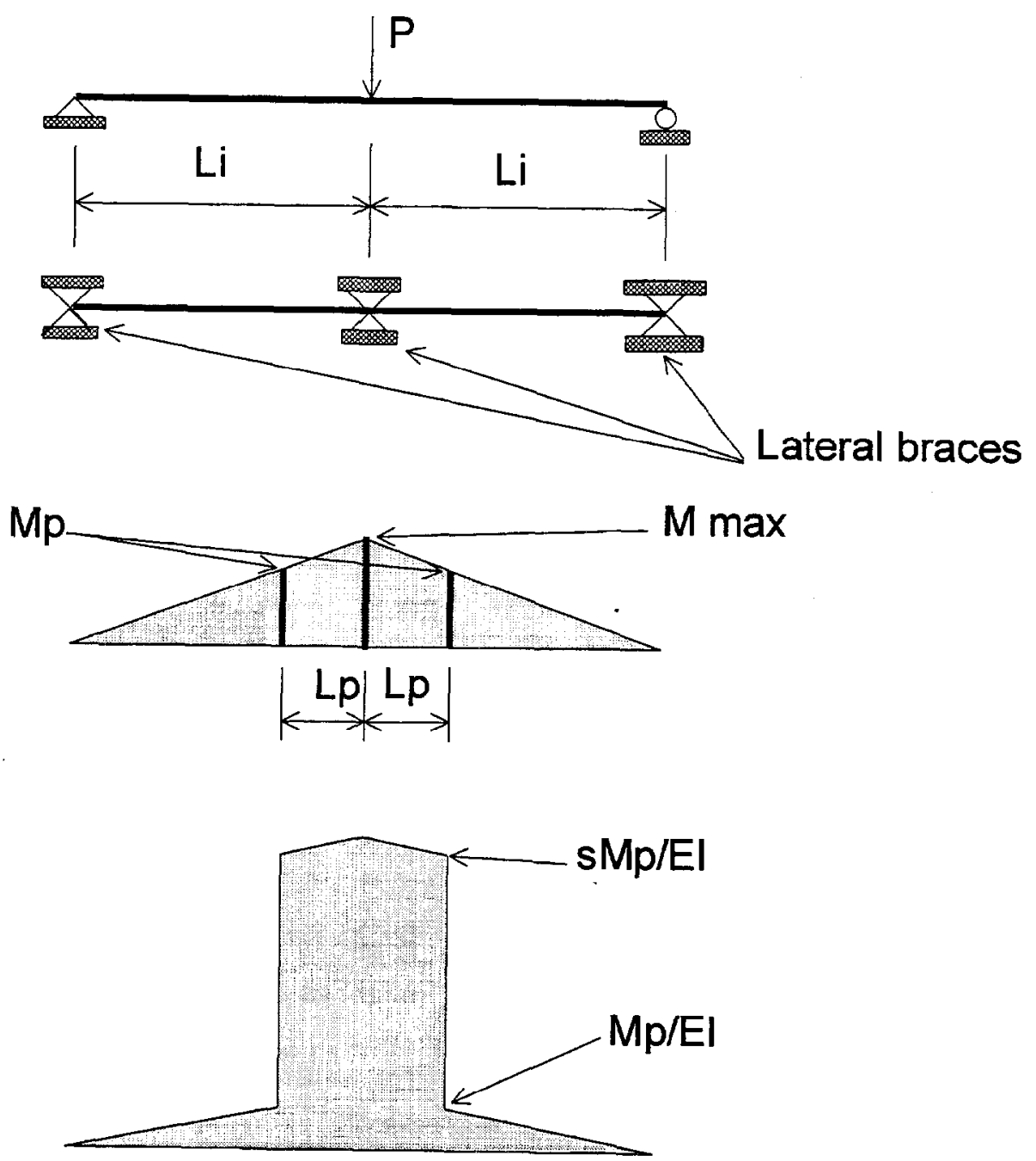
- For $s=10$ and $h=50$ the following empirical equations are given for rotation capacity:

Length between plastic moment and maximum moment

$$
L_{p}=0.067 L_{i}\left[\frac{60}{\lambda_{e}}\right]^{1.5}
$$

Rotation capacity

$$
\begin{aligned}
& R=45\left(\frac{L_{p}}{L_{i}}\right) \\
& \text { where }
\end{aligned}
$$

$$
\begin{aligned}
& \lambda_{e}=K_{f} K_{w}\left(\frac{L_{i}}{r_{y}}\right)\left(\frac{1}{\varepsilon}\right) \\
& K_{f}=\left(\frac{b_{f}}{2 t_{f}}\right)\left(\frac{1}{9 \varepsilon}\right) \\
& K_{w}=\left(\frac{h}{t_{w}}\right)\left(\frac{1}{70 \varepsilon}\right)
\end{aligned}
$$

and $\varepsilon=0.343 \sqrt{\frac{E}{F_{y}}}$ 
- Basic idea of Kemp's approach: Unloading below the maximum moment starts when the strain in the buckled compression flange equals the yield strain in the outer flange tip away from the local buckle

- The underlying mechanistic theory is formulated for any stress-strain curve with given parameters $s$ and $h$, but the development is not applicable for high-performance steels

- Extrapolation beyond the range of steels investigated by Kemp is probably not recommended

- There are many assumptions and empiricisms in the Kemp method so that tests would be required to verify extensions to the new high-performance steels

- It is probably not too fruitful to invest too much new effort on either the Kemp or the Lay methods because they depend very much on the plastic plateau length $s$ and the strain-hardening modulus ratio $h$ for their development. The stress-strain curves of the new steels do not lend themselves to such characterization 
- The big question is whether it will be possible to develop a new mechanistic theory ( as opposed to an empirical theory based on testing and finite element calculations)

- From the preliminary studies using both the Kemp and the Lay theories, it is questionable if the new high performance steels will be able to be good candidates for class 1 sections (e. g., useful for plastic design and for seismic design)

- Kemp's theory predicts rotation capacity rather well for conventional mild steels and high strength steel beams:

the 1996 paper compares 44 tests

$$
\frac{R_{\text {test }}}{R_{\text {prediction }}}=1.05 \text { (mean value), } 0.32 \text { (std. dev.) }
$$


Example of the Kemp method

Cross section: W16×26

$$
\begin{array}{ll}
\mathrm{b}_{f}=140 \cdot \mathrm{mm} & \mathrm{t}_{f}:=8.8 \cdot \mathrm{mm} \\
\mathrm{h}=361 \cdot \mathrm{mm} & \mathrm{t}_{\mathrm{w}}=6.35 \cdot \mathrm{mm} \\
\mathrm{r}_{y}:=28.5 \cdot \mathrm{mm} & \\
\mathrm{F}_{y}:=345 \cdot 10^{6} \cdot \mathrm{Pa} & \mathrm{E}:=200 \cdot 10^{9} \cdot \mathrm{Pa} \\
\lambda_{f}:=\frac{b_{f}}{2 \cdot t_{f}} & \lambda_{f}=7.955 \\
\lambda_{w}:=\frac{h}{t_{w}} & \lambda_{w}=56.85
\end{array}
$$

AISC limiting slenderness ratios:

$$
\begin{array}{lll}
\lambda_{p f}:=0.38 \cdot \sqrt{\frac{E}{F_{y}}} & \lambda_{p f}=9.149 \\
\lambda_{p w}:=3.76 \cdot \sqrt{\frac{E}{F_{y}}} & \lambda_{p w}=90.53 \\
L_{p d}:=0.12 \cdot \frac{E}{F_{y}} \cdot r_{y} & L_{p d}=1.983 \cdot 10^{3} \cdot \mathrm{mm} \\
\frac{L_{p d}}{r_{y}}=69.565 &
\end{array}
$$


rotation capacity according to Kemp , for $L_{1}=L_{p d}$

$$
\begin{array}{ll}
\varepsilon=0.0343 \cdot \sqrt{\frac{E}{F_{y}}} & K_{w}=\frac{\lambda_{w}}{70 \cdot \varepsilon} \\
K_{f}:=\frac{\lambda_{f}}{9 \cdot \varepsilon} & \\
L_{i}:=L_{p d} & \lambda_{e}=88.655 \\
\lambda_{e}:=\frac{K_{f} \cdot K_{w} \cdot L_{i}}{r_{y} \cdot \varepsilon} & L_{p}=73.958 \cdot \mathrm{mm} \\
L_{p}:=0.067 \cdot L_{i} \cdot\left(\frac{60}{\lambda}\right)^{1.5} & \\
R:=45 \cdot \frac{L_{p}}{L_{i}} & R=1.679
\end{array}
$$

$$
\begin{aligned}
& \text { For } L_{i}=50 r_{y} \\
& L_{i}:=50 \cdot r_{y} \\
& \lambda_{e}:=\frac{K_{f} \cdot K_{w} \cdot L_{i}}{r_{y} \cdot \varepsilon} \\
& L_{p}:=0.067 \cdot L_{i} \cdot\left(\frac{60}{\lambda_{e}}\right)^{1.5} \\
& R:=45 \cdot \frac{L_{p}}{L_{i}} \\
& R=2.755
\end{aligned}
$$


For $80 \mathrm{ksi}$ steel

$$
\begin{aligned}
& F_{y}:=552 \cdot 10^{6} \cdot \mathrm{Pa} \\
& \varepsilon:=0.0343 \cdot \sqrt{\frac{E}{F_{y}}}
\end{aligned}
$$

$K_{f}:=\frac{\lambda_{f}}{9 \cdot \varepsilon}$

$$
\mathrm{K}_{\mathrm{w}}:=\frac{\lambda_{\mathrm{w}}}{70 \cdot \varepsilon}
$$

$$
\begin{aligned}
& L_{i}=50 \cdot r_{y} \\
& \lambda_{e}:=\frac{K_{f} \cdot K_{w} \cdot L_{i}}{r_{y} \cdot \varepsilon}
\end{aligned}
$$

$L_{p}:=0.067 \cdot L_{i} \cdot\left(\frac{60}{\lambda_{e}}\right)^{1.5}$

$$
R:=45 \cdot \frac{L_{p}}{L_{i}}
$$

$$
R=0.957
$$




\section{Appendix 4 Work of Lay at Lehigh University}

Max Lay's Theory is contained in the following references. The theory builds on the previous work by Thurlimann, Haaijer, White, Kusuda, Lee and Galambos and it is experimentally buttressed by the experiments of Haaijer, Kusuda, Lee and Adams.

- Lay, M. G. (1965) Yielding of Uniformly Loaded Steel Members, ASCE J. Struct. Div., Vol 91, ST6, Dec. 1965, p. 49 - 68

- Lay, M. G. (1965) Flange Local Buckling in Wide-Flange Shapes, ASCE J. Struct. Div., Vol 91, ST6, Dec. 1965, p. 95 - 117

- Lay, M. G.,Galambos, T. V. (1965) Inelastic Steel Beams Under Uniform Moment, ASCE J. Struct. Div., Vol 91, ST6, Dec. 1965, p. 67 93

- Lay, M. G.,Galambos, T. V. (1967), Inelastic Steel beams Under Moment Gradient, ASCE J. Struct. Div., Vol 93, ST1, Feb. 1967, p. $381-399$ 
Lay's local buckling slenderness limit:

$$
\lambda_{\text {Lay }}=\sqrt{\frac{4.1}{3+\frac{F_{u}}{F_{y}}}} \cdot \sqrt{\frac{0.77 E}{F_{y}\left(1+\frac{h}{5.2}\right)}} \quad h=\frac{E}{E_{s t}}
$$

\begin{tabular}{|l|l|l|l|l|l|l|}
\hline Steel & $F_{y}$ & $\frac{F_{u}}{F_{y}}$ & $h$ & $\lambda_{\text {Lay }}$ & $\lambda_{\text {p(AISC) }}$ & $\lambda_{\text {p seismic }}$ \\
\hline$A$ & $483 \mathrm{MPa}(70 \mathrm{ksi})$ & 1.35 & 46 & 5.53 & 7.74 & 6.31 \\
\hline $\mathrm{B}$ & $820 \mathrm{MPa}(119 \mathrm{ksi})$ & 1.08 & 125 & 2.74 & 5.93 & 4.84 \\
\hline $\mathrm{C}$ & $331 \mathrm{MPa}(48 \mathrm{ksi})$ & 1.40 & 30 & 8.00 & 9.34 & 7.62 \\
\hline $\mathrm{D}$ & $586 \mathrm{MPa}(85 \mathrm{ksi})$ & 1.14 & 143 & 3.02 & 7.02 & 5.73 \\
\hline
\end{tabular}

Up to $345 \mathrm{MPa}$ ( $50 \mathrm{ksi}$ ) yield steels, adequate backup by theory and experiment.

letting $\sqrt{\frac{4.1}{3+\frac{F_{u}}{F_{y}}}} \cong 1$

$\mathrm{h}$ required to attain $\lambda_{p}=0.38 \sqrt{\frac{E}{F_{y}}}: h=23$

Value recommended by McDermott for A514 steel (steel B): $\lambda_{p}=5$ 
Lay's Lateral Buckling Model, Uniform Moment Case:

$$
\begin{gathered}
\left(\frac{L}{r_{y}}\right)_{p d}=\frac{\pi}{0.54} \sqrt{\frac{E}{F_{y}}} \frac{1}{\sqrt{1+F\left(\frac{h R}{s-1}\right)}} \\
h=\frac{E}{E_{s t}} \text { and } s=\frac{\varepsilon_{s t}}{\varepsilon_{y}} \\
R=\text { rotation capacity } \leq R_{\text {optimal }} \\
F=\frac{\frac{1}{2}+\frac{1}{2 \sqrt{h}}-\frac{1}{h}}{\frac{2}{\pi}+\frac{1}{2}\left(1-\frac{2}{\pi}\right)\left(1-\frac{1}{\sqrt{h}}\right)}
\end{gathered}
$$

For $\mathrm{R}=\mathrm{R}_{\mathrm{optimal}}$

$$
\left(\frac{L}{r_{y}}\right)_{\cdot p d}=\frac{\pi}{0.54} \sqrt{\frac{F_{y}}{F_{y}}} \frac{1}{\sqrt{1+0 .}}
$$

\begin{tabular}{|l|l|l|l|l|}
\hline Steel Type & $F_{y}$ & $h$ & $\left(\frac{L}{r_{y}}\right)_{p d}^{\text {Lay }}$ & $\left(\frac{L}{r_{y}}\right)_{p d}^{\text {AISC }}$ \\
\hline$A$ & $483 \mathrm{MPa}(70 \mathrm{ksi})$ & 46 & 23 & 18 \\
\hline$B$ & $820 \mathrm{MPa}(119 \mathrm{ksi})$ & 125 & 11 & 11 \\
\hline $\mathrm{C}$ & $331 \mathrm{MPa}(48 \mathrm{ksi})$ & 30 & 34 & 27 \\
\hline $\mathrm{D}$ & $586 \mathrm{MPa}(85 \mathrm{ksi})$ & 143 & 12 & 15 \\
\hline
\end{tabular}

